\title{
Baseline Graphite Characterization: First Billet
}

\author{
Mark Carroll \\ Joe Lord \\ David Rohrbaugh
}

The INL is a

U.S. Department of Energy

National Laboratory

operated by

Battelle Energy Alliance

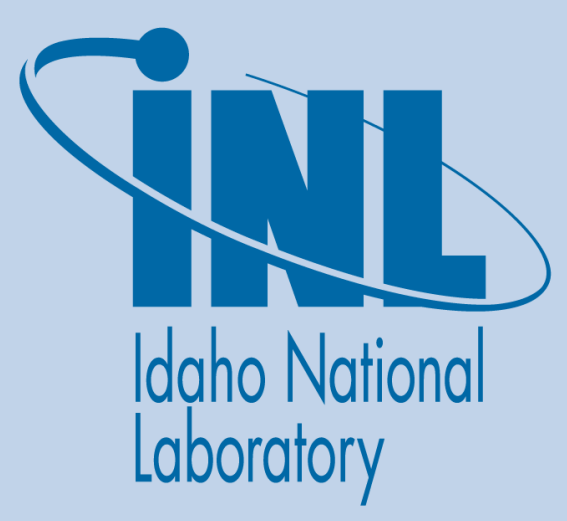

September 2010

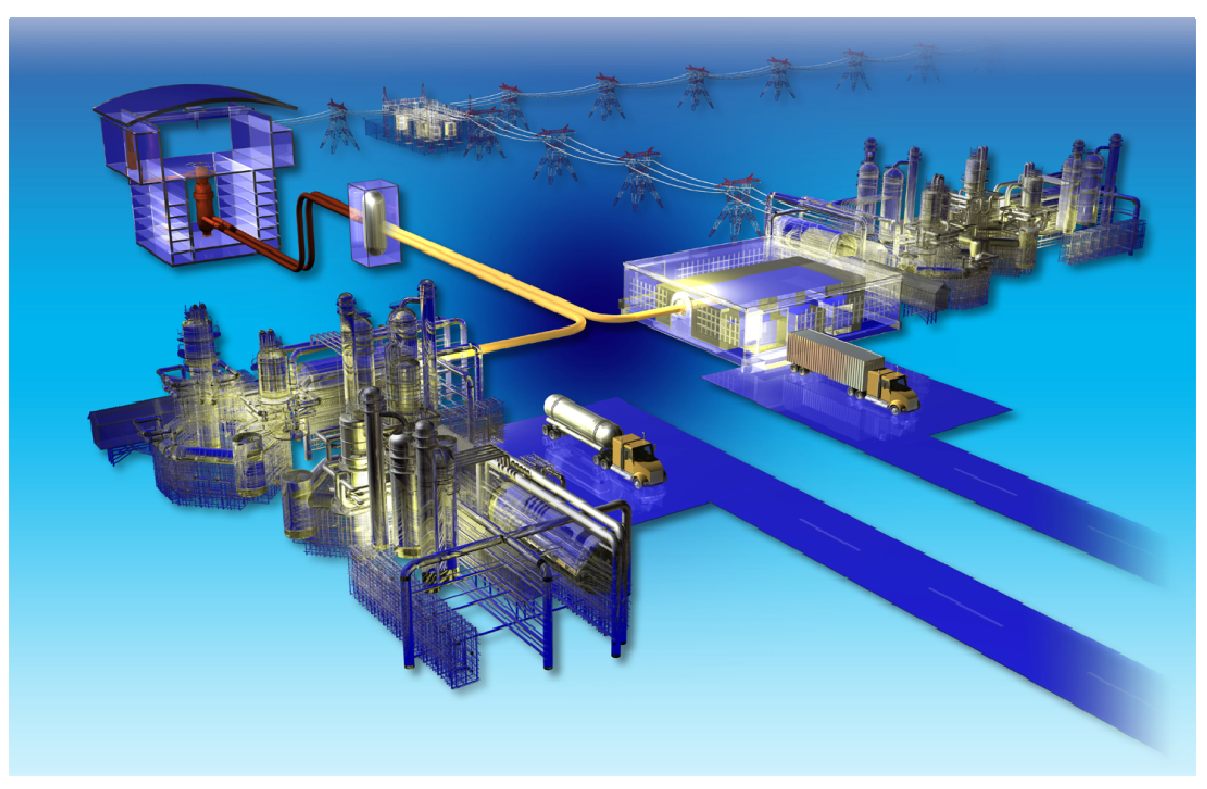




\section{DISCLAIMER}

This information was prepared as an account of work sponsored by an agency of the U.S. Government. Neither the U.S. Government nor any agency thereof, nor any of their employees, makes any warranty, expressed or implied, or assumes any legal liability or responsibility for the accuracy, completeness, or usefulness, of any information, apparatus, product, or process disclosed, or represents that its use would not infringe privately owned rights. References herein to any specific commercial product, process, or service by trade name, trade mark, manufacturer, or otherwise, does not necessarily constitute or imply its endorsement, recommendation, or favoring by the U.S. Government or any agency thereof. The views and opinions of authors expressed herein do not necessarily state or reflect those of the U.S. Government or any agency thereof. 


\title{
Baseline Graphite Characterization: First Billet
}

\author{
Mark Carroll, Joe Lord, and David Rohrbaugh
}

September 2010

Idaho National Laboratory

Next Generation Nuclear Plant Project

Idaho Falls, Idaho 83415

http://www.inl.gov

Prepared for the

U.S. Department of Energy

Office of Nuclear Energy

Under DOE Idaho Operations Office

Contract DE-AC07-05ID14517 
This page is intentionally left blank 
Next Generation Nuclear Plant Project

Baseline Graphite Characterization: First Billet

INL/EXT-10-19910

September 2010

Approved by:

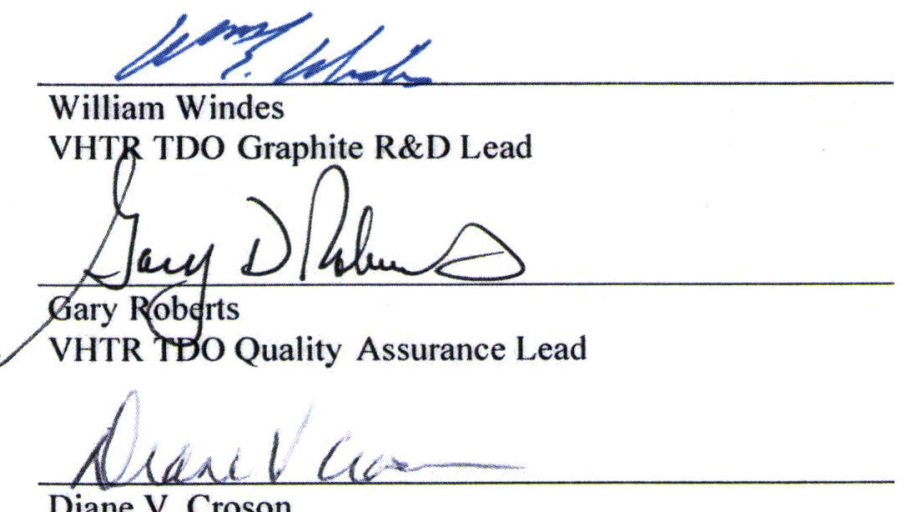

Diane V. Croon

VHTR TDO Deputy Director
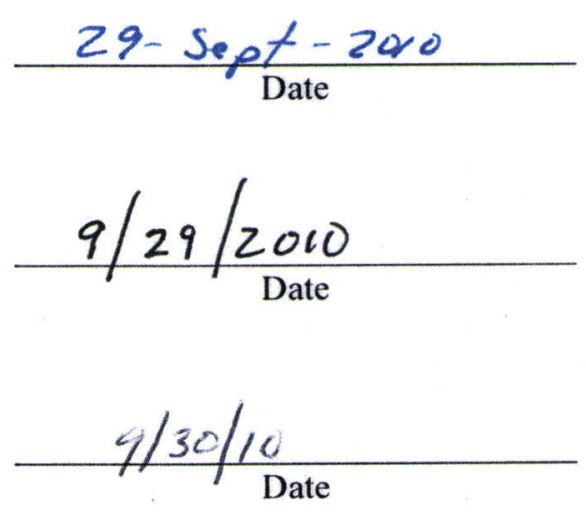
This page is intentionally left blank 


\section{SUMMARY}

The Next Generation Nuclear Plant Project Graphite Research and Development program is currently establishing the safe operating envelope of graphite core components for a very high temperature reactor design. To meet this goal, the program is generating the extensive amount of quantitative data necessary for predicting the behavior and operating performance of the available nuclear graphite grades. In order determine the in-service behavior of the graphite for the latest proposed designs, two main programs are underway. The first, the Advanced Graphite Creep (AGC) program, is a set of experiments that is designed to evaluate the irradiated properties and behavior of nuclear grade graphite over a large spectrum of temperatures, neutron fluences, and compressive loads. Despite the aggressive experimental matrix that comprises the set of AGC test runs, a limited amount of data can be generated based upon the availability of space within the Advanced Test Reactor and the geometric constraints placed on the AGC specimens that will be inserted. In order to supplement the AGC data set, the Baseline Graphite Characterization program will endeavor to provide supplemental data that will characterize the inherent property variability in nuclear-grade graphite without the testing constraints of the AGC program. This variability in properties is a natural artifact of graphite due to the geologic raw materials that are utilized in its production. This variability will be quantified not only within a single billet of as-produced graphite, but also from billets within a single lot, billets from different lots of the same grade, and across different billets of the numerous grades of nuclear graphite that are presently available. The thorough understanding of this variability will provide added detail to the irradiated property data, and provide a more thorough understanding of the behavior of graphite that will be used in reactor design and licensing.

This report covers the development of the Baseline Graphite Characterization program from a testing and data collection standpoint through the completion of characterization on the first billet of nuclear-grade graphite. This data set is the starting point for all future evaluations and comparisons of material properties. 
This page is intentionally left blank 


\section{CONTENTS}

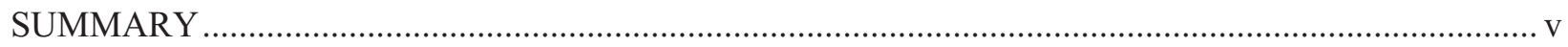

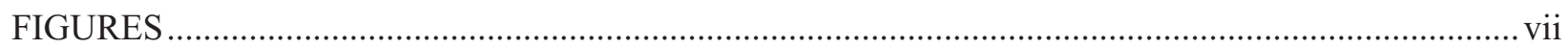

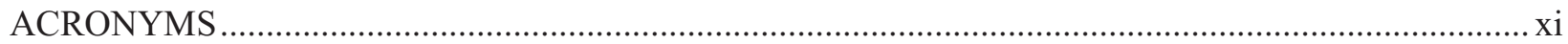

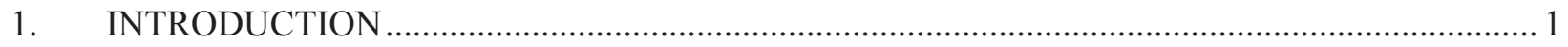

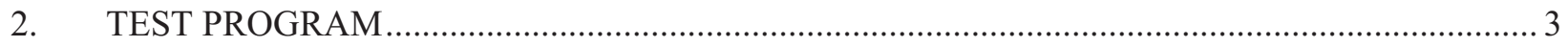

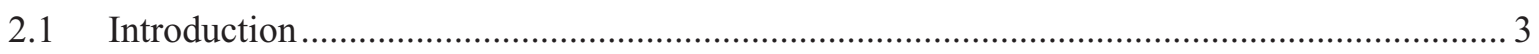

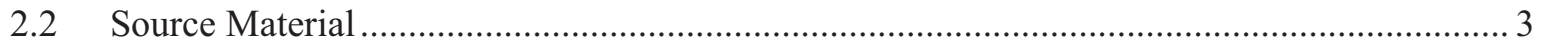

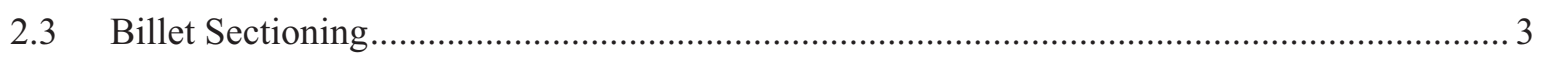

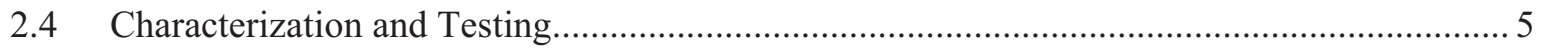

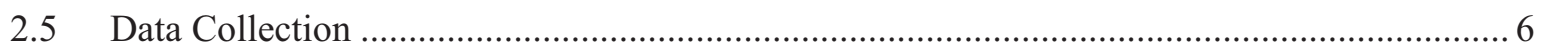

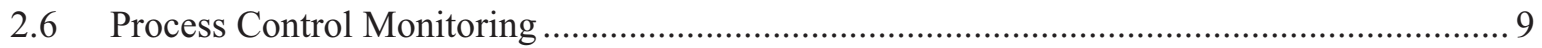

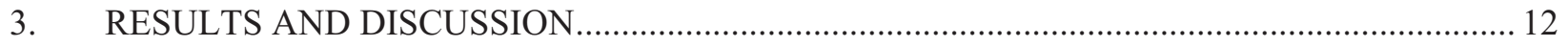

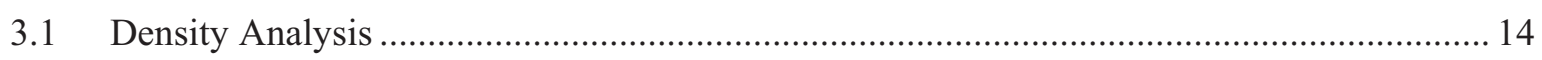

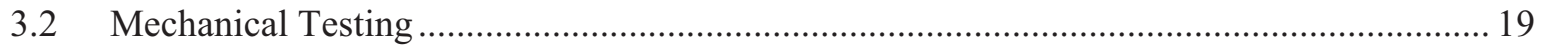

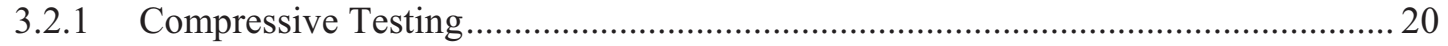

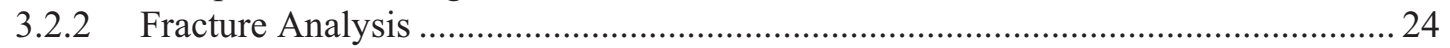

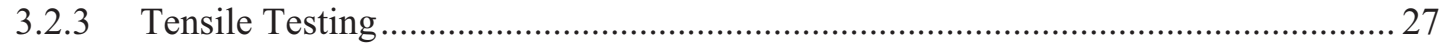

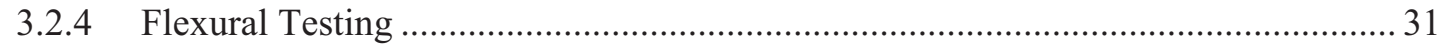

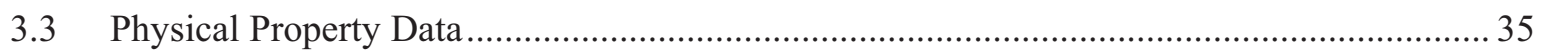

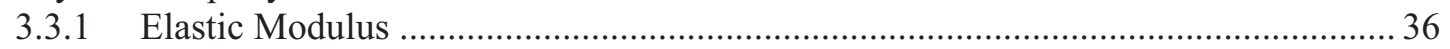

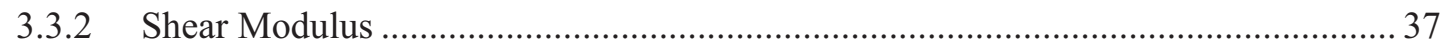

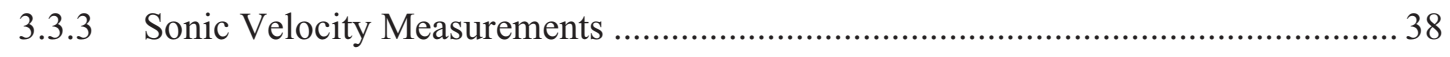

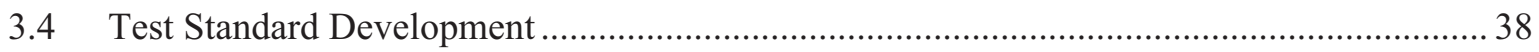

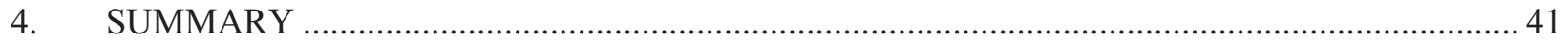

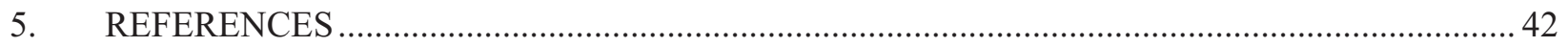

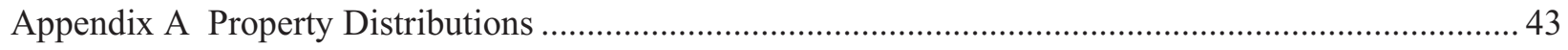

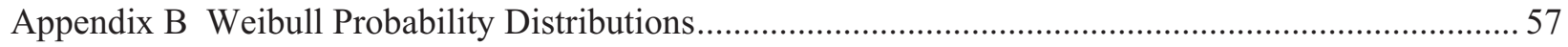

\section{FIGURES}

Figure 1. A thorough evaluation of graphite properties must include numerous comparison

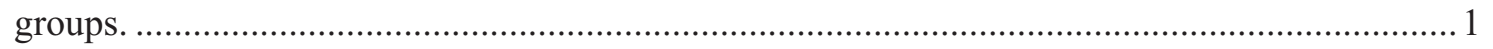

Figure 2. Graphite billets become extensive individual data sets that are pooled to determine

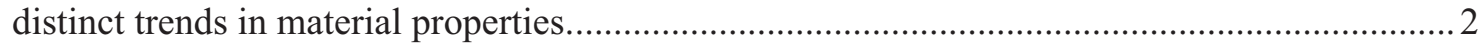

Figure 3. The three types of mechanical test specimens that will be machined from stock graphite and provide the basis for material property evaluations. 
Figure 4. Quality-accepted billets of nuclear-grade graphite pre-labeled by project personnel prior to sectioning in order to ensure traceability of individual locations. .

Figure 5. Sectioning plan for the first billet. The resulting sections consist of quartered layers................. 4

Figure 6. Detail of the extraction of test specimens from respective sub-blocks....................................... 5

Figure 7. Detail of a small section of compression testing data (NBG-18-635-14C.xls) shows the individual tabs of other evaluations or measurements being carried out on the same specimens.

Figure 8 . The bar code system (inset) used on each specimen ensures full specimen traceability along with rapid and accurate data tracking from receipt through all phases of testing and evaluation.

Figure 9. The macro window for recording of dimensional measurements recognizes the specimen type based on the output of the bar code reader and opens the proper dimensional format. 8

Figure 10. The layout of the graphite mechanical test area at the INL Research Center.....

Figure 11. The run chart for elastic modulus during tensile testing is evaluated and obvious outliers are quickly identified.

Figure 12. Trending data outside of the normal distribution alerts the evaluator to investigate potential test of equipment anomalies.

Figure 13. Operations outside of the actual data collection can assist in providing validated data in this case, the performance of the machine shop in maintaining accurate tolerances......

Figure 14. Illustration of the the types of logical data groups that can be directly compared, in this case for density values.

Figure 15. A box plot demonstrates visually the comparison of mean data set values and associated distributions.

Figure 16. Analysis of variance window demonstrates the differences in means through a low $(<0.05) \mathrm{P}$ value.

Figure 17. Regression analysis showing the relationship between density values and measured compressive stress.

Figure 18. Box plots of data group means show the variations in density by group along the billet's long $(\mathrm{Z})$ axis.

Figure 19. Data groups illustrate the shift in density between material at the center of the billet and material toward the outer edges.

Figure 20. Data sets can be broken down into increasingly smaller groups, but the resolution is limited by the reduction in data populations and increased effects of data scatter.

Figure 21. Imaging in 4-dimensional space (X-Y-Z and color) gives a qualitative picture of density distribution.

Figure 22. Orientations within the billet must be analyzed in order to determine potential effects of textures that may have developed during processing. 20

Figure 23. Test setup and specimen diagram for compressive testing on the first billet. .21

Figure 24. Histograms and descriptive statistics of the compression test results. .22 
Figure 25. Box plot of compressive strength shows equivalence of compressive strength values in different orientations.

Figure 26. ANOVA result demonstrates equivalence between the mean value of compressive strength based on orientation through a $\mathrm{P}$ value $>0.05$........

Figure 27. Box plots grouped by X-Y trend from the billet centerline as compared between different slabs (Z-height positions).

Figure 28. Examples of the three main fracture patterns being quantified.

Figure 29. Description window from compressive specimen classification program to quantify fracture patterns.

Figure 30. Category 2, or the shear pattern of fracture, was the most prevalent fracture description.

Figure 31. Fractures demonstrating the Category 1 (beltline) pattern may have been occurring at lower ultimate stresses.

Figure 32. Tensile test setup for applying a uniaxial load (left) and associated specimen diagram (right).

Figure 33. Descriptive results and distribution of strength properties from tensile testing of the first billet.

Figure 34. Grouped stresses by Z-axis position do not indicate a strong trend based on location along the billet's long axis.

Figure 35. No differences in mean values for stress are indicated by the high $\mathrm{P}$ value between parallel $(\mathrm{P})$ and transverse $(\mathrm{T})$ orientations.

Figure 36. The $\mathrm{P}$ value is much closer to 0.05 when the transverse orientations are broken down into $\mathrm{A} / \mathrm{C}$ and $\mathrm{B} / \mathrm{D}$ groupings.

Figure 37. The box plot of the three orthogonal orientations demonstrates visually that the trend for tensile stress values is higher in one transverse orientation $(B / D)$ than in the parallel orientation, and lower in the other $(\mathrm{A} / \mathrm{C})$......

Figure 38. 4-point, third-point flexural test setup (left) and graphite test specimen dimensions for samples from the first billet.

Figure 39. Distribution of flexural strength values and descriptive statistics for strength and mid-span deflection values.

Figure 41. The visual trend seen in Figure 40 is confirmed as an existing difference in mean strength values, demonstrated by the $\mathrm{P}$ value of 0.009 .

Figure 42. Flexural strength relationships for the trend of material properties moving from the billet centerline to the outer edges (broken down by orientation groups). Reduced specimen populations by position in the transverse orientation limit trend resolution

Figure 43. Modulus measurements can be made by allowing a specimen to vibrate at its fundamental frequency between specific nodes.

Figure 44. The distribution for dynamic Young's (elastic) modulus is centered on a mean value of $1.21 \mathrm{GPa}$, higher than that measured during tensile and flexural testing.

Figure 45. Shear modulus values from flexural specimens vibrated in the torsional mode (left). Modulus values from compression tests (center) are closer to the shear modulus values 
than they are to the elastic modulus values, which may be a product of the deformation mode leading to fracture (right).

Figure 46. Descriptive statistics of modulus and Poisson's ration values calculated from the sonic velocity measured in compressive specimens.

Figure 47. Regression analysis shows little correlation between failure in tension (amount of strain at failure) and relative humidity in the environment.....

Figure 48. ANOVA shows no statistical correlation between either the failure stress or strain and ambient humidity levels during staging and testing of tensile specimens.

Figure 49. Epoxy placed on the surface of the gauge section of tensile bars was initiated to prevent breakage at the contact point of the extensometer, held against the specimen by knife edges and spring tension.

Figure 50.3-dimensional property representations will be possible as data set differences are sorted and distinct trends can be statistically validated. 


\section{ACRONYMS}

NGNP Next Generation Nuclear Plant

HTGR high temperature gas-cooled reactor

INL Idaho National Laboratory

NQA Nuclear Quality Assurance

NDMAS NGNP Data Management and Storage

RAID redundant array of independent disks

ANOVA analysis of variance 
This page is intentionally left blank 


\section{Baseline Graphite Characterization Report}

\section{INTRODUCTION}

The Next Generation Nuclear Plant (NGNP) will be a high temperature gas-cooled reactor (HTGR) with a large graphite core. Graphite is a proven material from a performance standpoint, and has been effectively used as both structural and moderator material in research as well as commercial HTGRs. While the general characteristics necessary for producing nuclear grade graphite are understood, historical nuclear grades no longer exist. New grades must therefore be fabricated, characterized, and irradiated in order to demonstrate that current grades of graphite exhibit acceptable irradiated and nonirradiated properties, upon which the thermomechanical design of the structural graphite in the NGNP is based.

Nuclear graphite type H-451, used previously in the United States for HTGR graphite components, is no longer available. New graphite types have been developed and are considered suitable candidates for the new NGNP reactor design. To support the design and licensing of NGNP core components within a commercial reactor, a comprehensive properties database must be developed for these current grades of graphite. The Baseline Graphite Characterization program will be a major contributor to this database, providing an extensive evaluation of variations in graphite not only within a single billet of as-produced graphite, but also from billets within a single lot, billets from different lots of the same grade, and across different billets of the numerous grades of nuclear graphite that are presently available (Figure 1).

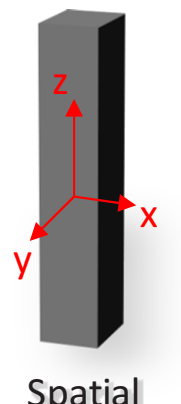

Spatial

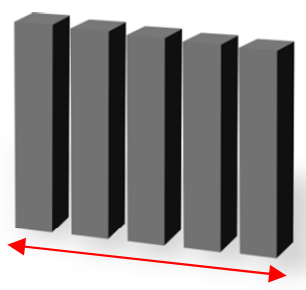

Billet to Billet

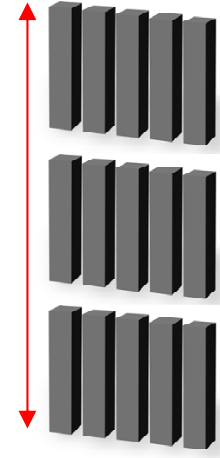

Lot to Lot

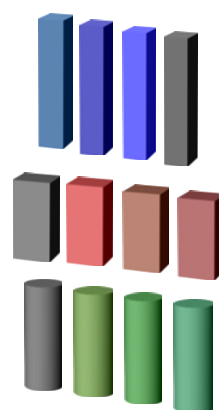

Graphite Grades

Figure 1. A thorough evaluation of graphite properties must include numerous comparison groups.

This report will cover the baseline bulk property characterization of the first billet of nuclear-grade graphite to be evaluated in this program. The graphite billet, NBG-18 635-14, is a block of molded isotropic graphite with a large grain structure. Future billets will include not only sister billets of NBG-18, but other grades of graphite that cover a range of production and molding techniques and ultimate material characteristic textures and grain sizes. The methods for testing and data collection will be presented as the process that has been established for all future billets and grades of graphite that will provide input to the expanding Baseline Graphite Characterization data set. Examples of the types of evaluations that have been carried out and the strategies for future refinement of the property relationships will be outlined, but little in the way of raw data or actual test result files will be included in appendix form or otherwise due to the sheer volume of data that has been generated on this single billet. The data output from the mechanical testing alone consists of over 5.6 million raw data points stored in 3,800 individual electronic files based on the results obtained from 770 mechanical test specimens. Even the main Baseline mechanical properties database, which is comprised of the results data alone from each of the different evaluations (mechanical testing and physical properties) in summary form, consists of tabbed spreadsheets being occupied by over 63,000 cells of individual characteristic or property results and associated tagging information. 
The end result of this extensive amount of data collection is the establishment of distinct property relationships that represent the expected variation patterns in as-produced billets of nuclear-grade graphite of varying grades or production techniques. An idealized example of the characterization life cycle is shown in Figure 2, where nuclear graphite billets are converted to individual data sets based on spatial position within the billet. These data sets form the basis for extensive trend analysis combinations, illustrating the actual variation patterns within the individual billets that can be used from a design and application standpoint.

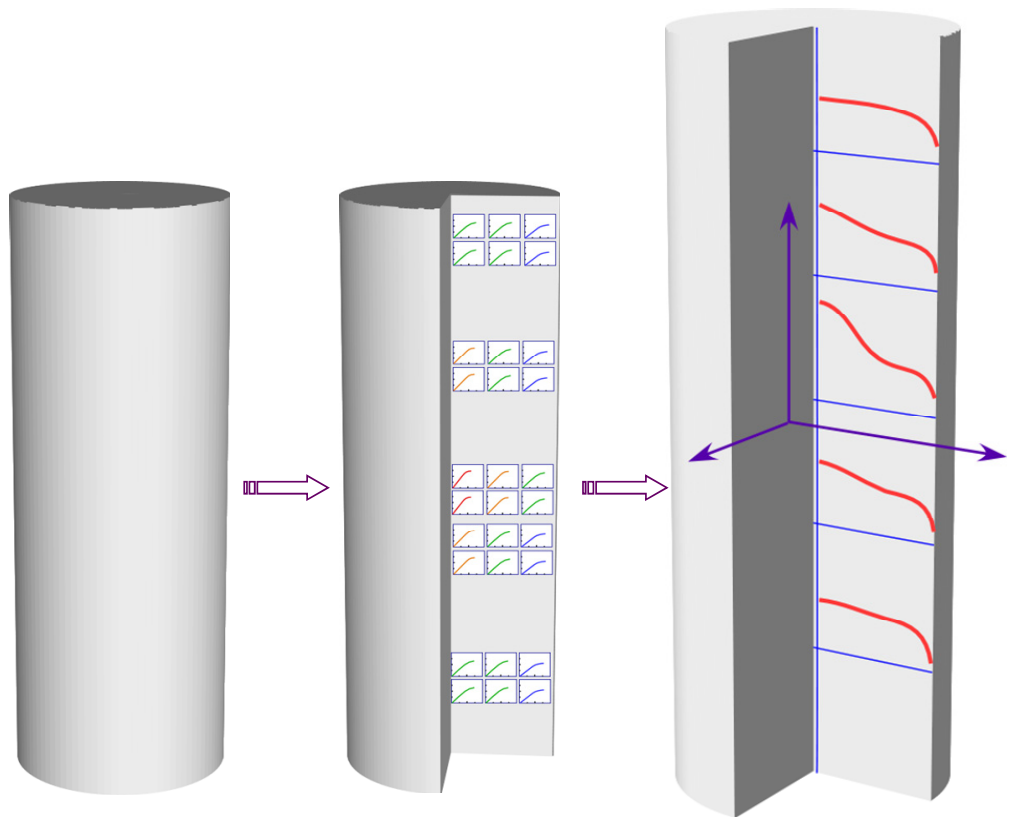

Figure 2. Graphite billets become extensive individual data sets that are pooled to determine distinct trends in material properties.

The main component of the Baseline Graphite Characterization program is based on extensive mechanical testing of three main types. Figure 3 shows the individual test specimens for each type of mechanical test. The first type, compressive testing, consists of stressing the specimens to failure under a compressive load, or uniaxial squeezing force. Tensile testing consists of gripping specimen ends and pulling it to failure under tensile forces. Flexural testing evaluates the bending strength by flexing specimens to failure under a fixed load radius. As will be detailed in future sections of this report, numerous other evaluations can be performed using these specimen types as the basis. The collection of comprehensive groups of data that can be cross-checked with corroborating techniques or confirmatory evaluations will allow the goals of this program to be realized.
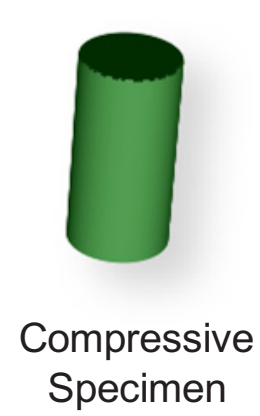

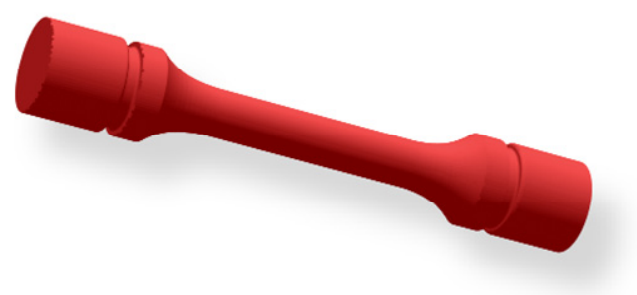

Tensile Specimen

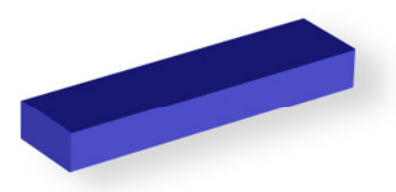

Flexural Specimen

Figure 3. The three types of mechanical test specimens that will be machined from stock graphite and provide the basis for material property evaluations. 


\section{TEST PROGRAM}

\subsection{Introduction}

The objective of the Baseline Graphite Characterization program is to accurately test and disseminate data from machined specimens that are carefully controlled in order to provide full traceability back to the original source, position, and orientation from within the graphite being tested. Through thorough control of the testing and data collection procedures, variability from unintended testing artifacts can be minimized and, as a result, measured variability in material properties can be more accurately assigned to the actual characteristic of interest, whether it be spatial position, orientation, or actual material source.

\subsection{Source Material}

Material traceability begins with the procurement of qualified billets of nuclear-grade graphite. The storage of these billets falls under the requirements of NQA-1 Section I Requirement $13^{1}$ and Idaho National Laboratory (INL) LWP-13120, "Identifying and Controlling Items." is the staging point for individual billets prior to being marked, sectioned, and machined into test specimens.

\subsection{Billet Sectioning}

The sectioning of each billet begins with the pre-labeling of individual billets (Figure 4) by quality assurance number, slab, and sub-block. Accurate labeling at this stage of the process limits the potential loss of traceability by billet position at a very early stage, and assists the machining vendor by limiting the liability for maintaining traceability even at the quality level required for the Baseline program. The first billet to be sectioned was over $6 \mathrm{ft}$ in length and weighed over 1 ton, requiring the employment of an outside facility that could assist in handling the billet and making the initial cuts. Billet sectioning prior to the machining of actual test specimens was covered in INL SOW-8182, "Sectioning of NBG-18 Graphite Billets."
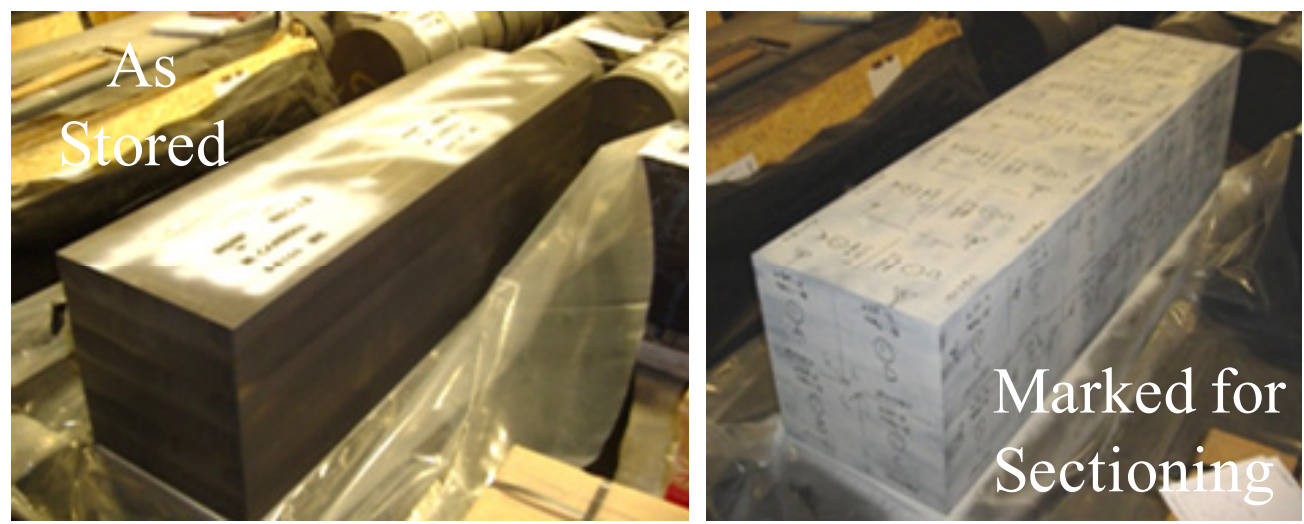

Figure 4. Quality-accepted billets of nuclear-grade graphite pre-labeled by project personnel prior to sectioning in order to ensure traceability of individual locations.

The initial billet sectioning was carried out in accordance with INL Drawing 759142, "NBG-18 Billet Plan 1,"a resulting in a division of the billet into seven numbered slabs, each of which was further divided into four sub-blocks labeled A-D (Figure 5). From these sections, a statistical sampling of individual slabs or sub-blocks were chosen for further machining that included both "random" and "forced" selections. While a true statistical cross-section would have relied on purely random selections, enveloping the data by the logical boundary conditions required the forced inclusion of both end slabs (1 and 7) and the center

a. INL Drawing 759142, 2009, "NBG-18 Billet Plan 1 Baseline Graphite Characterization Slab and Sub Block Details,” 2009. 
slab (4). The additional random slabs chosen for the full characterization data set were the four sub-blocks from Slabs 2 and 5 and individual sub-blocks 3D and 6B (Figure 5, right).
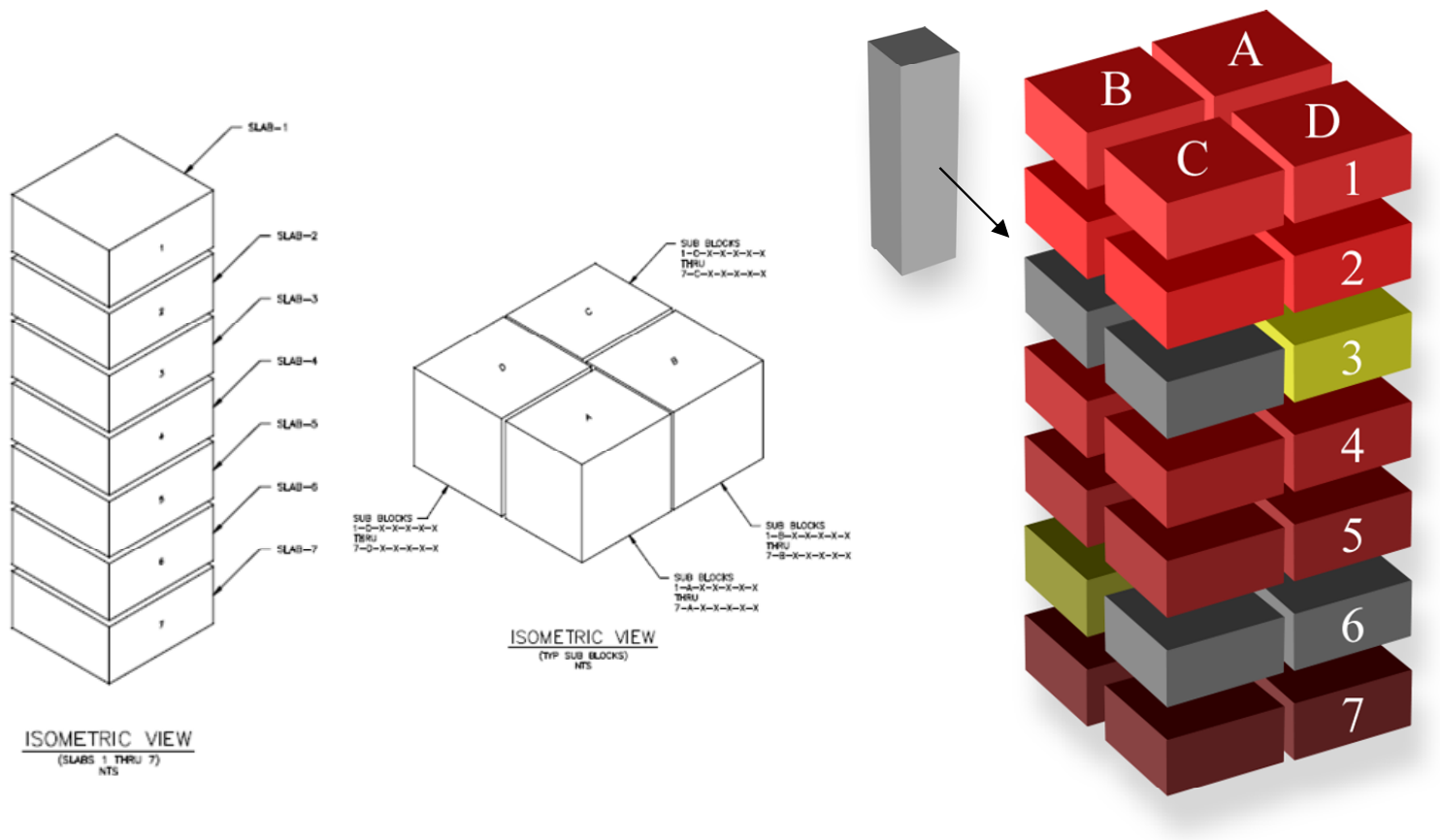

Figure 5. Sectioning plan for the first billet. The resulting sections consist of quartered layers.

Reducing the full-sized billet into sub-blocks also assisted in rendering the graphite more readily able to be handled and shipped to the respective machine shop for reduction into individual test specimens. The machining plan used for the first billet was INL SOW-7227, "Machining Graphite for Baseline Characterization," which employed the extraction of test specimens per INL Drawing 759292, "NBG-18 Billet 1A Standard Specimen and Block Details." According to the plan, each sub-block was further sectioned into rows and divided into individual coupons, from which either a single tensile specimen or one compression and one flexural specimen could be extracted; the detail and example of which is shown in Figure 6. As a corollary to this report, a mirror program is also in progress at Oak Ridge National Laboratory that will be employing the same billet sectioning and ultimate test plan in order to provide additional data to the graphite material properties database, and also to act as an independent reviewer and evaluator of the experimental results based on shared expertise in this type of testing.

b. INL Drawing 759292, 2010, "NBG-18 Billet 1A Baseline Graphite Characterization Standard Specimen Block and Specimen Sample Details,” 2010. 

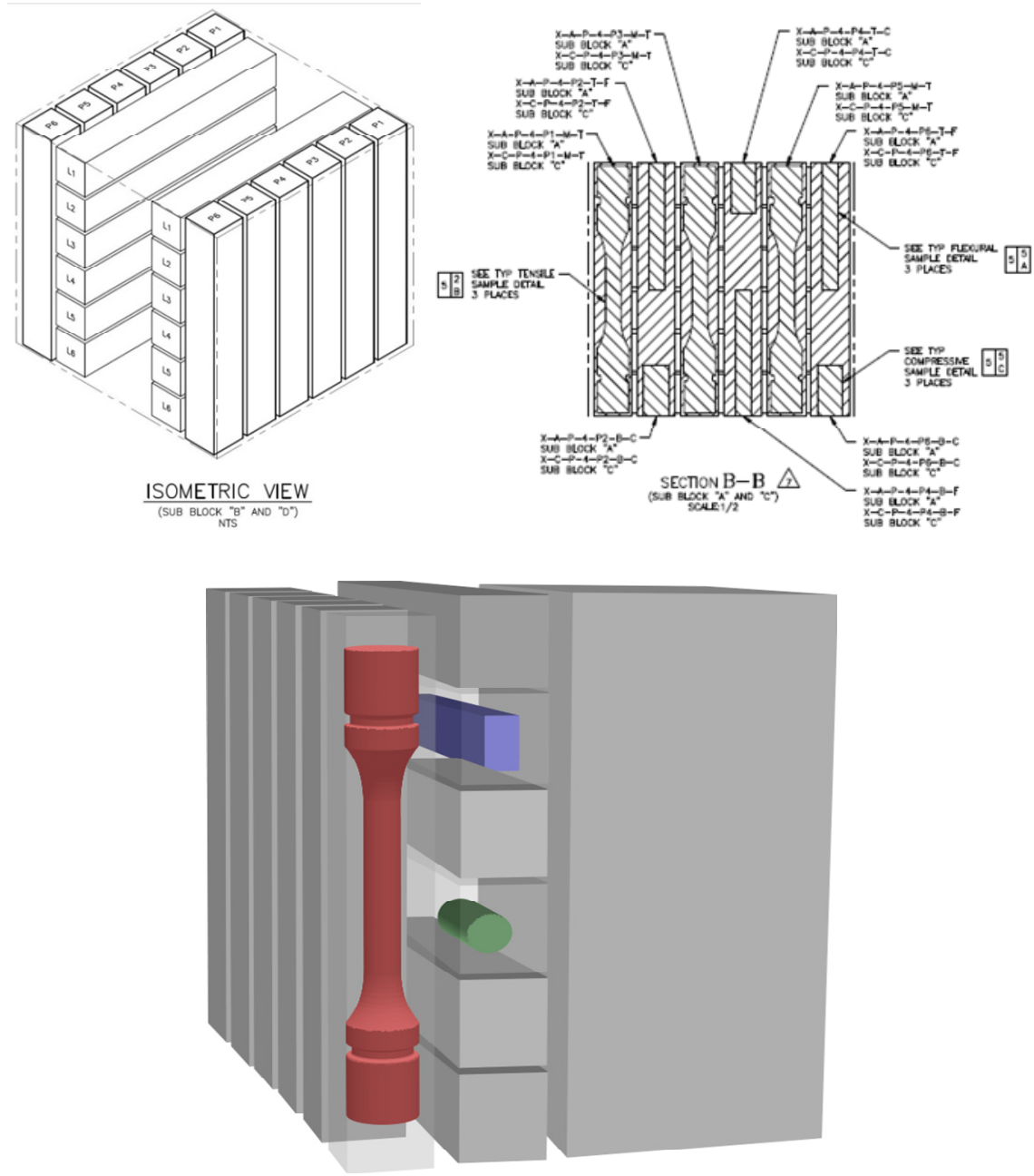

Figure 6. Detail of the extraction of test specimens from respective sub-blocks.

\subsection{Characterization and Testing}

At the core of the Baseline Graphite Characterization program is the mechanical testing of graphite in three distinct deformation modes: tension, compression, and bending. Each of these specific tests follows the guidance of the applicable ASTM standards for the mechanical testing of graphite, the details and clarifications of which are described in detail in INL PLN-3348, "Graphite Mechanical Testing." Tensile testing is in accordance with ASTM C749-08, ${ }^{6}$ compressive testing follows ASTM C695-91, ${ }^{7}$ and four-point flexural (bend) testing is carried out per ASTM C651-91. ${ }^{8}$ Resulting data from each of those test types is covered in Section 3.

The machined specimens, having already been carefully tracked with regard to position and orientation from within the source billet, also lend themselves in some cases to additional property analyses that are non-destructive in nature and can be carried out prior to mechanical testing. Evaluations of density, modulus via longitudinal and torsional fundamental frequency, and modulus via sonic velocity can be easily obtained on either flexural or compressive specimens. Details of this type of additional evaluations are also described in the corresponding areas of Section 3. 


\subsection{Data Collection}

Data collection and storage is an important component of the Baseline Graphite Characterization program. Aside from the obvious need to collect data that is accurate, the ability to maintain this accuracy while maintaining a testing pace that will provide a large amount of data in the most efficient manner requires a process that will accommodate the actual test input/output formats and, wherever possible, automate the tracking, collection, and backup of the data being generated.

The main data sets are initially organized as Excel ${ }^{\mathrm{TM}}$ spreadsheets by individual mechanical tests from a single billet. Subsequent data storage will be carried out by forwarding these spreadsheet files directly to the applicable database manager for the NGNP Data Management and Storage (NDMAS) system, which will be the main repository for NGNP data as outlined in INL PLN-3467, "Baseline Graphite Characterization Plan." "For this report, the three data sets incorporate the grade and billet number (NBG-18, 635-14) in the file name. Individual evaluations that are carried out on specific specimen types are incorporated as separate tabs in the data file. An example of this organization is shown in Figure 7.

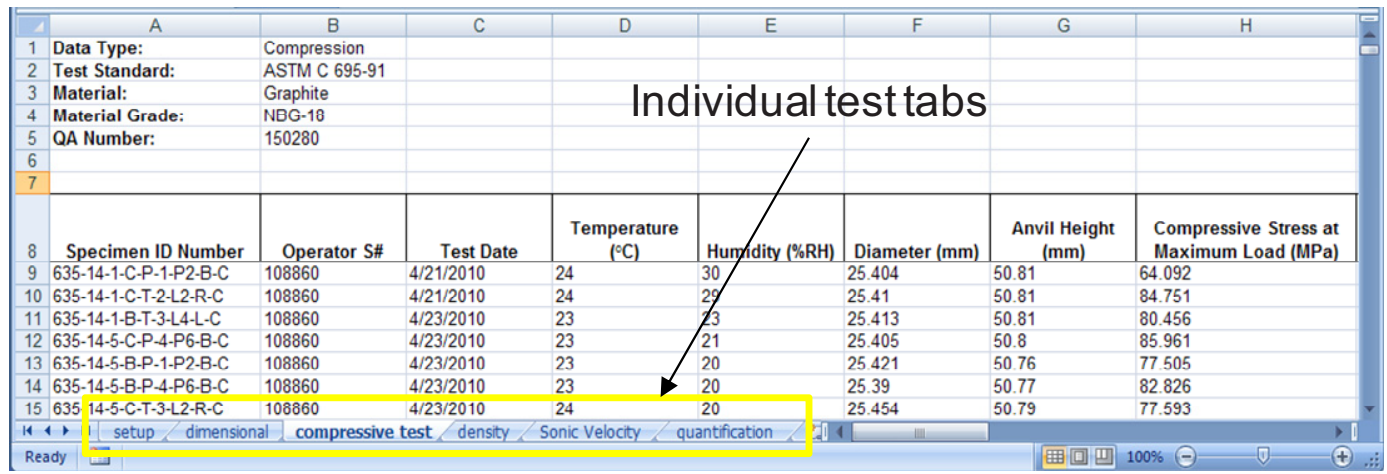

Figure 7. Detail of a small section of compression testing data (NBG-18-635-14C.xls) shows the individual tabs of other evaluations or measurements being carried out on the same specimens.

The efficiency of data collection was greatly enhanced through the development of automated test screens and networking of test computers through customized LabView ${ }^{\mathrm{TM}}$ programs. Each test, from the recording of dimensional measurements through the output of mechanical test file formats all the way to data backup and archiving has been automated through programs validated in accordance with INL PLN-2247, "General Software Management Plan for the VHTR TDO." 10 This level of data automation was further enhanced by the incorporation of a bar code system that captures the individual specimen identification codes and can parse out the pertinent information to assign the correct test screen to a particular specimen type, or to record the proper data set in the appropriate data base tab by test and specimen. While the bar code system was successfully employed for specimen tracking of the Advanced Graphite Creep (AGC) program specimens, the AGC program is limited in the geometry and location of individual specimen types so that sequential ordering was adequate. For the baseline program, each identification code represents a large amount of information regarding not only source material and billet number, but also position information such as slab, sub-section, row, layer, orientation, and coupon relative position in addition to actual test specimen type. The automation of the system required that each of these bits of information be recorded in a manner that would not only properly bin the resulting information, but also allow the individual data sets to be sorted by any one of a number of characteristics of interest. Bar code labels are attached to specimens as part of the receipt evaluation of machined samples upon return from the vendor. From this point forward, individual specimens are tracked via a bar code reader - no further recording of specimen identification by any other means is necessary at any stage of the process (Figure 8). 


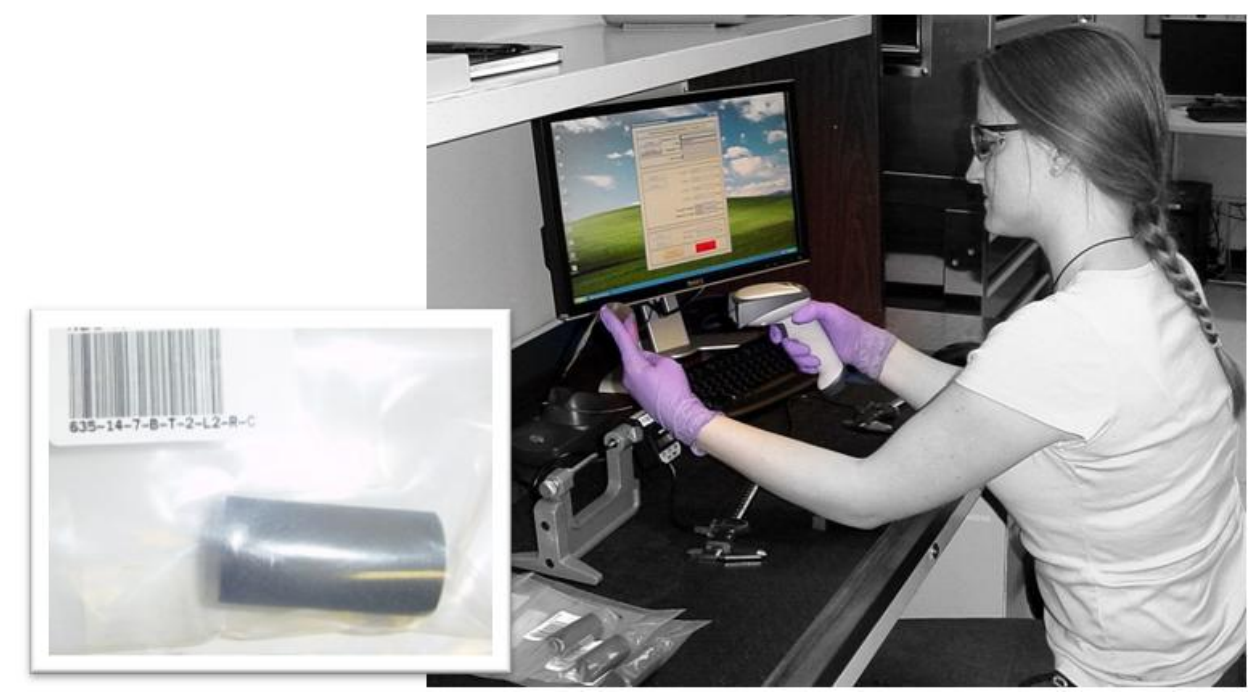

Figure 8 . The bar code system (inset) used on each specimen ensures full specimen traceability along with rapid and accurate data tracking from receipt through all phases of testing and evaluation.

An example of the type of graphic interface that utilizes the bar code outputs is shown in Figure 9. The initial data of record for each specimen type are measurements of the critical dimensions. The majority of evaluations done after this point will require these measurements. As can be seen from the figure, the first sheet of the dimensional measurement interface evaluates the bar code and opens the correct window for that specific specimen type. Upon completion and acceptance of the individual measurements, the program automatically outputs the information to the applicable specimen database by identification code, simultaneously archiving supplemental information such as user, data, and environmental conditions. Additionally, the calculation is automatically performed that converts the specimen identification code based on billet section information into a scalar X-Y-Z value, defining the strict position in the as-produced billet based on a defined origin and known billet dimensions. The fully-sorted information is then readily available for automated call-up via bar code when other evaluation windows are opened and dimensional measurements are needed for a particular test or analysis type for that specific specimen. Each of the test computers is networked in a manner that facilitates this process, allowing the individual test computers to share information from individual specimen measurements or data points as necessary to prevent having to re-collect or transpose identical information that is required at different test stations. The network system also provides a means to incorporate an automated data backup routine that collects and archives each data set from both the AGC and Baseline programs and stores the individual files on a RAID (redundant array of independent disks) drive system located on the opposite side of a physical fire wall. 


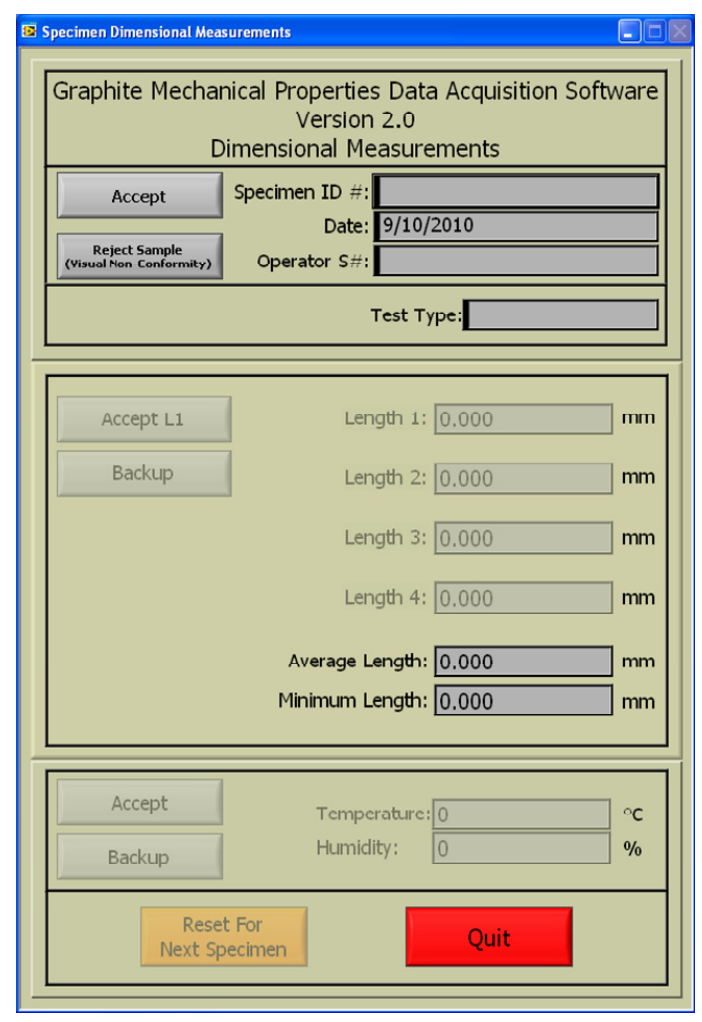

Figure 9. The macro window for recording of dimensional measurements recognizes the specimen type based on the output of the bar code reader and opens the proper dimensional format.

The load frames used for mechanical testing are located next to the station used for dimensional measurements and the storage/staging area for individual test specimens (Figure 10). The two Instron 5582 electromechanical test frames employ Instron's Bluehill software suite for test control, and have the ability to generate files of different types that can be used for archiving purposes. For the Baseline program, each test generates five output files - two Bluehill test-specific files, a hard-copy report with test results, a raw data file with individual data points based on test run time with regard to load and deflection, and an output file with ASTM standard-specific report information that can be re-exported automatically to the main billet-specific database. 


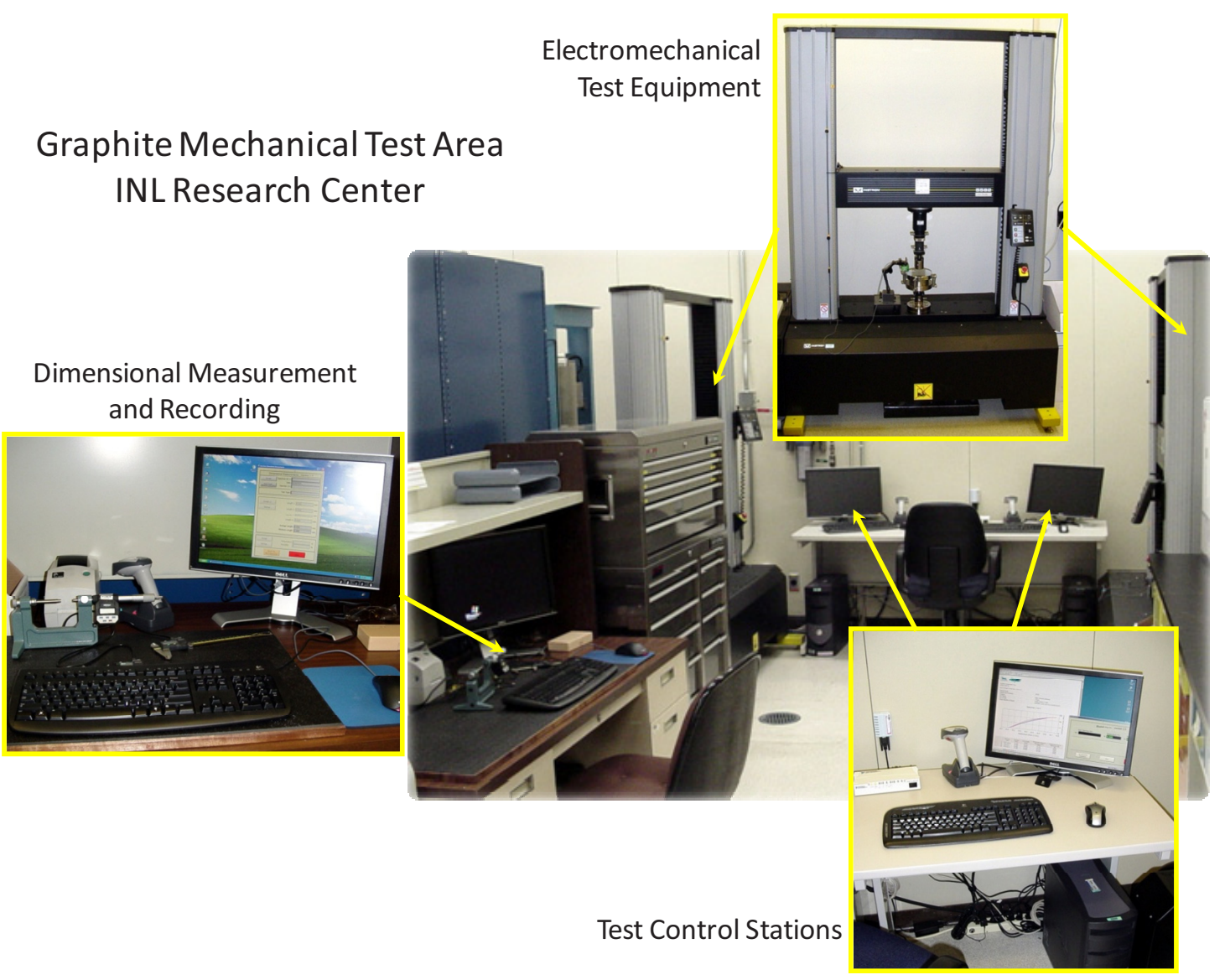

Figure 10. The layout of the graphite mechanical test area at the INL Research Center.

\subsection{Process Control Monitoring}

The goal of streamlining the data collection process is only effective if proper control of each individual step is maintained. To this end, an automated system was put in place that allowed a rapid snapshot of the data being collected through detailed run charts. Much like the Xbar-R charting system provides ready feedback to formally-monitored industrial processes, data stream run charts provide a means to identify outliers, pattern anomalies, or data trending "out of control" that requires further scrutiny.

An example of a run chart is shown in Figure 11, in which the modulus of elasticity is plotted over the entire range of specimens tested from the first graphite billet. While most of the data appears to fall neatly within or two standard deviations of the mean value, a single data point with an extraordinarily high modulus can be quickly identified. The investigation of this type of outlier is easily addressed by returning to the raw test data, available in a separate file from the main properties database, to determine the cause of the data outlier or provide legitimate grounds for rejection of that particular data point. 


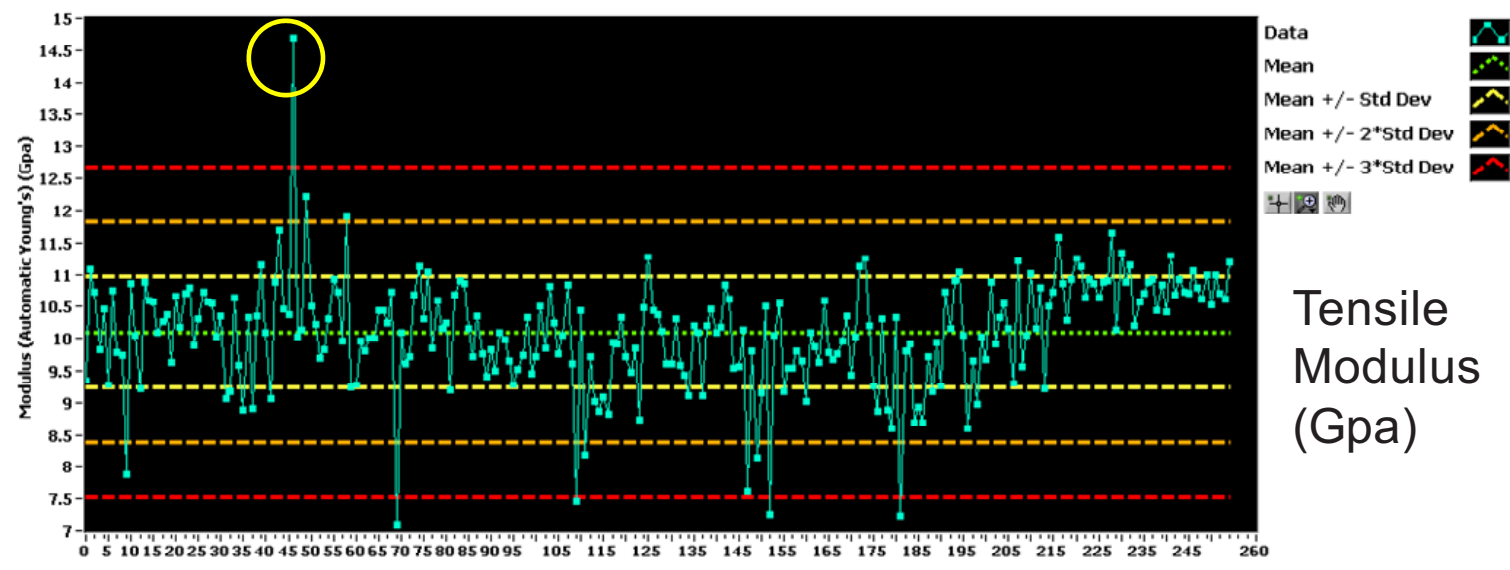

Figure 11. The run chart for elastic modulus during tensile testing is evaluated and obvious outliers are quickly identified.

Trend analysis can also alert the program to possible compromises in the test equipment or applicable procedures. Figure 12 is an example of this type of trend that might cause concern in this area - a sudden reduction in the mean density value over a number of specimens being evaluated. In this particular case, further investigation revealed that the density measurements on these flexural specimens were done shortly after the specimens were returned from the machine shop. Rather than being tested in a random run order, this section of data was from a single slab (Slab 1), which trended to lower density values as corroborated by density measurements of the compression specimens from the same slab.

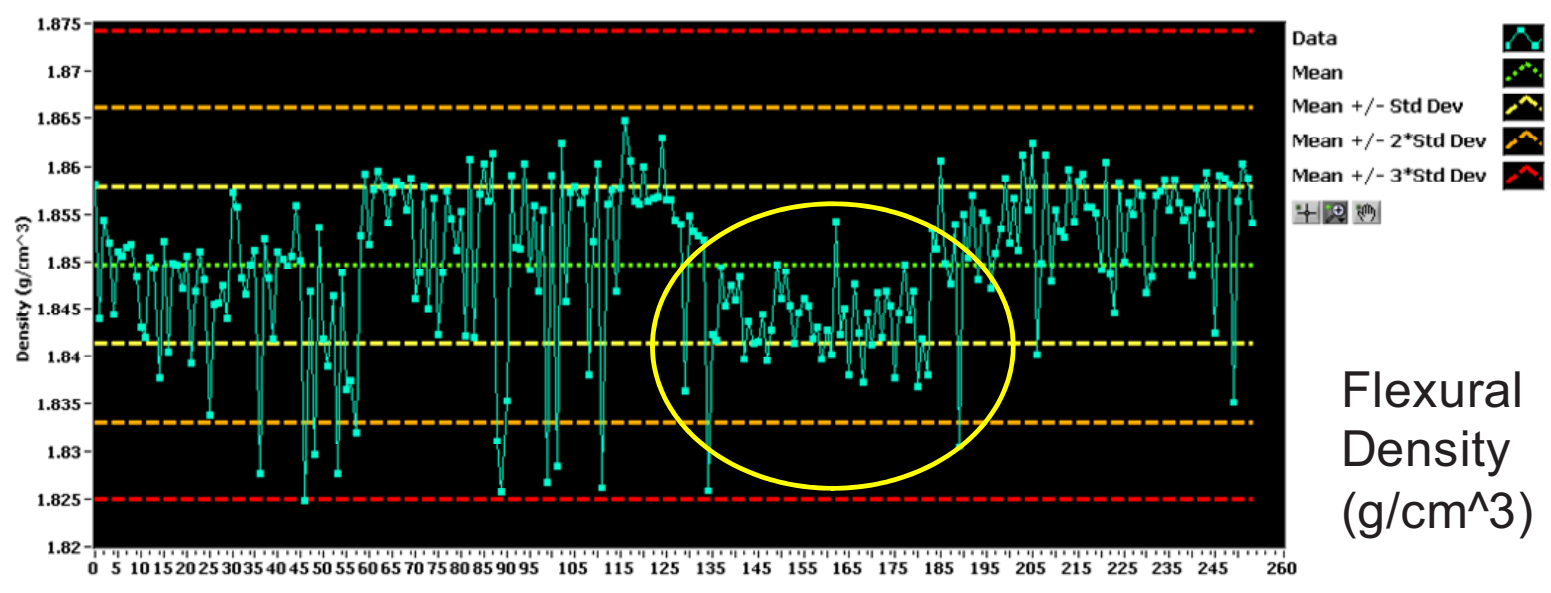

Figure 12. Trending data outside of the normal distribution alerts the evaluator to investigate potential test of equipment anomalies.

This technique for data monitoring can even provide valuable data validation prior to any tests being run. Figure 13 shows a run chart of the performance of the approved shops contracted to machine graphite test specimens. Early on, the drawing used for specimen dimensions had an allowable tolerance below the nominal specimen width. A subsequent revision tightened this tolerance, easily seen in the run chart by a steadying of the width values to a tightly-controlled minimum dimension. The dedicated use of this type of process monitoring gives further evidence that the data and associated experimental techniques are being collected or applied in a consistent and accurate manner. 


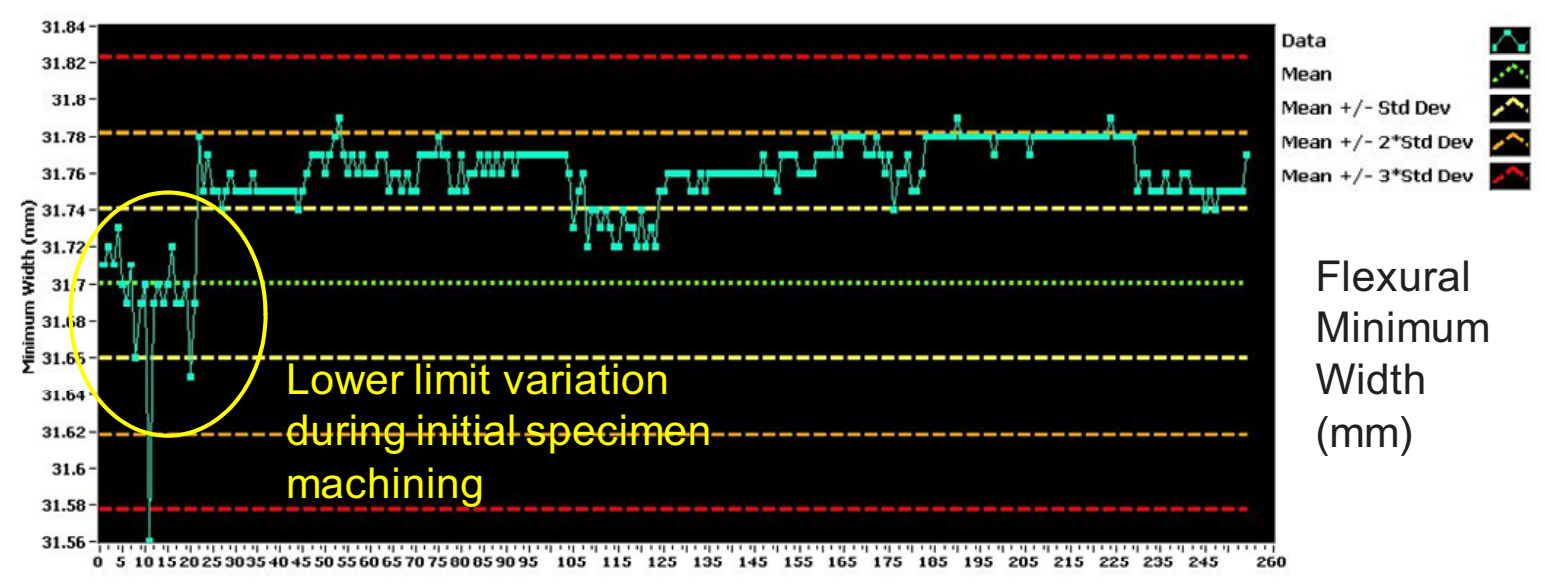

Figure 13. Operations outside of the actual data collection can assist in providing validated data - in this case, the performance of the machine shop in maintaining accurate tolerances. 


\section{RESULTS AND DISCUSSION}

The purpose of the Baseline Graphite Characterization program is to quantify the property characteristic variations across numerous factors. For material that is processed in a similar manner and utilizes essentially the same raw materials regardless of grade or manufacturer (as has been done on the first graphite billet), this will require an extensive population in order to define minor variations with statistical accuracy. Regardless of whether the complete picture can be constructed from the graphite in a single billet, this report will provide a snapshot of the characterization of the first billet and the techniques that were employed in order to provide an initial look at the complexity of the analyses that are involved. Variations that do not appear to be distinctively defined either do not exist or do not have a large enough data set to represent the variation in a statistically significant means. The tools that are being used to make these determinations will be illustrated for each of the specimen types and the tests that were performed.

Detailed statistical analyses required the use of commercial-grade software developed for that very purpose. The results presented in this section utilized not only the Statistical Analysis ToolPak included with Excel software for basic representations, but also the more powerful statistics packages of SAS and MiniTab. Aside from reporting the statistical average of the property characteristics gleaned from the tests being run and their associated variations, the actual analysis of data from an elemental viewpoint relies on one basic premise - whether or not a variation exists between the data sets being analyzed. For the characterization of the first billet, this analysis is focused on two differing factors. One factor is the relative position in the billet from an X-Y-Z reference; the other the orientation of the specimen within the billet. As an example of the types of analyses that will be presented in this section, Figure 14 shows an illustration of a density comparison early in the data collection phase. For this example, the density is compared between two logical data sets - "inside" and "outside" positions, as collected from the existing database from the stored $\mathrm{X}-\mathrm{Y}-\mathrm{Z}$ coordinates for a group of specimens. The values are shown as a distribution in the form of individual histograms. A direct comparison between the groups of data is shown graphically in the form a box plot (Figure 15), which shows not only data set mean values, but also the relative distribution of data within the sets by quartile. 


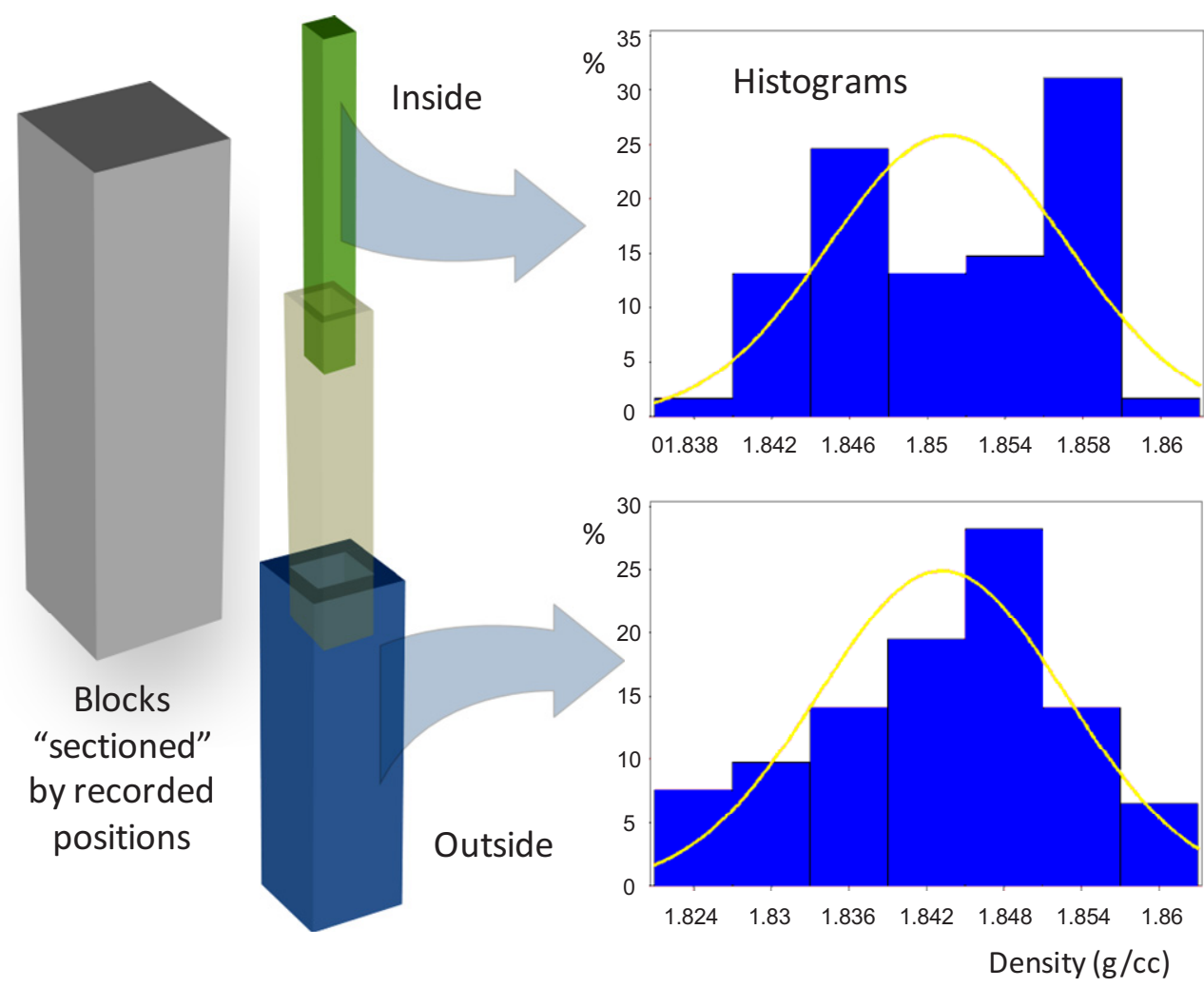

Figure 14. Illustration of the the types of logical data groups that can be directly compared, in this case for density values.

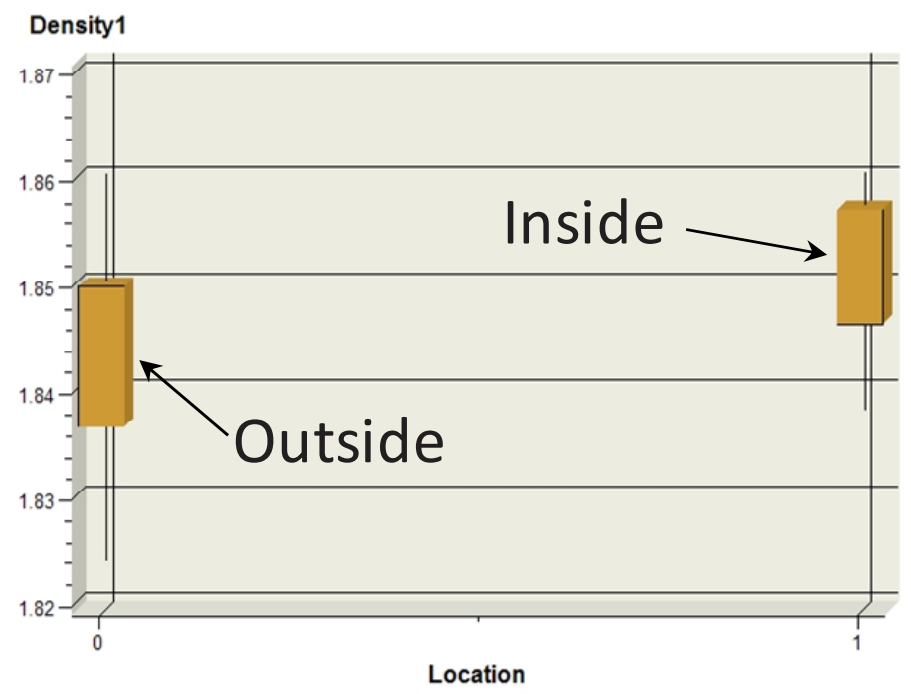

Figure 15. A box plot demonstrates visually the comparison of mean data set values and associated distributions.

The detailed comparison is made numerically through the analysis of variance (ANOVA) evaluation, in which the difference between sample group means is hypothesized and then rejected or accepted to a specific confidence level based upon whether a difference exists between mean values. For this example and for data analysis in the Baseline Characterization program, the consistent confidence interval of 95\% 
will be used, meaning that a $\mathrm{P}$ value of less than 0.05 indicates that a difference exists between sample group means. In the inside vs. outside example, the $\mathrm{P}$ value of 0.000 indicates that there is, in fact, a difference in mean values between the graphite density in the center positions as compared to the density in the outer positions, despite the fact that the difference is only $1.8511 \mathrm{vs} .1 .8432 \mathrm{~g} / \mathrm{cc}$. This difference is illustrated graphically in the example by the spread of means in the $95 \%$ confidence interval in the lower section of the MiniTab result (Figure 16).

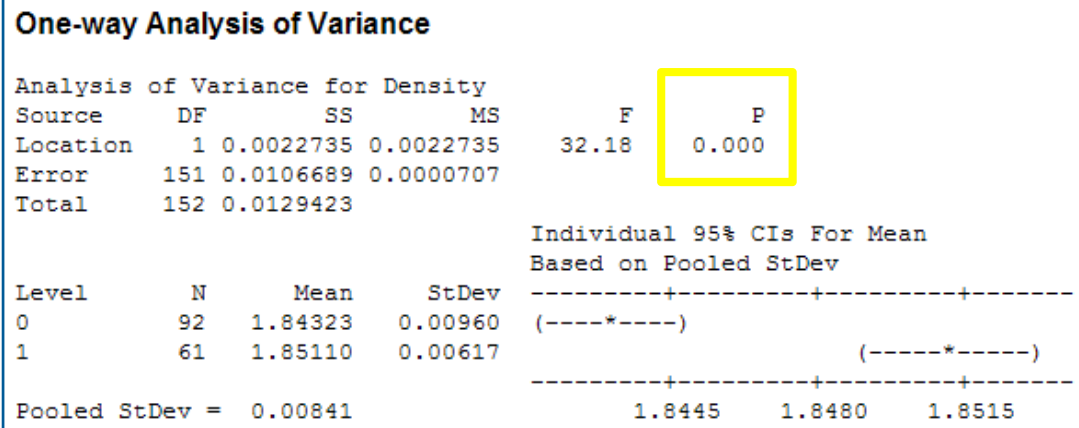

Figure 16. Analysis of variance window demonstrates the differences in means through a low $(<0.05)$ P value.

\subsection{Density Analysis}

The density analyses done on the first billet are a logical starting point for the data reporting, as they are the starting point for all other testing that is performed. Per ASTM Standard C559-90, density evaluations require detailed dimensional information, which is not only useful for the accurate measurement of density but is also necessary for numerous other tests, including the pre-recording of cross-sectional area for mechanical testing. The density evaluation is also the most comprehensive data set, as the simple geometries of both the compressive and flexural specimens are ideal for recording accurate volumetric measurements. The resulting set of density values is therefore roughly twice as large as the sets of individual points for any other test. The relative density within a graphite billet is also a valuable precursor to mechanical property measurements as the characteristics are generally related. Based on Baseline data alone, an example of this is illustrated in Figure 17 which shows a regression analysis of the correlation between density and compressive strength. While the $\mathrm{R}$ Square value is a relatively moderate 0.418 , there is a distinct slope to the predicted values of compressive stress based on measured density. 


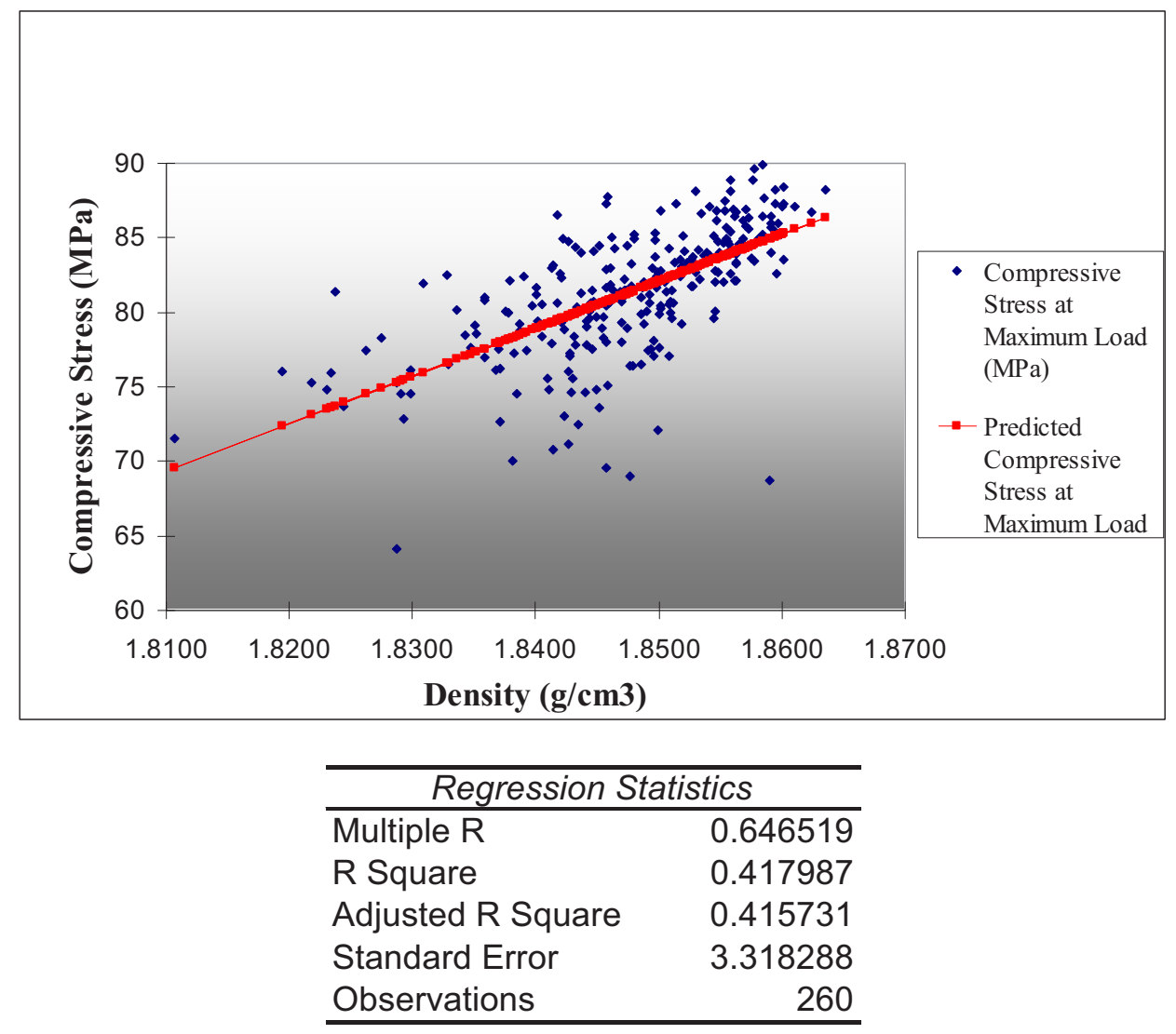

Figure 17. Regression analysis showing the relationship between density values and measured compressive stress.

The relationships for density by scalar position groups are fairly straightforward, as the density is normalized to measured volume and is not subject to orientation effects outside of the actual value at that position. As was mentioned in the previous section, this allows the pooling of data points between compressive and flexural specimens. Figure 18 shows the relationship between grouped density values and Z-axis layers in 2-in. increments. While the density distribution appears to be fairly uniform around $1.85 \mathrm{~g} / \mathrm{cc}$, some degree of variation can be seen when directly comparing the groups at the billet ends against the central positions. The density values are slightly higher toward the billet Z-axis central location. Another grouping that can be easily extracted from the available data is the centerline of the billet in the X-Y plane and the outer edges of the specimen. Figure 19 shows the distribution for this particular grouping. Again, the overall distribution is relatively tight, but a shift in values can be seen as the data group averages decrease from just above $1.85 \mathrm{~g} / \mathrm{cc}$ down to approximately $1.845 \mathrm{~g} / \mathrm{cc}$ as the outer edges are approached. In order to provide more resolution to the actual density variations, these groups can be further broken down into sequentially smaller data sets. This approach is illustrated in Figure 20, which again groups the relationship between density and distance from the centerline in the X-Y plane, but also breaks down the individual groups by slab number. This effectively demonstrates a Z-axis component to the density relationship. The figure further illustrates the continued breakdown of the individual slabs (in this case, Slab 4) into groupings by scalar Z-axis values within the specific slab. As can be seen from the figure, the groupings into smaller and smaller data sets can lend further resolution to the actual shift in density values as the positions shift from the center to the outside of the billet. There is a limit, however, based upon the finite number of individual data points that are available. Note that the example in Figure 20 shows a wider amount of scatter in the trend being observed as the data sets are broken into smaller groups and subsequent populations decrease. The tradeoff for increased resolution in 
the property variations is therefore to continue to grow the data populations to tighten the individual property distributions. Continued sectioning and evaluation of billets is the natural mechanism to increase these data point populations as the Baseline Graphite Characterization program continues to move forward.
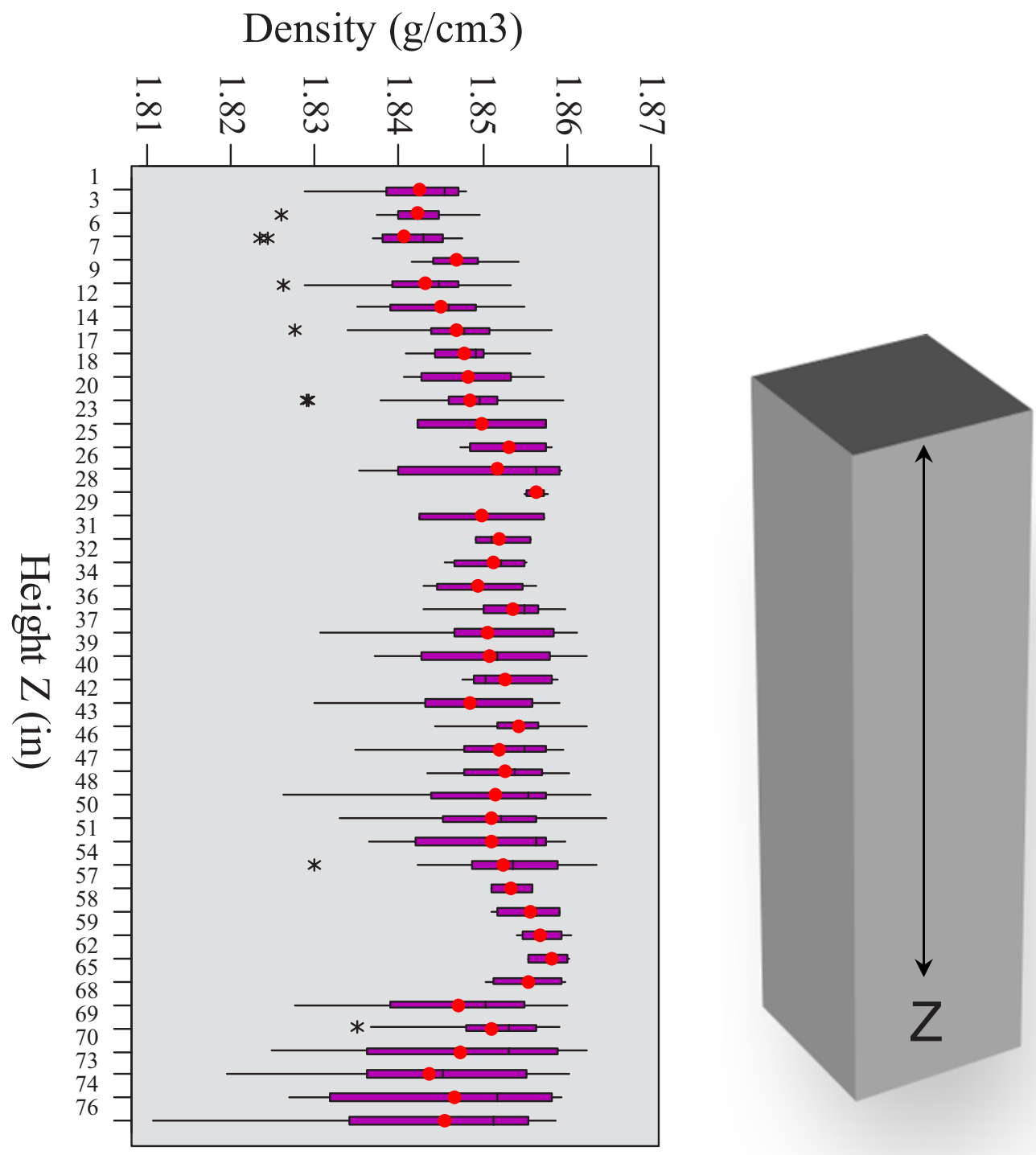

Figure 18. Box plots of data group means show the variations in density by group along the billet's long (Z) axis. 

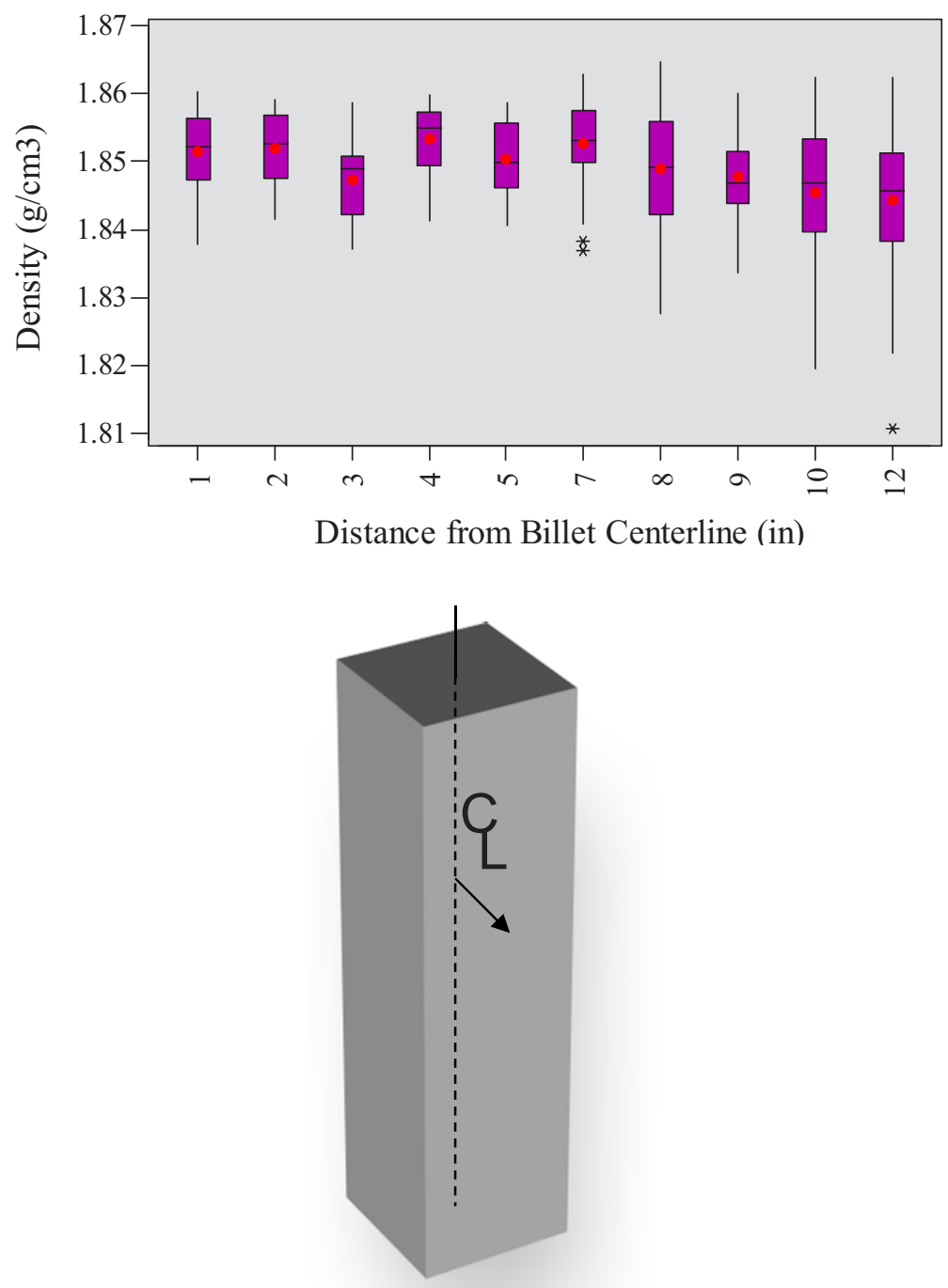

Figure 19. Data groups illustrate the shift in density between material at the center of the billet and material toward the outer edges. 


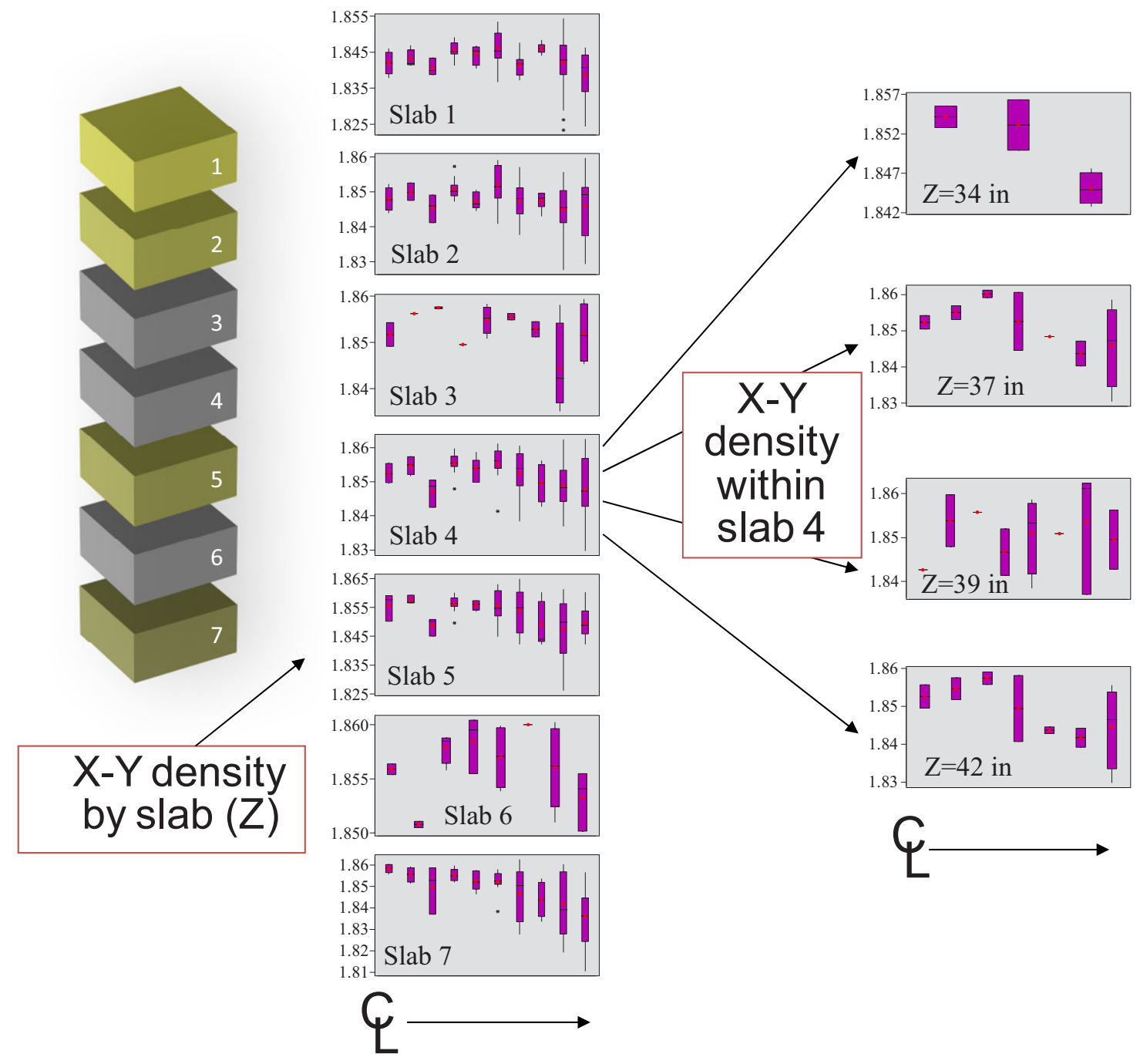

Figure 20. Data sets can be broken down into increasingly smaller groups, but the resolution is limited by the reduction in data populations and increased effects of data scatter.

Another approach is being employed that does not have the constraints of data distributions within individual sets, but is more qualitative in nature. The smallest breakdown of a given sample population is into individual points, which can also be utilized to demonstrate trends in property characteristics.

Figure 21 shows an example of the density distribution within the billet based upon singular data points. The distribution requires the inclusion of a fourth dimension in order to represent the material properties in three-dimensional (X-Y-Z) space, which is accomplished by representing the actual material property on a transitional color scale. A similar relationship can be seen for density distribution as could be inferred from the box plots; that is, the density values tend to be higher in the billet center and decrease as the edges are approached. The lowest single-point values are at the extreme ends of the billet. As with groupings by data sets, the qualitative resolution is increased as more data points are added. In single-point distributions, local outliers become less and less visible as the density of points in specific color ranges saturate the mapped volume. 

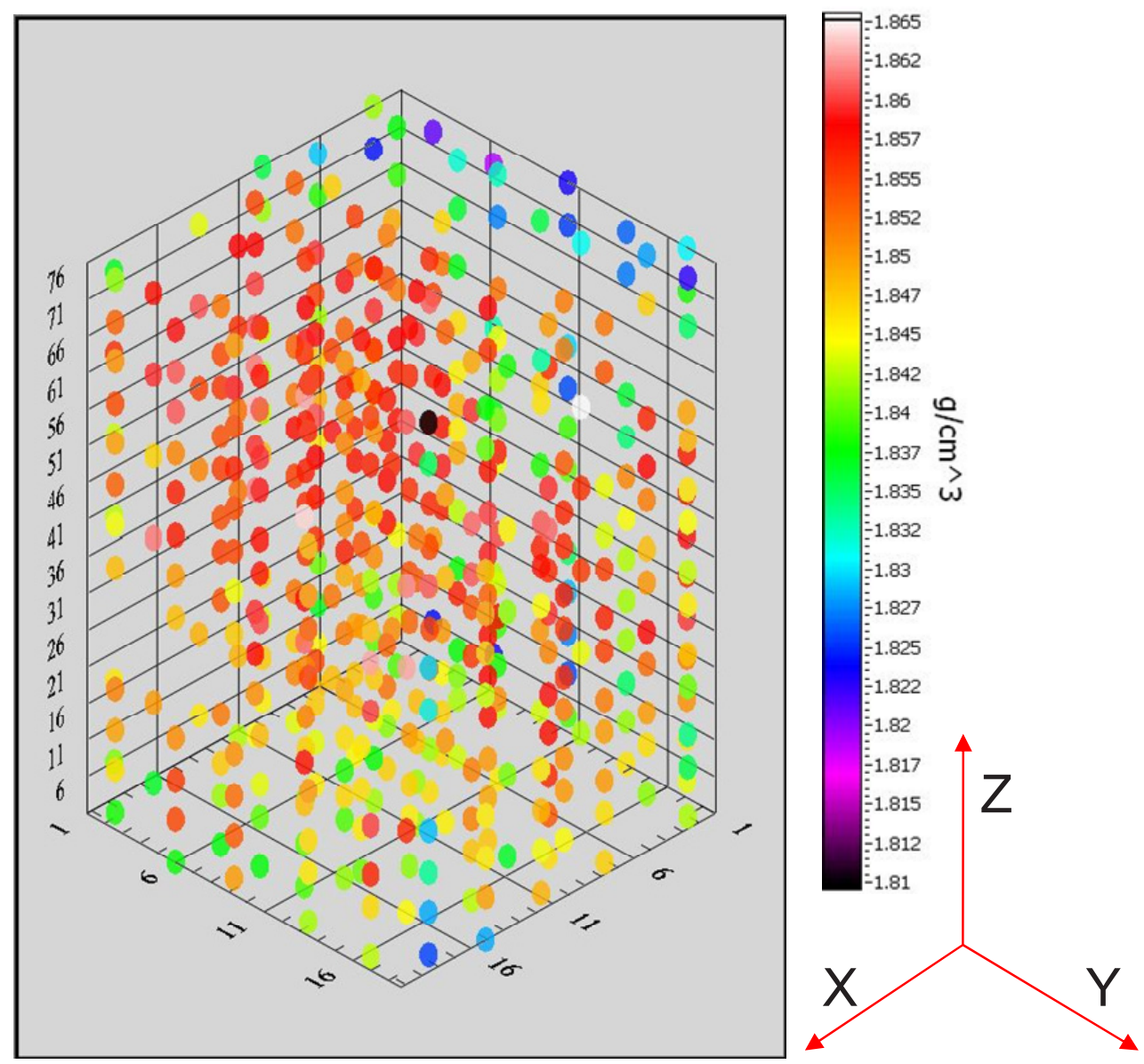

Figure 21. Imaging in 4-dimensional space (X-Y-Z and color) gives a qualitative picture of density distribution.

\subsection{Mechanical Testing}

The following section covers the data analysis of varying spatial groupings based upon the results of mechanical testing to failure of specimens from the first billet. As an enormous amount of data group combinations are available for representation, selected groupings will be presented within the context of this report. Continued data collection and analysis over the course of the program will build upon the number of data groups being analyzed for property relationships. For the purpose of demonstrating the type of relationships seen from this specific billet, several general categories of data will be presented in addition to the general descriptive statistics of each of the mechanical property types. First, as was shown in the previous section, groups by spatial distribution will be illustrated in terms of the applicable X-Y $-\mathrm{Z}$ values. A second type of grouping will be necessary that was not a contributing characteristic of density measurements - the variation in data based on orientation within the billet resulting from potential texturing effects during the production process. For this billet, the orientations are organized in three orthogonal groupings that are consistent throughout the billet. Based upon the sectioning plan, these orientations are shown in Figure 22. As seen from the figure, the three distinct orientations lie along either the Z-axis, or parallel direction to the billet long axis, or in the X-Y plane, identified as the transverse orientation based upon the rows extracted from Sub-blocks A and C or Sub-blocks B and D. These orientations will continue to be referred to as a logical group breakdown based upon the data being presented. 


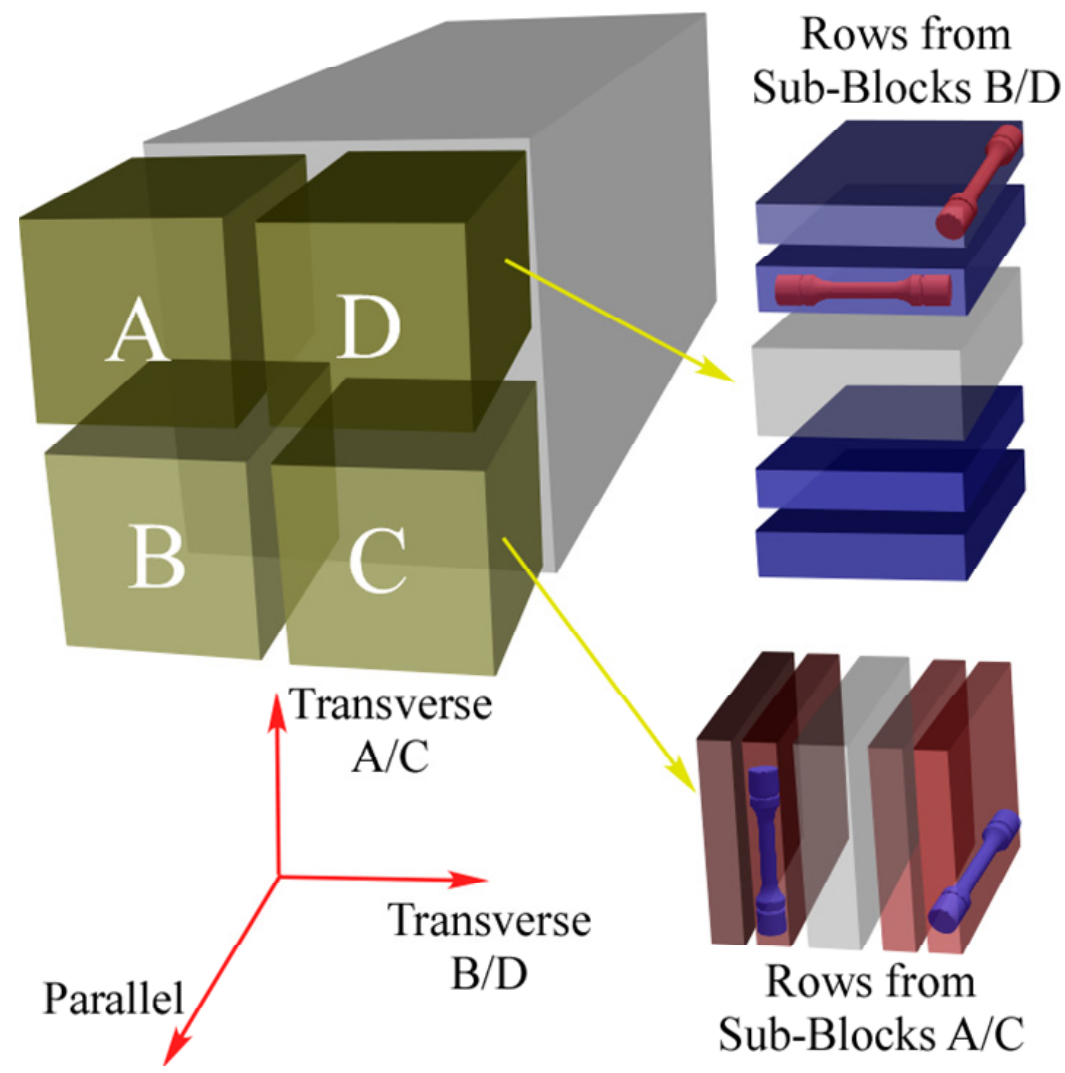

Figure 22. Orientations within the billet must be analyzed in order to determine potential effects of textures that may have developed during processing.

\subsubsection{Compressive Testing}

Testing of graphite under compressive loading was carried out in accordance with ASTM Standard C695-91 ${ }^{8}$ and INL PLN-3467. ${ }^{9}$ The test setup and machining diagram for the right circular cylinder specimens is shown in Figure 23. Specimens were loaded to failure at $1.25 \mathrm{~mm} / \mathrm{min}$, with strain recording via a deflectometer measuring extension of the upper spherical bearing block. 

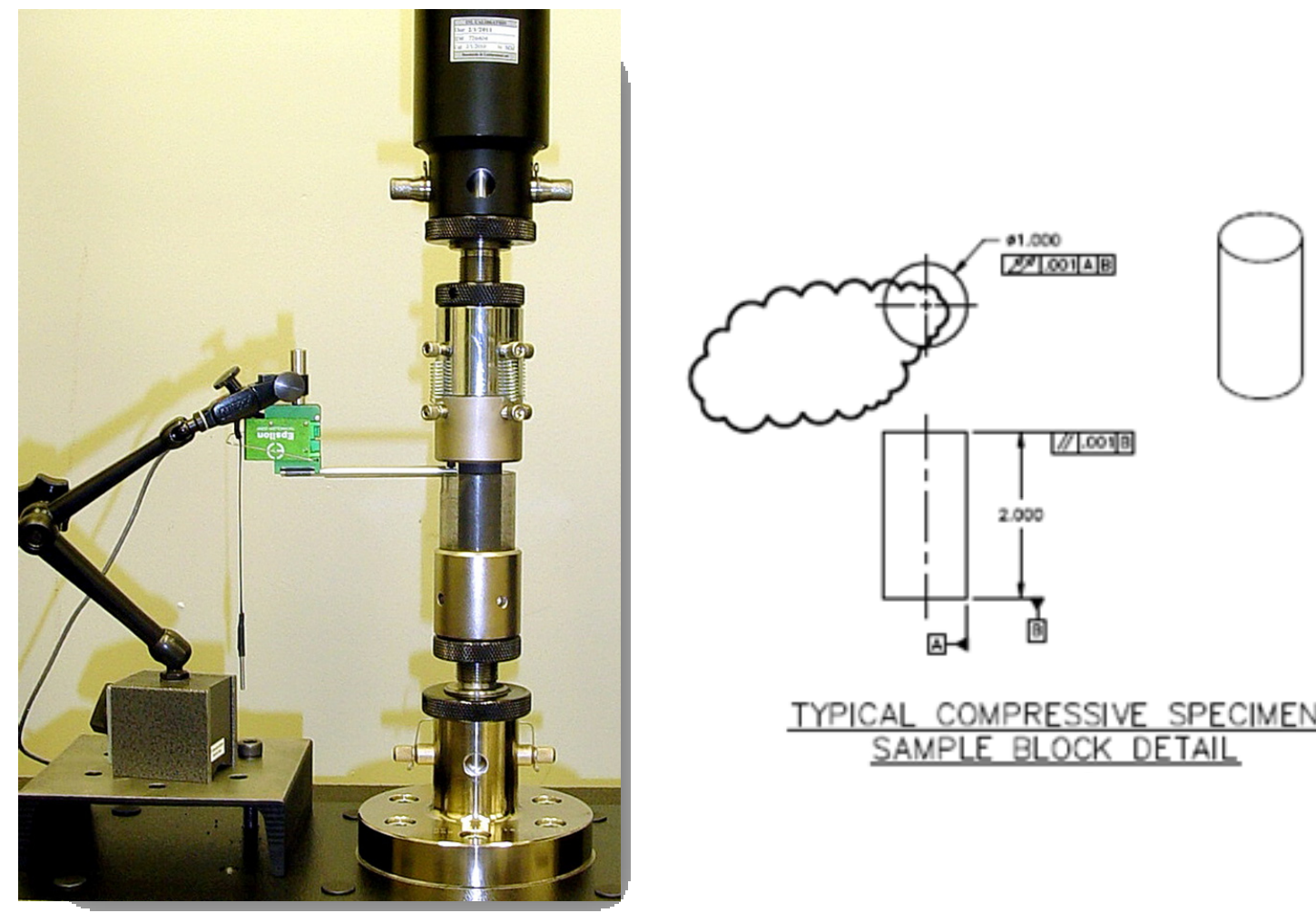

TYPICAL COMPRESSIVE SPECIMEN SAMPLE BLOCK DETAIL

Figure 23. Test setup and specimen diagram for compressive testing on the first billet.

The distributions and descriptive statistics of the compressive stress and strain at failure are shown in Figure 24. As can be seen from the figure, the distributions in both cases are skewed toward the upper limits for stress and strain values, with averages of $81.3 \mathrm{MPa}$ and $2.52 \%$, respectively, for the data from the entire billet. 

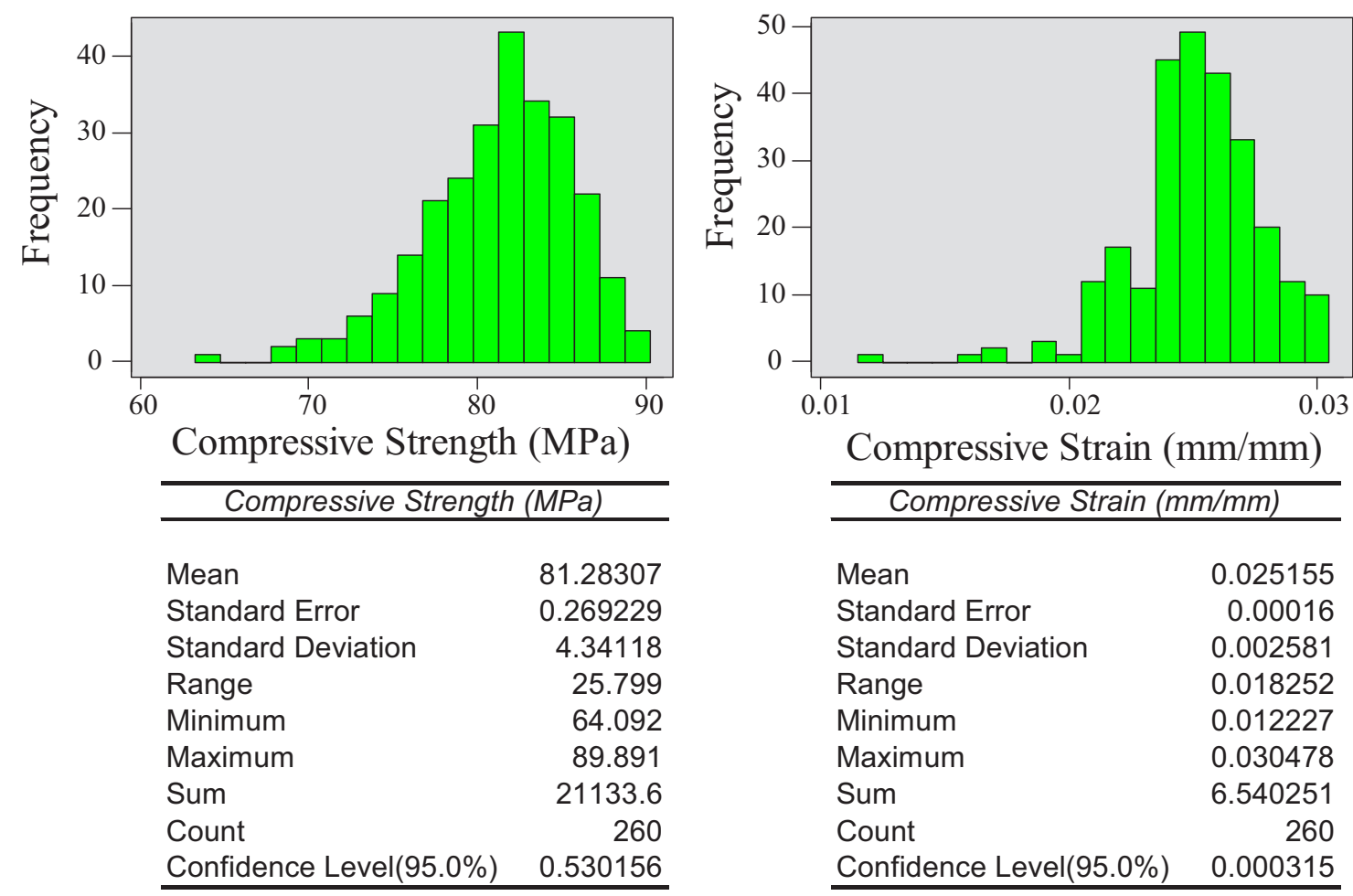

Figure 24. Histograms and descriptive statistics of the compression test results.

Further breakdown into spatial groupings was initiated from the orientations of the test specimens into their most basic groupings - parallel (P) and transverse (T) orientations. The data means are fairly consistent from the box plot distribution (Figure 25), and the detailed analysis of the data groups by ANOVA (Figure 26) show that the data means are equal within the confidence level of $95 \%$. In reality, some subjectivity is left to the analyst as the $\mathrm{P}$ value of 0.059 is just above the hypothesis rejection limit of 0.05 . For the purpose of this illustration, however, the relationships will be considered equal such that further breakdown along those data groupings is not necessary. Figure 27 shows the relationship between the compressive strength and the distance from the center of the billet in the $\mathrm{X}-\mathrm{Y}$ plane grouped by Z-axis position based on slab number. The respective strengths in the parallel and transverse orientations are combined in the illustrated data groups as a result of their statistically-equivalent mean values. As was seen in the density plots, some variation is seen in the compressive strength plot as the values are taken from positions closer and closer to the outer edge. Although the average strength values for each of the plotted groups are within a few MPa, the trend shows generally decreasing strength at the outer billet positions throughout the span of the $\mathrm{Z}$ axis. 


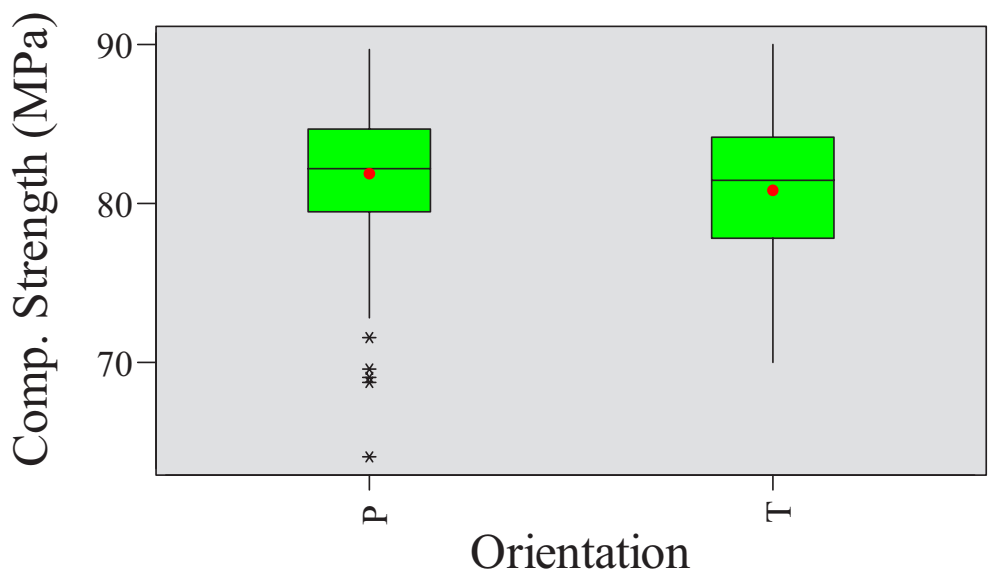

Figure 25. Box plot of compressive strength shows equivalence of compressive strength values in different orientations.

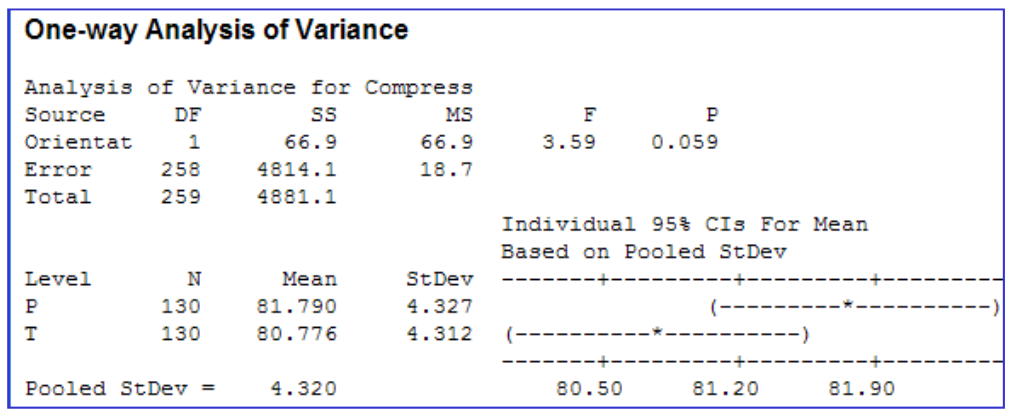

Figure 26. ANOVA result demonstrates equivalence between the mean value of compressive strength based on orientation through a $\mathrm{P}$ value $>0.05$. 

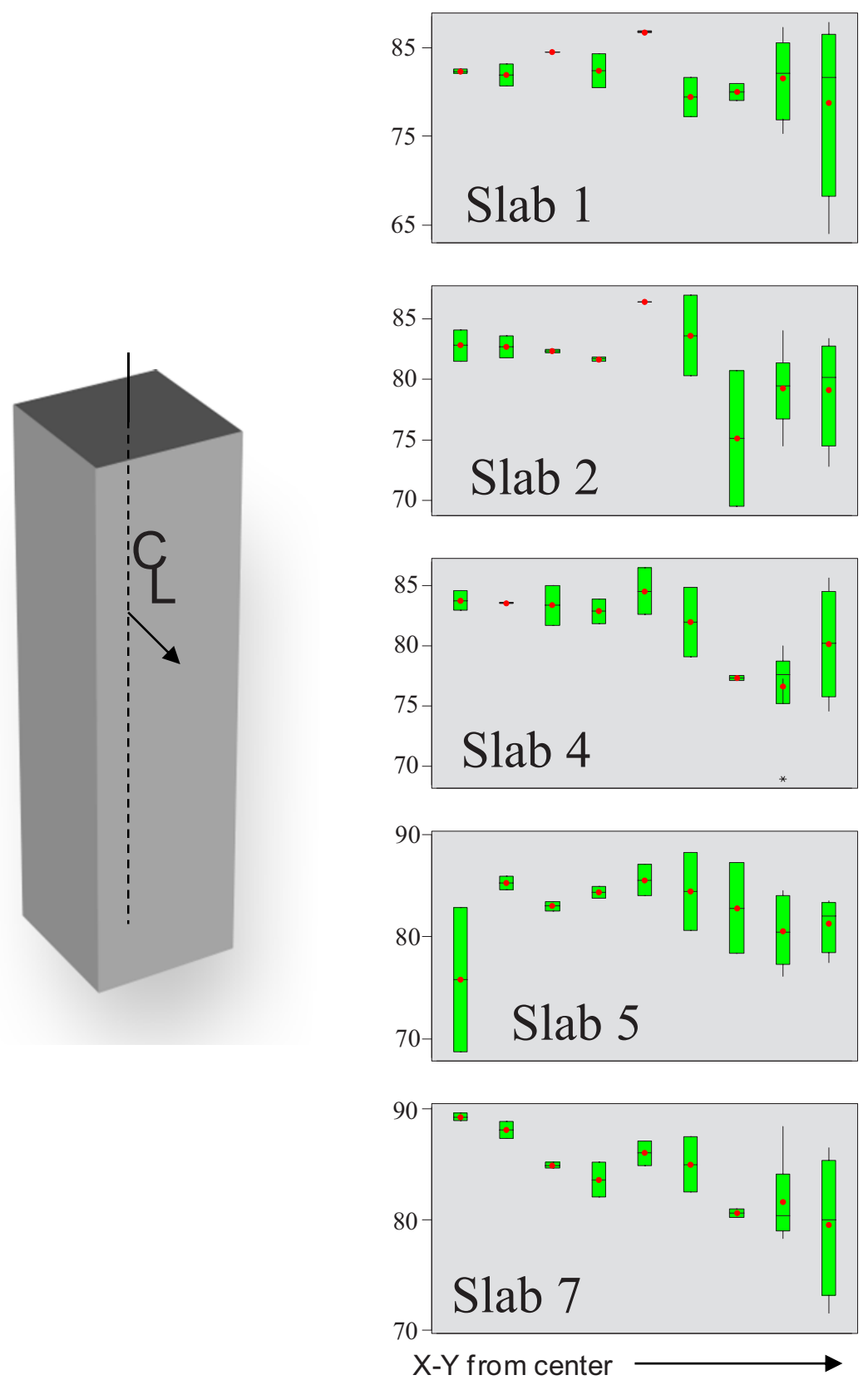

Figure 27. Box plots grouped by X-Y trend from the billet centerline as compared between different slabs (Z-height positions).

\subsubsection{Fracture Analysis}

Evaluation of the broken compressive specimens indicated that an additional parameter of mechanical behavior might be quantifiable. The pattern of fracture was reasonably consistent within a few descriptive areas based upon the remnant pieces from each specimen. Figure 28 is an example of the common fracture patterns seen throughout the testing of the 260 specimens from the first billet. Category 1 fracture, or beltline fracture, is being described as the type of fracture that initiates away from the specimen ends and results in a wedge-shaped section crumbling from the specimen surface at failure. 

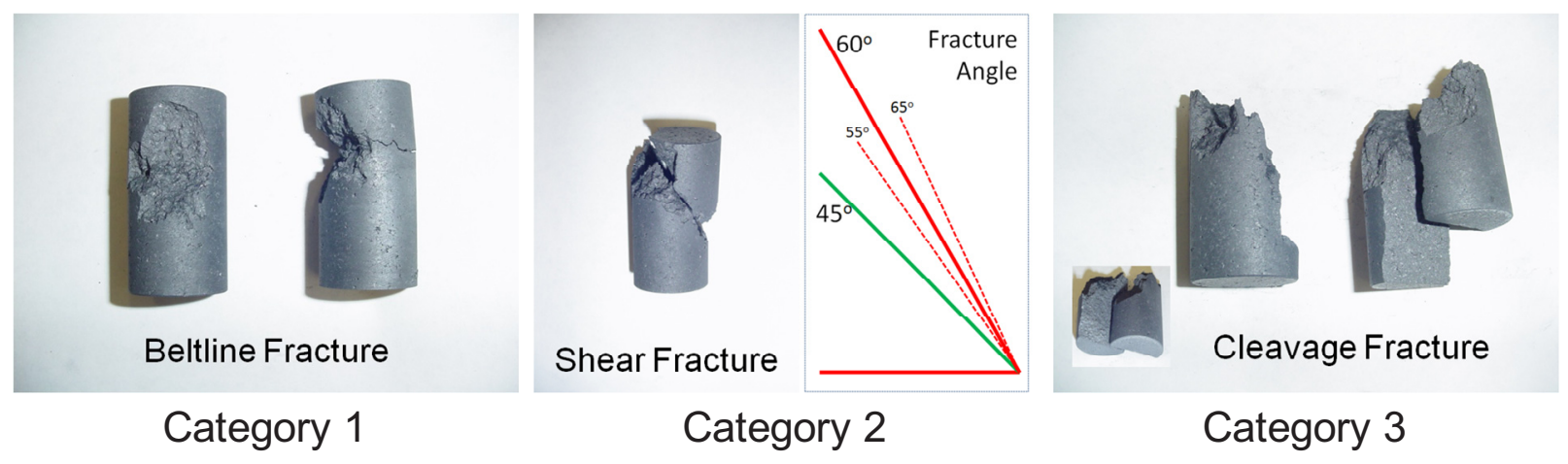

Figure 28. Examples of the three main fracture patterns being quantified.

Compression of some ceramic materials results in a failure in tension around the beltline of right-circular cylinder specimens due to the binding of the specimen ends against the platen. ${ }^{11}$ This has been speculated to result in an uneven deformation around the center of the specimen as it effectively bows out under a compressive load. Although further characterization would be necessary to conclude that this type of barrel-shaped deformation and failure is occurring, the Category 1 fracture may be an indication that this deformation component exists.

Category 2 fracture, or shear fracture, is described in this data set as fracture that occurs in shear as evidenced by a planar fracture surface at some angle from the central axis of the specimen. For an isotropic, homogeneous material under pure shear loading, this angle is commonly $45^{\circ}$ from the centerline axis. Over the course of compression testing on the first billet, specimens failed consistently at a fracture angle much closer to $60^{\circ}$. This evaluation was confirmed through the use of a simple comparative visual standard.

Category 3 fracture, or cleavage fracture, involved a large fracture surface area that was parallel to the load direction. The physical separation of the graphite specimens generally included a visible shear segment prior to the cleavage occurring, but this type of fracture was considered predominant if the surface area of cleavage contained at least $50 \%$ of the specimen center plane area. Category 4 fracture was the default characterization for fracture remnants that sis not appear to positively reflect any of the distinct fracture types. An automated program was devised to utilize photographic standards to tabulate data on the type of fracture that was most distinct from each broken specimen. Figure 29 shows the fracture descriptions that were available to the evaluator to give further detail to the photographic standard guidance. Figure 30 is the resulting distribution of fracture types based upon these descriptions. Although each of the specimens examined consistently showed a combination of fracture types, and a case could be made for the correlation between each of the types simply based on the location of failure initiation, the most common fracture type observed was Category 2. Since specimen binding against the platen is enough of a concern for some materials that special geometries are designed or specimen-end lubricants are used, this type of test anomaly requires some degree of consideration. The quantification of each of the fracture types demonstrated that Category 1 fracture was not a commonly observed fracture type. Coupled with the fact that the beltline failures rarely, if ever, manifested themselves around the majority circumference of the specimen, it is quite likely that these failures were also attributable to simple shear failure that initiated in a location that was at some point of the specimen beltline that would result in a wedge-shaped failure propagation. This may be further evidenced by the slightly decreased mean value (Figure 31) for stress at failure of Category 1 fractures - failure was initiated at an existing flaw that was not necessarily under the maximum resolved stress based on the applied load. Based upon these observations, no modifications to the compression testing procedure are deemed necessary to prevent anomalous failures resulting from the specimen ends binding against the platen surfaces. 


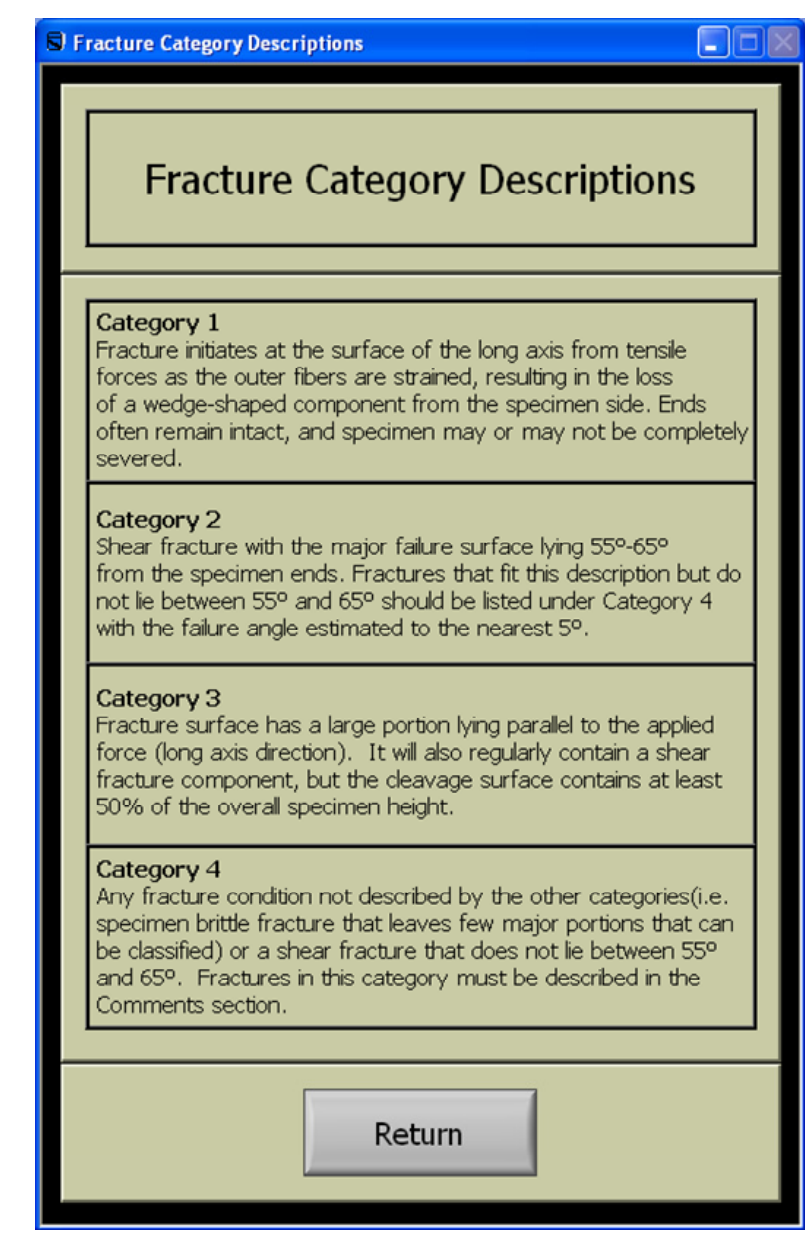

Figure 29. Description window from compressive specimen classification program to quantify fracture patterns.

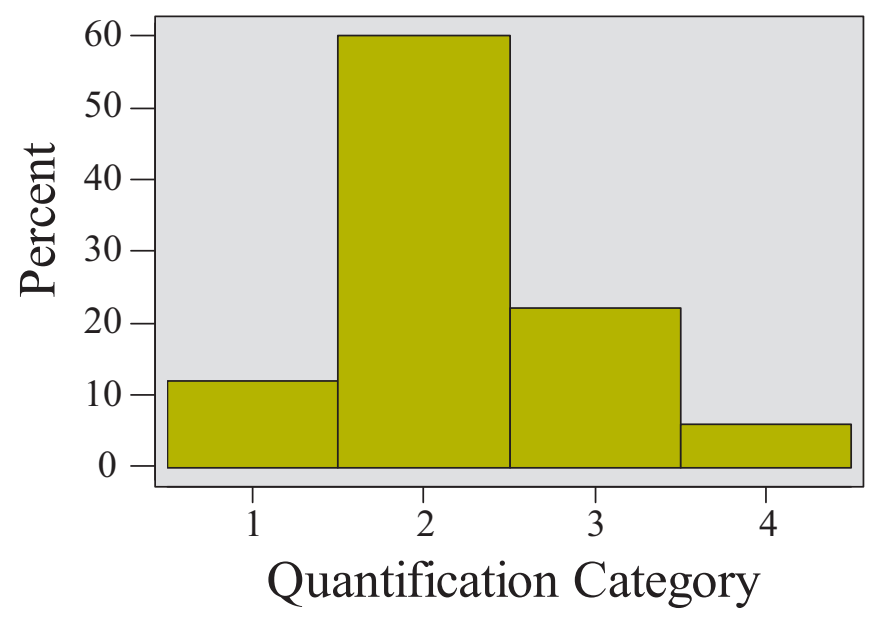

Figure 30. Category 2, or the shear pattern of fracture, was the most prevalent fracture description. 


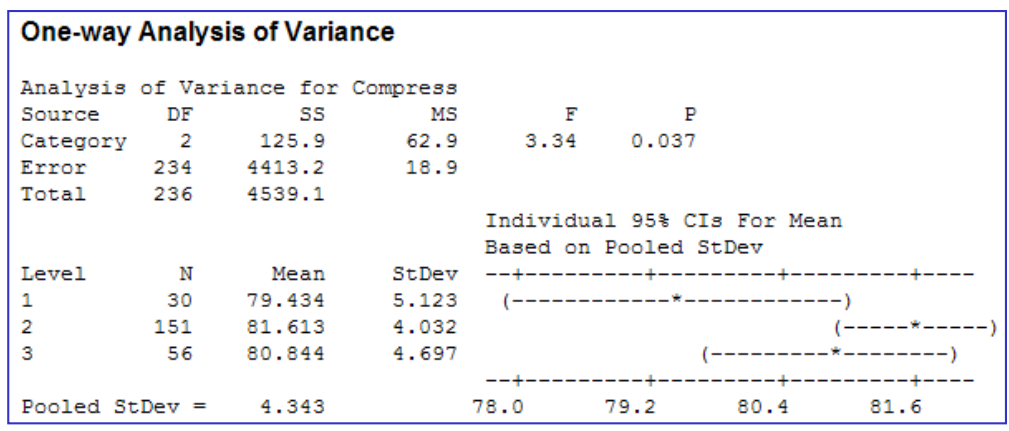

Figure 31. Fractures demonstrating the Category 1 (beltline) pattern may have been occurring at lower ultimate stresses.

\subsubsection{Tensile Testing}

The testing of graphite under tensile loading was carried out under the guidance of ASTM Standard C749-0 $8^{6}$ and PLN-3467. ${ }^{9}$ In order to allow the uniaxial loading of the specimen while applying a pulling load, tensile test specimens are somewhat more complicated in shape than compression or flexural specimens, which limited the additional testing that could be done on these specimen types outside of the specific mechanical test that it was designed for. The applicable setup and machining diagram for the right circular cylinder specimens is shown in Figure 32. Specimens were subjected to a linear increasing load rate to failure of $\mathrm{MPa} / \mathrm{min}$. A biaxial extensometer with strain measurement on opposing sides of the specimen gauge was used so that differential strains and the presence of bending moments could be recorded. 

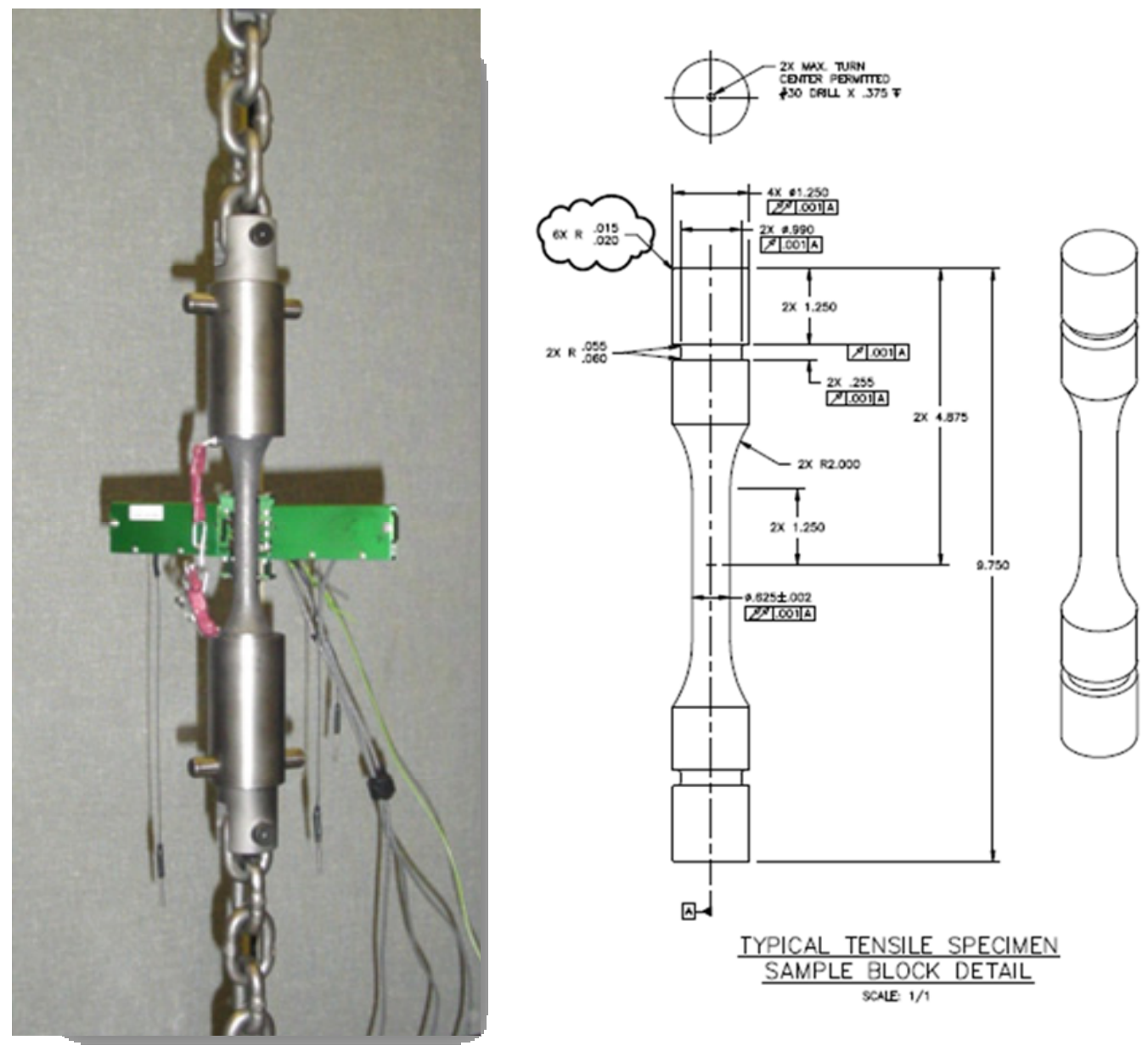

Figure 32. Tensile test setup for applying a uniaxial load (left) and associated specimen diagram (right).

The basic mechanical properties measured during the tensile testing of 255 specimens from the first billet are shown in Figure 33. The stress at failure over the entire set of test results averaged 19.6 MPa, at an average strain of $0.263 \%$. The modulus of elasticity during deformation was also recorded, but will be presented along with other evaluations of modulus in Section 3.3.1. 


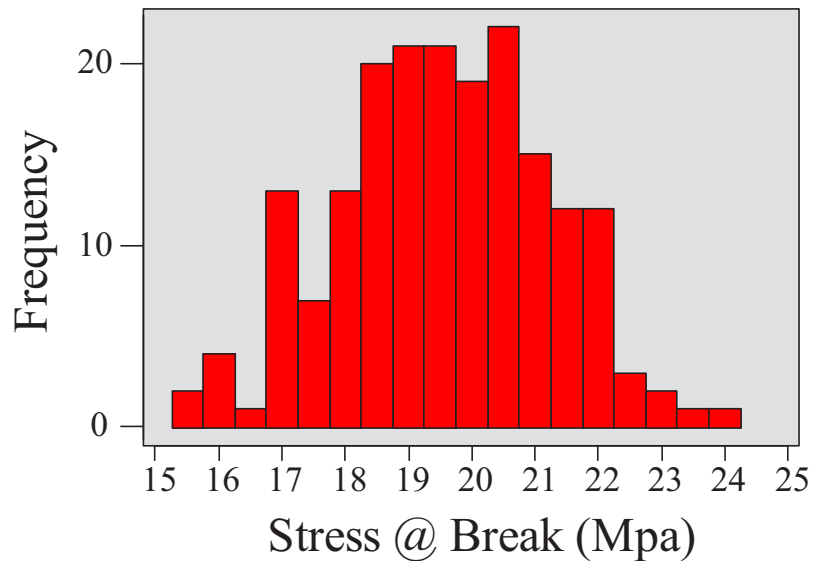

\begin{tabular}{lr}
\hline \multicolumn{2}{c}{ Stress @ Brk (Mpa) } \\
\hline & \\
Mean & 19.59909 \\
Standard Error & 0.103198 \\
Median & 19.621 \\
Mode & 19.145 \\
Standard Deviation & 1.647942 \\
Range & 8.146 \\
Minimum & 15.615 \\
Maximum & 23.761 \\
Sum & 4997.769 \\
Count & 255 \\
Confidence Level(95.0\%) & 0.203233 \\
\hline
\end{tabular}

\begin{tabular}{lr}
\hline \multicolumn{2}{c}{ Average Strain @ Break (\%) } \\
\hline & \\
Mean & 0.263263 \\
Standard Error & 0.001673 \\
Median & 0.26166 \\
Mode & 0.24507 \\
Standard Deviation & 0.026713 \\
Range & 0.16048 \\
Minimum & 0.19951 \\
Maximum & 0.35999 \\
Sum & 67.13195 \\
Count & 255 \\
Confidence Level(95.0\%) & 0.003294 \\
\hline
\end{tabular}

Figure 33. Descriptive results and distribution of strength properties from tensile testing of the first billet.

Evaluating the spatial relationships of tensile properties, the variation of tensile strength along the $\mathrm{Z}$ axis (Figure 34) does not indicate any strong specific trend. The values are relatively tight and little variation in one way or another seems dependent upon the Z-axis position within the billet. 


\section{Stress@Brk (Mpa)}
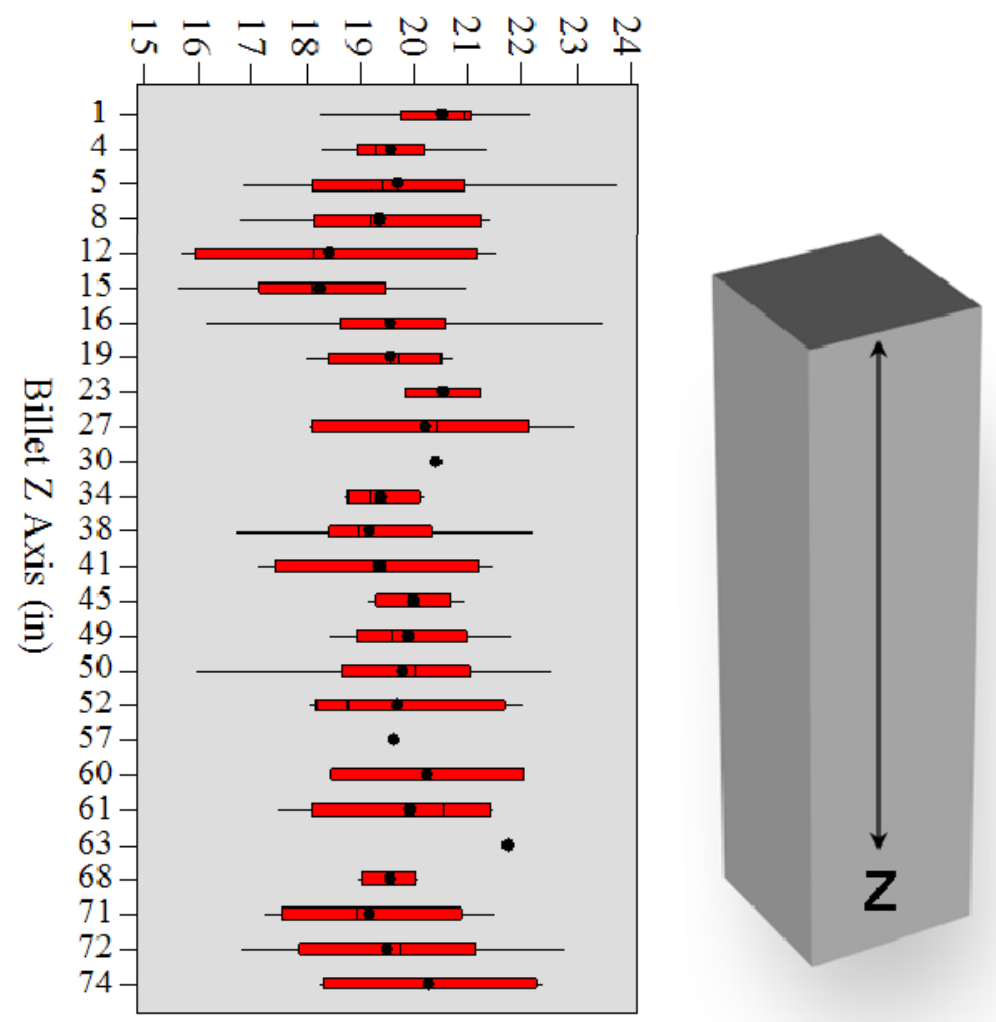

Figure 34. Grouped stresses by Z-axis position do not indicate a strong trend based on location along the billet's long axis.

Breaking down the tensile strength by orientation also yields fairly close average values within the specific data sets (Figure 35) between the pooled transverse orientation and the parallel direction. For some types of production processes, it is expected that there is a strong enough texturing effect between with-grain and against-grain orientations that strength measurements can be disparate by several percent. ${ }^{12}$ That does not appear to be the case with this billet, although a clearer picture of any inherent texturing might be evident when breaking down the transverse orientation by the two orthogonal directions, $\mathrm{A} / \mathrm{C}$ and $\mathrm{B} / \mathrm{D}$. The resulting $\mathrm{P}$ value (Figure 36 ) is much less indicative of matching mean values, although at 0.055 it is still above the level to predict a quantifiable difference in means with a confidence level of $95 \%$. An interesting feature of this outcome is that the parallel orientation actually has relative strength values that are between the two X-Y plane directions - the transverse orientations are actually more disparate from each other (Figure 37) than from the parallel-oriented specimens. This is the type of observation that is not clear enough to make a distinction based upon the available data sets, but can be compared to other similar trends from other mechanical property measurements or supplemented by microstructural investigations in order to determine from observation whether texturing effects are prevalent between the orientations being compared. 


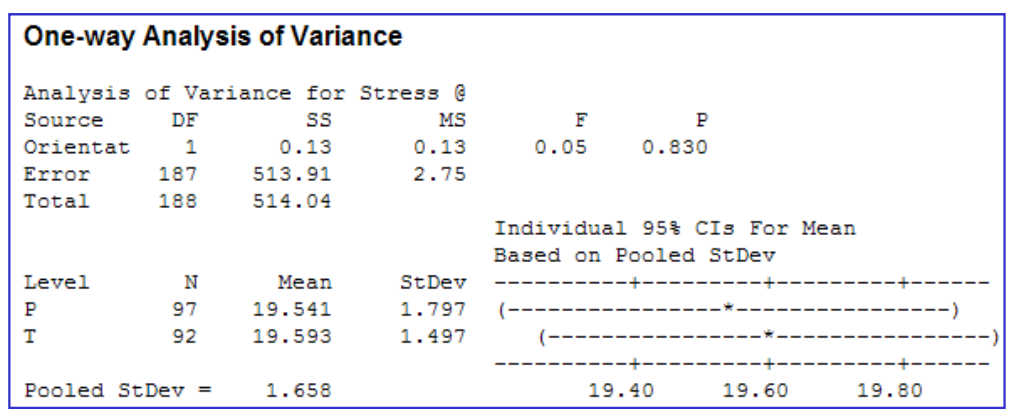

Figure 35. No differences in mean values for stress are indicated by the high $\mathrm{P}$ value between parallel (P) and transverse $(\mathrm{T})$ orientations.

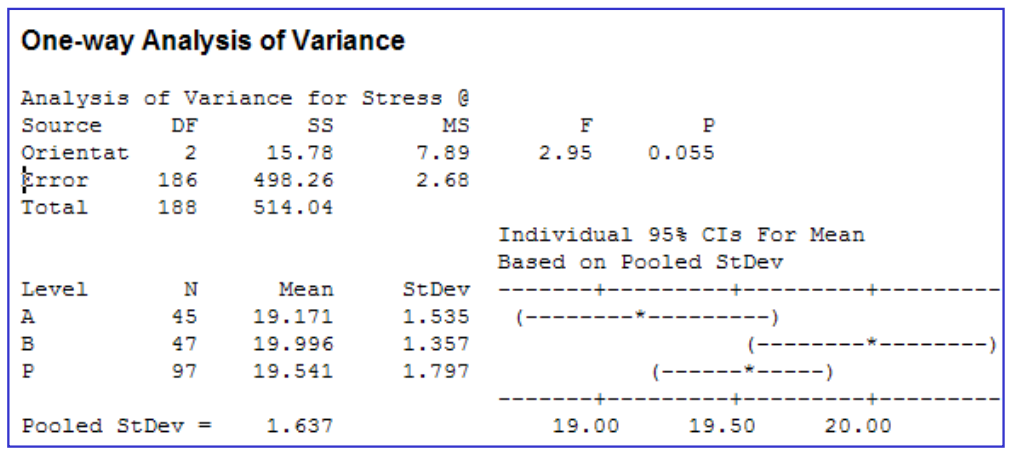

Figure 36. The $\mathrm{P}$ value is much closer to 0.05 when the transverse orientations are broken down into $\mathrm{A} / \mathrm{C}$ and $\mathrm{B} / \mathrm{D}$ groupings.

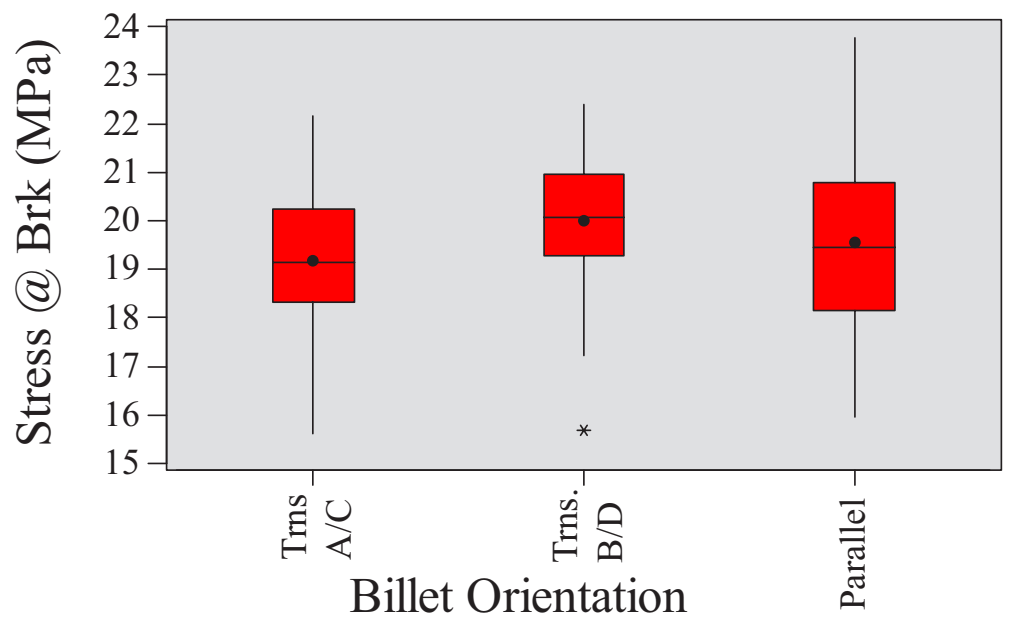

Figure 37. The box plot of the three orthogonal orientations demonstrates visually that the trend for tensile stress values is higher in one transverse orientation $(\mathrm{B} / \mathrm{D})$ than in the parallel orientation, and lower in the other $(\mathrm{A} / \mathrm{C})$.

\subsubsection{Flexural Testing}

The testing of graphite under a bending stress was performed in accordance with ASTM Standard C651-91 ${ }^{7}$ and INL PLN-3467. ${ }^{9}$ The test specimens and setup, shown in Figure 38, were designed to apply a uniform load by rollers $40 \mathrm{~mm}$ apart to a specimen supported by rollers $120 \mathrm{~mm}$ apart, resulting in a 4-point, one-third point flexural test. In order for additional data to be made available for a more fundamental understanding of the stress response characteristics of graphite in bending, the full deflection 
range was measured and recorded using a deflectometer positioned under the center location of the specimen between the load rollers. This setup results in an accurate measurement of the maximum specimen deflection in bending.
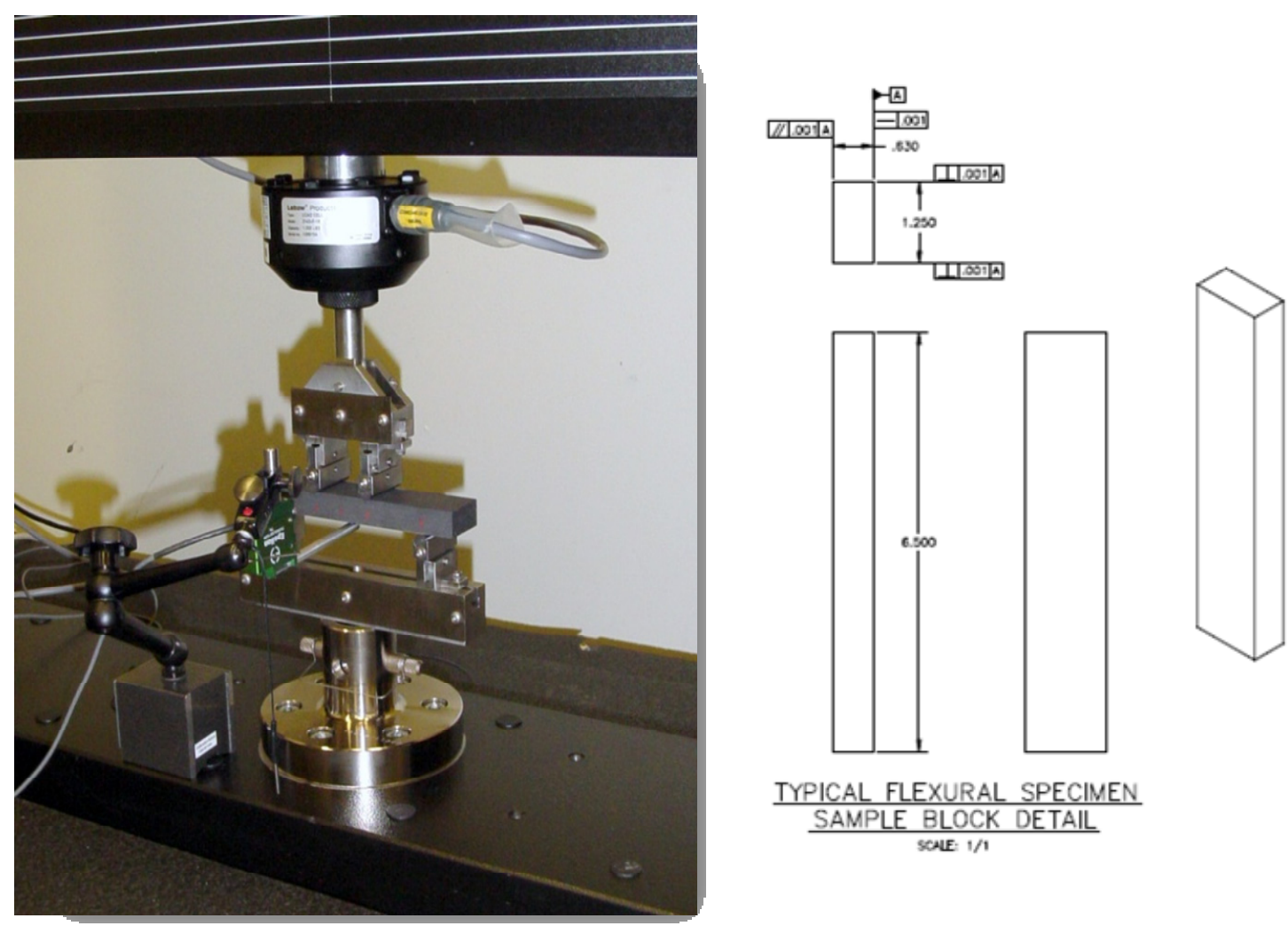

Figure 38. 4-point, third-point flexural test setup (left) and graphite test specimen dimensions for samples from the first billet.

The distribution of flexural strength and descriptive statistics of the flexural results from the entire billet are shown in Figure 39. The distribution is well-centered on the mean flexural strength of $27.8 \mathrm{MPa}$. Measured deflection of the specimens averaged $0.629 \mathrm{~mm}$ in the compressive (negative) direction. 


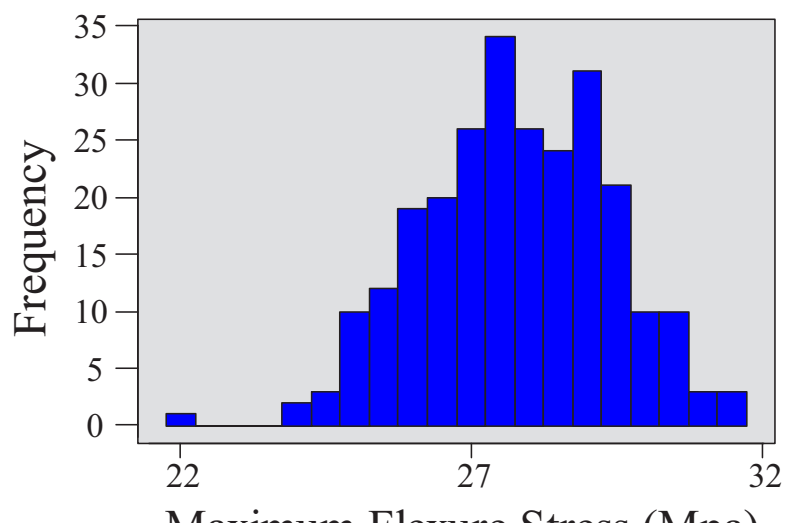

Maximum Flexure Stress (Mpa)

\begin{tabular}{lr}
\hline \multicolumn{2}{c}{ Maximum Flexure Stress (Mpa) } \\
\hline & \\
Mean & 27.76608 \\
Standard Error & 0.10143 \\
Standard Deviation & 1.619704 \\
Range & 9.3 \\
Minimum & 22.15 \\
Maximum & 31.45 \\
Sum & 7080.35 \\
Count & 255 \\
Confidence Level(95.0\%) & 0.199751 \\
\hline
\end{tabular}

\begin{tabular}{lr}
\hline Mid-span Deflection @ Pmax $(\mathrm{mm})$ \\
\hline & \\
Mean & -0.629424 \\
Standard Error & 0.00236 \\
Standard Deviation & 0.037693 \\
Range & 0.228 \\
Minimum & -0.727 \\
Maximum & -0.499 \\
Sum & -160.503 \\
Count & 255 \\
Confidence Level(95.0\%) & 0.004649 \\
\hline
\end{tabular}

Figure 39. Distribution of flexural strength values and descriptive statistics for strength and mid-span deflection values.

To re-affirm the observations made in tensile testing by orientation within the billet, Figure 40 shows the difference in values for flexural strength based on specimens with the same orientation for outer-fiber loading as was evaluated across the gauge under load during tensile testing. Demonstrating similarity between the two data sets, the relative mean for the specimens strained in the parallel orientation lies slightly between the transverse A/C orientation (lower) and the transverse B/D orientation. Quantified proof of this difference is shown in the ANOVA result (Figure 41), which accepts the hypothesis of differing means as manifested by the calculated $\mathrm{P}$ value of 0.009 .

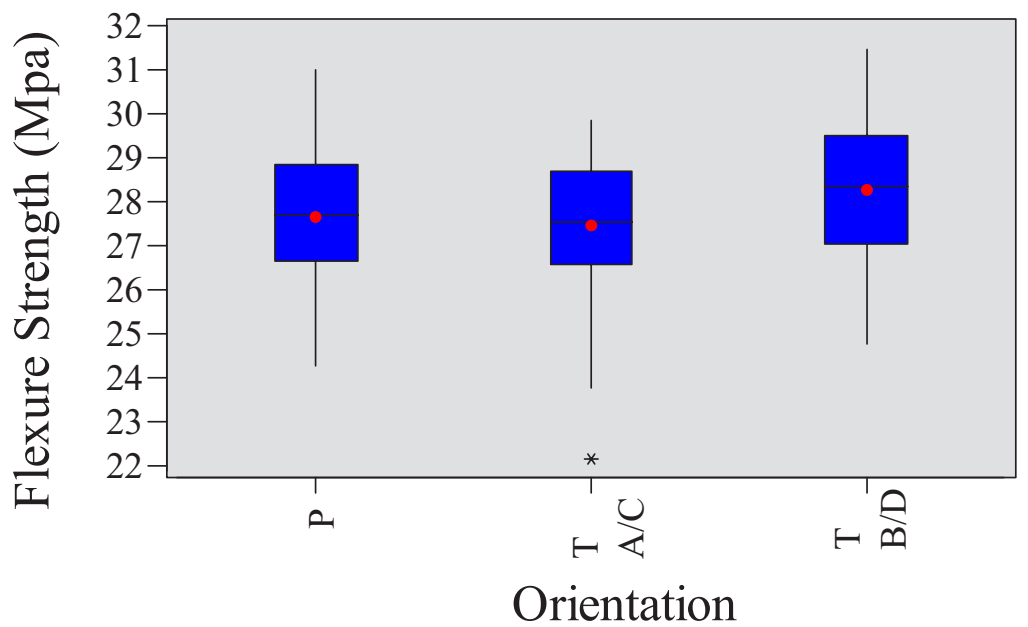

Figure 40. Flexure strength vs. orientation shows the same pattern seen in flexural test results for orientation effects on specimen strength. 


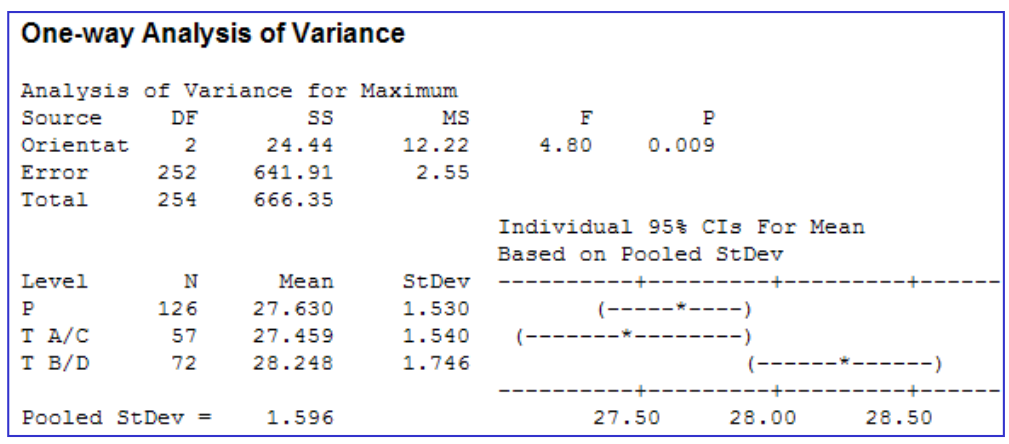

Figure 41. The visual trend seen in Figure 40 is confirmed as an existing difference in mean strength values, demonstrated by the $\mathrm{P}$ value of 0.009 .

Utilizing the information gained in evaluating the orientation relationships, those specific subgroups can be used to evaluate variations along other data sets. An example of the breakdown by orientation is seen in Figure 42 for X-Y plan variation in flexural strength based upon the three distinct billet orientations. As seen in the figure, this specific subgroup breakdown does not indicate any specific trend in the flexural stress at failure as the specimens are taken from sections of the billet closer and closer to the edge. Some decrease in stress is seen in the parallel direction, but the trend is not visibly distinct. For the transverse orientations, the specimen geometry limited the number of specimens that could physically be extracted from the billet from different locations in the transverse orientation, limiting the effective data population at this point to a level that will not allow distinct trends to emerge. 


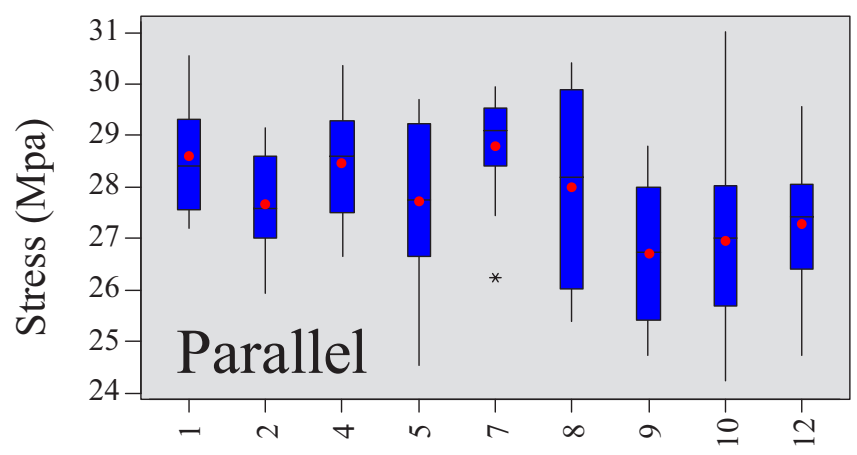

Distance from Centerline (in)

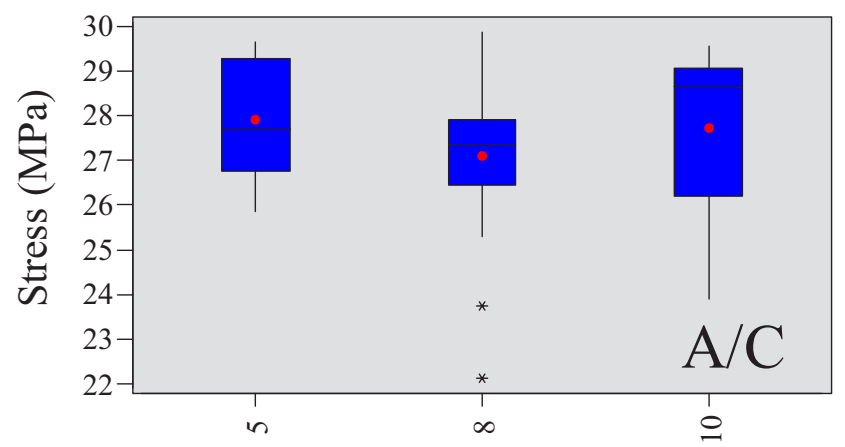

Distance from Centerline (in)

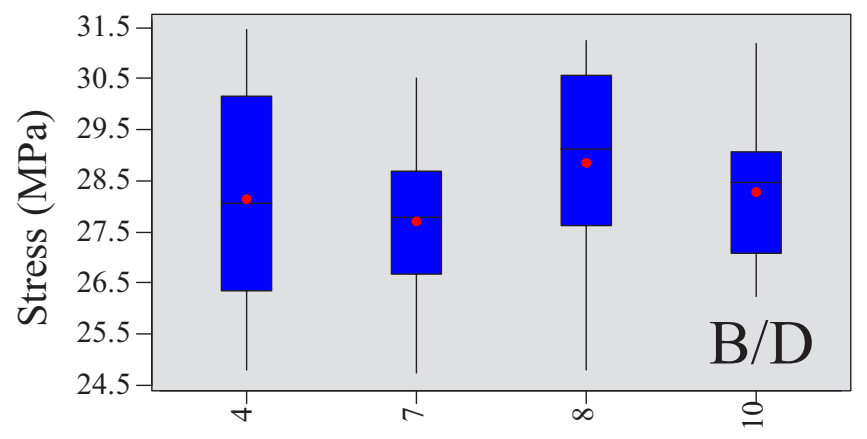

Distance from Centerline (in)

Figure 42. Flexural strength relationships for the trend of material properties moving from the billet centerline to the outer edges (broken down by orientation groups). Reduced specimen populations by position in the transverse orientation limit trend resolution.

\subsection{Physical Property Data}

In addition to the extensive density measurements that were measured and recorded, other types of evaluations were possible prior to mechanical testing that gave further information on the physical behavior and characteristics of the graphite from the first billet. Flexural specimens were ideal for modulus calculations through the recording of fundamental frequency measurements, and modulus calculations could also be made on compression specimens through the measurement of sonic velocity through the material. The comparison of these measurements with actual recorded measurements from mechanical testing provides a method whereby the techniques for evaluating the properties of nuclear graphite can be validated, or, where differences exist, provide a direction for refining the techniques or investigating whether additional bulk properties have an effect on measured characteristic values. 
Improvements to existing test approaches based upon a more accurate understanding of the difference between compressive and tensile moduli ${ }^{13}$ is a realistic outcome of this program.

\subsubsection{Elastic Modulus}

Striking a specimen that is supported a specific node points that facilitate vibration in a specific mode can be used to record the fundamental vibration frequency of the material (Figure 43). This value for fundamental frequency can be converted to a value representing the material's dynamic Young's modulus, as is specifically outlined in ASTM Standard C747-93. ${ }^{14}$ For this program, the refinement of the technique had already been established during the analysis of AGC specimens (INL PLN-3267, "AGC-2 Characterization Plan" ${ }^{\text {"15 }}$ ) through the employment of frequency measurement techniques detailed in ASTM Standard C1259-08. ${ }^{16}$ As the flexural specimens were geometrically ideal for this type of measurement, every one of the machined flexural samples was tested in the flexural mode and the respective moduli calculated.

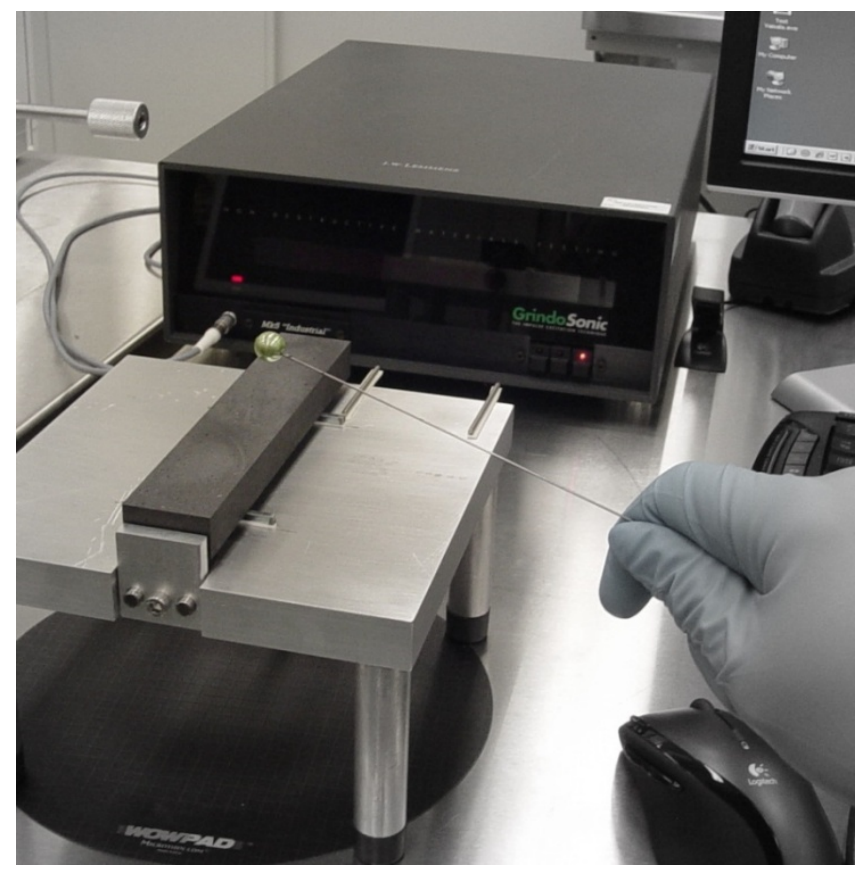

Figure 43. Modulus measurements can be made by allowing a specimen to vibrate at its fundamental frequency between specific nodes.

Figure 44 shows the resulting histogram for the dynamic Young's modulus (left) based on fundamental frequency measurements in the flexural mode. Modulus values were also recorded during the running of tensile tests, with the descriptive statistics shown in the upper right of Figure 44. For flexural testing, a 20\% sampling was taken from raw files of the flexural results, and data for the flexural modulus was calculated by assuming that the linear region of the stress-strain curve was the range of data from 0 to $10 \mathrm{MPa}$. The average values for the moduli from flexural and tensile testing are quite similar, although both values are below the average modulus $(12.1 \mathrm{GPa})$ measured via fundamental frequency calculations. 


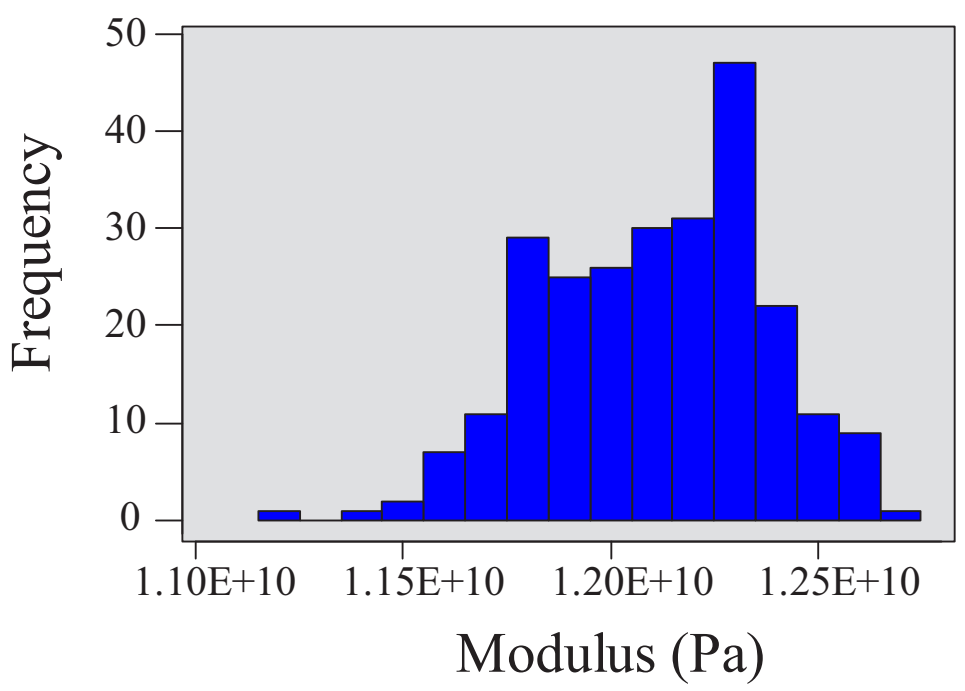

\begin{tabular}{lr}
\hline \multicolumn{2}{l}{ Modulus (Automatic Young's) (Gpa) } \\
\hline Mean & 10.09938 \\
Standard Error & 0.053665 \\
Median & 10.16 \\
Mode & 10.434 \\
Standard Deviation & 0.856965 \\
Range & 7.6124 \\
Minimum & 7.0826 \\
Maximum & 14.695 \\
Sum & 2575.342 \\
Count & 255 \\
Confidence Level(95.0\%) & 0.105685 \\
\hline \multicolumn{2}{c}{ Elastic Modulus (Flexural) } \\
\hline \multicolumn{2}{c}{$r$} \\
\hline Mean & $9.941 \mathrm{E}+09$ \\
Standard Error & $3.310 \mathrm{E}+\mathrm{U} /$ \\
Standard Deviation & $2.368 \mathrm{E}+08$ \\
Range & $1.149 \mathrm{E}+09$ \\
Minimum & $9.443 \mathrm{E}+09$ \\
Maximum & $1.059 \mathrm{E}+10$ \\
Sum & $5.070 \mathrm{E}+11$ \\
Count & 51 \\
Confidence Level(95.0\%) & $6.66 \mathrm{E}+07$ \\
\hline \multicolumn{2}{c}{}
\end{tabular}

Figure 44. The distribution for dynamic Young's (elastic) modulus is centered on a mean value of 1.21 $\mathrm{GPa}$, higher than that measured during tensile and flexural testing.

\subsubsection{Shear Modulus}

Measuring the fundamental frequency in torsion can be converted to the material's shear modulus value, also with guidance from ASTM Standard C747-93. ${ }^{14}$ The calculated shear modulus values (Figure 45) average $4.92 \mathrm{GPa}$, which, as is normally observed for homogeneous materials, is well below the calculated values for the elastic modulus. Interestingly, the compressive modulus values compare more favorably with the shear modulus that they do for the elasticity modulus values seen in Figure 44. The modulus values, taken as a $20 \%$ sampling based on results listed in raw data files, may be indicative of an elastic shear strain component during compressive testing - manifested to some extent by the fracture pattern most commonly seen (Figure 45, right) in the specimens from this graphite billet.

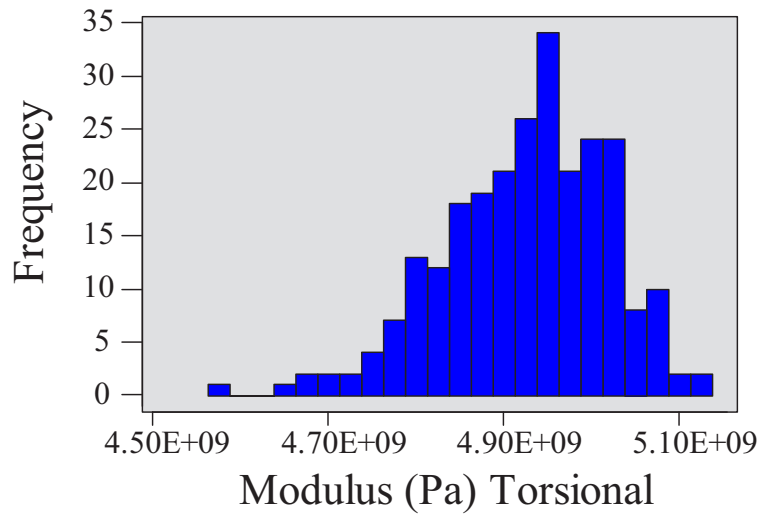

\begin{tabular}{lr}
\hline \multicolumn{2}{c}{ Elastic Modulus (Compressive) } \\
\hline \multirow{2}{*}{ Mean } & $6.504 \mathrm{E}+09$ \\
Standard Error & $3.483 \mathrm{E}+07$ \\
Standard Deviation & $2.512 \mathrm{E}+08$ \\
Range & $1.141 \mathrm{E}+09$ \\
Minimum & $5.931 \mathrm{E}+09$ \\
Maximum & $7.072 \mathrm{E}+09$ \\
Sum & $3.382 \mathrm{E}+11$ \\
Count & 52 \\
Confidence Level(95.0\%) & $6.99 \mathrm{E}+07$ \\
\hline
\end{tabular}

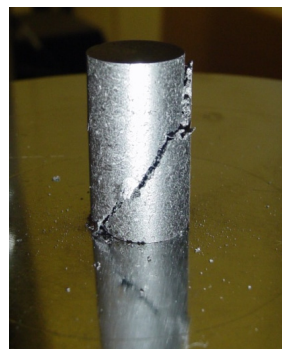

Figure 45. Shear modulus values from flexural specimens vibrated in the torsional mode (left). Modulus values from compression tests (center) are closer to the shear modulus values than they are to the elastic modulus values, which may be a product of the deformation mode leading to fracture (right). 


\subsubsection{Sonic Velocity Measurements}

Modulus values were also extracted from compressive specimens via measurements of sonic velocity in accordance with ASTM Standard C769-09. ${ }^{17}$ The descriptive statistics of the results, taken on a 41-specimen sampling of the compressive specimen population, are shown in Figure 46. The results of these values indicate a close correlation with those measured via fundamental frequency of flexural specimens. The values are slightly higher, and in the case of the elastic modulus are more accurate when corrected for measured Poisson's ratio $(\mu)$ values (Figure 46, lower left).

\begin{tabular}{lr}
\hline \multicolumn{2}{c}{ Elastic Modulus, [Pa] } \\
\hline Mean & $1.572 \mathrm{E}+10$ \\
Standard Error & $5.089 \mathrm{E}+07$ \\
Median & $1.577 \mathrm{E}+10$ \\
Sample Variance & $1.062 \mathrm{E}+17$ \\
Minimum & $1.485 \mathrm{E}+10$ \\
Maximum & $1.638 \mathrm{E}+10$ \\
Sum & $6.447 \mathrm{E}+11$ \\
Count & 41 \\
Confidence Level(95.0\%) & $1.03 \mathrm{E}+08$ \\
\hline \multicolumn{1}{c}{ Elastic Modulus, [Pa] $(\mu)$} \\
\hline & \\
\hline & \\
Mean & $1.318 \mathrm{E}+10$ \\
Standard Error & $3.377 \mathrm{E}+07$ \\
Median & $1.314 \mathrm{E}+10$ \\
Sample Variance & $4.675 \mathrm{E}+16$ \\
Minimum & $1.264 \mathrm{E}+10$ \\
Maximum & $1.369 \mathrm{E}+10$ \\
Sum & $5.404 \mathrm{E}+11$ \\
Count & 41 \\
Confidence Level(95.0\%) & $6.82 \mathrm{E}+07$ \\
\hline
\end{tabular}

\begin{tabular}{lr}
\hline \multicolumn{2}{c}{ Poisson's Ratio } \\
\hline Mean & 0.246682501 \\
Standard Error & 0.000912735 \\
Median & 0.247062101 \\
Sample Variance & $3.41565 \mathrm{E}-05$ \\
Minimum & 0.235182144 \\
Maximum & 0.258777899 \\
Sum & 10.11398255 \\
Count & 41 \\
Confidence Level(95.0\%) & 0.001844707 \\
\hline \multicolumn{1}{c}{ Shear Modulus, $\left[\begin{array}{r} \\
\hline\end{array}\right.$} \\
\hline & \\
Mean & $5.286 \mathrm{E}+09$ \\
Standard Error & $1.353 \mathrm{E}+07$ \\
Median & $5.281 \mathrm{E}+09$ \\
Sample Variance & $7.511 \mathrm{E}+15$ \\
Minimum & $5.102 \mathrm{E}+09$ \\
Maximum & $5.524 \mathrm{E}+09$ \\
Sum & $2.167 \mathrm{E}+11$ \\
Count & \\
Confidence Level(95.0\%) & $2.74 \mathrm{E}+07$ \\
\hline
\end{tabular}

Figure 46. Descriptive statistics of modulus and Poisson's ration values calculated from the sonic velocity measured in compressive specimens.

\subsection{Test Standard Development}

An additional benefit to the highly-controlled execution of numerous tests using limited variation in fabrication and source material is the ability to help refine existing test standards outside of formal round-robin evaluations. Direct involvement with the ASTM committees on petroleum products (graphite) allows the sharing of empirical evidence or observations that can prove useful in determining whether test parameters or restrictions are appropriate in the context of the published standards. Observations during extensive tensile testing provided feedback on several factors that are presently included in ASTM standards that regulate the testing of graphite. One observation does not necessarily apply directly to tensile testing, but rather to flexural testing, in which the standard (ASTM C651-91 ${ }^{8}$ ) presently prescribes that specimens must be dried for two hours in a drying oven and held in a desiccator for storage until ready to test. The requirement is germane to the testing of ceramics, which are often the basis for the graphite standards, but no specific evaluations have been carried out measuring the effects of moisture at different ambient levels in a laboratory environment. The concern over moisture is based upon the loss of strength which could occur if excessive moisture is adsorbed onto the extensive surface area of graphite, which is highly porous in nature. Failure in flexural testing is regarded as the breaking in tension of the outer fiber while deflecting under a bending moment, which would indicate that tensile testing provides a similar failure mechanism. Regression analysis (Figure 47) of the effects of humidity on tensile deflection at failure, however, indicate that there is no discernable correlation between the ambient 
humidity in the laboratory on the 255 tensile tests that were run, despite the variation in humidity that was recorded at between approximately $15 \%$ and $45 \%$ over the time that tensile tests were being carried out. The resulting R Square value of the relationship between humidity and strain at failure is less than $0.011-$ a value which essentially indicates that no correlation exists. The flat nature of the predicted strain values at break with respect to humidity levels provide visual representation that strain values neither increase nor decrease with increasing humidity levels, and hence no dependence upon humidity is observed. While other factors exist and this observation alone is not absolutely conclusive, comprehensive and strict data sets such as this provide a means for evaluation and discussion by the respective ASTM committees. Early results of this nature were partly responsible for the rewording of this requirement in ASTM Standard C651 that will take effect upon the acceptance of the next revision, which is presently up for a full re-ballot.

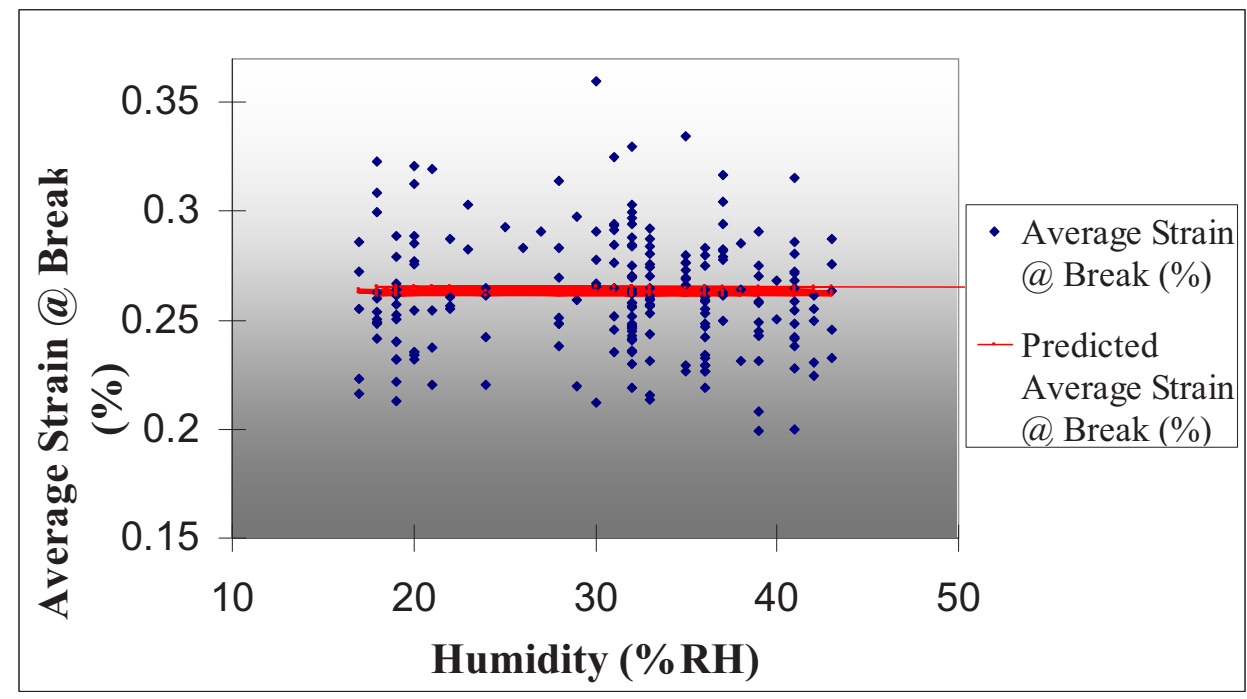

\begin{tabular}{|lr|}
\hline \multicolumn{2}{|c|}{ Regression Statistics } \\
\hline Multiple R & 0.104608 \\
R Square & 0.010943 \\
Adjusted R Square & 0.007034 \\
Standard Error & 1.642136 \\
Observations & 255 \\
\hline
\end{tabular}

Figure 47. Regression analysis shows little correlation between failure in tension (amount of strain at failure) and relative humidity in the environment.

A test result more directly related to the tensile test itself concerns the collection of "valid" test results based on the location of the gauge section fracture at failure. As written, the standard for tensile testing of graphite requires that breakage outside of the gauge section is grounds for disqualification of that particular test. ${ }^{6}$ The gauge section is the actual section of the tensile bar between the extensometer edges being directly measured while the specimen is under load. Presumably, the area beyond this zone cannot be accurately measured during straining of the specimen - and a failure in the zone beyond these limits would suggest that there may be anomalous strain that is taking place and not being directly measured. An analysis of the actual test results of the 255 tensile failures, however, indicates that there is no significant difference between a failure that occurs inside the gauge limits and outside (or at the extensometer edge, for that matter). Figure 48 shows an ANOVA evaluation of stress and strain at failure based on fracture location. $\mathrm{P}$ values of 0.903 and 0.678 , respectively, are well above the $\mathrm{P}$ value upper limit of 0.05 required for confirmation that the data means actually differ, indicating that in terms of average values there is no difference in either characteristic regardless of the break location. 

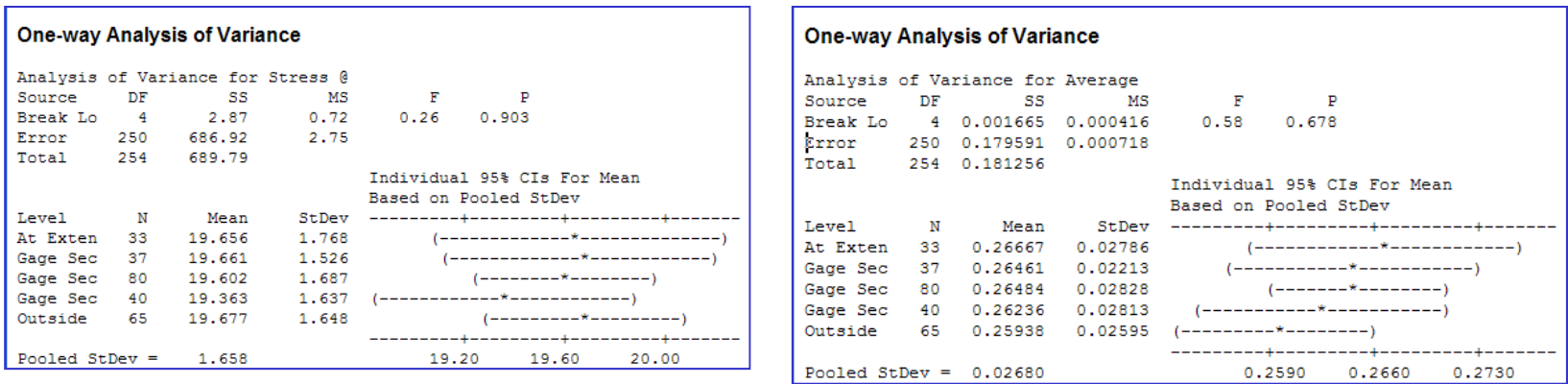

Figure 48. ANOVA shows no statistical correlation between either the failure stress or strain and ambient humidity levels during staging and testing of tensile specimens.

Further evaluation during tensile testing may provide a means to refine other section of applicable standards. ASTM Standard C749-08 indicates that knife edges on extensometer strain-measuring devices may cause damage to the graphite at the contact point, resulting in a pre-existing flaw that would compromise the data by causing an early failure. Provision is made to protect the graphite surface by alternate means, up to and including a collar device that fits around the gauge section and provides a hardened contact point for the extensometer edges. ${ }^{6}$ Per INL PLN-3467, ${ }^{9}$ an alternative method was proposed for the baseline program - protecting the graphite surface with small dabs of epoxy that the extensometer edge would contact during the test, as shown in Figure 49, protecting the actual graphite surface. A sampling of tensile testing with no epoxy layer, however, indicated that there was no reduction in the incidence of failure at the extensometer edge regardless of whether or not the surface was protected. For the "protected" specimens, 30 out of 232 specimens failed at a location classified as the "extensometer edge", a failure rate of $12.9 \%$. For "unprotected" specimens, 3 out of 24 failed at the edge - a $12.5 \%$ failure rate. As additions to the specimen between the extensometer and the actual surface may cause an anomalous strain response regardless of the technique used, the testing of graphite while avoiding such potential artifacts will continue to be evaluated.

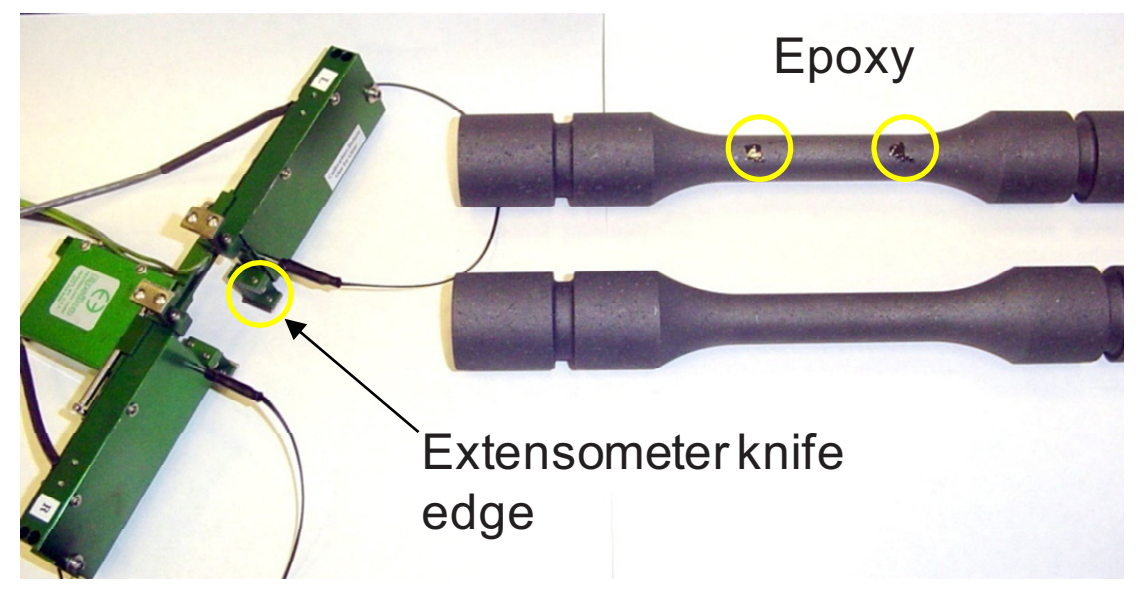

Figure 49. Epoxy placed on the surface of the gauge section of tensile bars was initiated to prevent breakage at the contact point of the extensometer, held against the specimen by knife edges and spring tension. 


\section{SUMMARY}

The Baseline Graphite Characterization program has completed the testing on the first billet of nuclear graphite to be evaluated. Section 3 gave an overview of the analysis techniques utilized to examine potential trends in material properties based on logical data set groups, but were a relatively small portion of the level of analysis that is being done and will continue to be carried out as more billets are sectioned for analysis and the data populations continue to grow. The ultimate goal that is being pursued is to establish the distinct trends that exist in graphite based upon manufacturing processes and raw materials to the extent that data sets can be accurately represented by material bulk property maps, such as the hypothetical example represented by Figure 50.

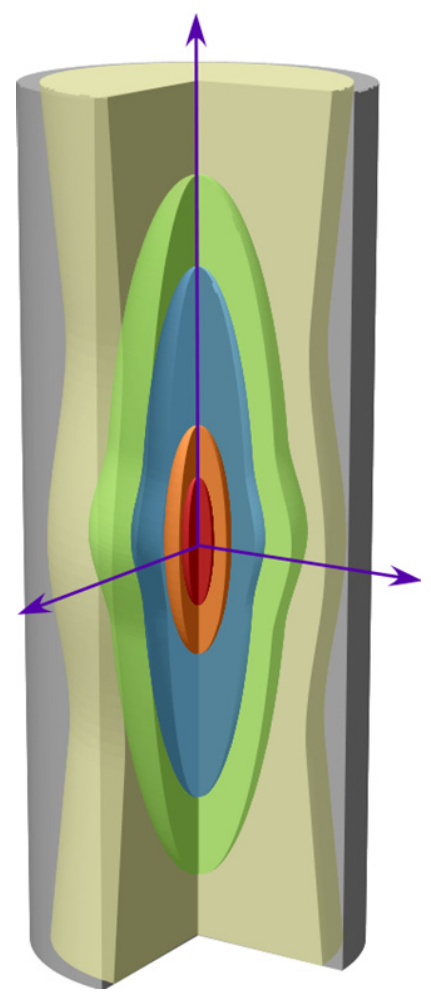

Figure 50. 3-dimensional property representations will be possible as data set differences are sorted and distinct trends can be statistically validated.

Aside from visual representations that show relative relationships between material properties and positions, the raw data results being collected are contributing to the growing nuclear graphite characteristics database that will provide the means for countless further analysis projects that endeavor to provide the necessary means to utilize graphite in the most efficient and effective form in future high-temperature reactor designs. 


\section{REFERENCES}

1. ASME NQA-1, 2000, "Quality Assurance Requirements for Nuclear Facilities," American Society of Mechanical Engineers, New York, NY (2000).

2. Idaho National Laboratory LWP-13120, “Identifying and Controlling Items," Rev. 2, (2007).

3. Idaho National Laboratory SOW-8182, "Sectioning of NBG-18 Graphite Billets," Rev. 0, (2010).

4. Idaho National Laboratory SOW-7227, "Machining Graphite for Baseline Characterization: NBG-18 Billet 1A," Rev. 2, (2010).

5. Idaho National Laboratory PLN-3348, “Graphite Mechanical Testing,” Rev. 1, (2010).

6. ASTM, 2010, "Standard Test Method for Tensile Stress-Strain of Carbon and Graphite," ASTM Standard C749-08, ASTM International, West Conshohocken, PA (2010).

7. ASTM, 2010, "Standard Test Method for Compressive Strength of Carbon and Graphite," ASTM Standard C695-91, ASTM International, West Conshohocken, PA (2010).

8. ASTM, 2005, "Standard Test Method for Flexural Strength of Manufactured Carbon and Graphite Articles Using Four-Point Loading at Room Temperature," ASTM Standard C651-91, ASTM International, West Conshohocken, PA (2005).

9. Idaho National Laboratory PLN-3467, "Baseline Graphite Characterization Plan: Electromechanical Testing," Rev. 0, (2010).

10. Idaho National Laboratory PLN-2247, "General Software Management Plan for the VHTR TDO," Rev. 1, (2009).

11. Birch, J.M., B. Wilshire, D.J.R.Owen, D. Shantaram, 2006, “The Influence of Stress Distribution on the Deformation and Fracture Behaviour of Ceramic Materials under Compression Creep Conditions," Journal of Materials Science 11 1817-1825 (1976).

12. Albers, T.L., 2009, "High-Temperature Properties of Nuclear Graphite," Journal of Engineering for Gas Turbines and Power 131 (2009).

13. Arai, T. and T. Oku, 1979, "The Effect of Non-Linear Stress-Strain Relationship on the bend Strength of Isotropic Graphite,” Journal of Nuclear Materials 79 227-234 (1979).

14. ASTM, 2010, "Standard Test Method for Moduli of Elasticity and Fundamental Frequencies of Carbon and Graphite Materials by Sonic Resonance," ASTM Standard C747-93, ASTM International, West Conshohocken, PA (2010).

15. Idaho National Laboratory PLN-3267, “AGC-2 Characterization Plan,” Rev. 0, (2010).

16. ASTM, 2010, "Standard Test Method for Dynamic Young's Modulus, Shear Modulus, and Poisson's Ratio for Advanced Ceramics by Impulse Excitation of Vibration," ASTM Standard C1259-08, ASTM International, West Conshohocken, PA (2010).

17. ASTM, 2009, "Standard Test Method for Sonic Velocity in Manufactured Carbon and Graphite Materials for Use in Obtaining Young's Modulus," ASTM Standard C769-09, ASTM International, West Conshohocken, PA (2009). 
Appendix A

\section{Property Distributions}




\section{Appendix A \\ Property Distributions}

The following appendix files are representations of the individual data sets for each of the mechanical properties of interest. The results are the pooled data of each of the respective test types; there is no further breakdown of categories within each of the data sets. The information is provided solely as information regarding the general distribution and range of values for each of the property types. 


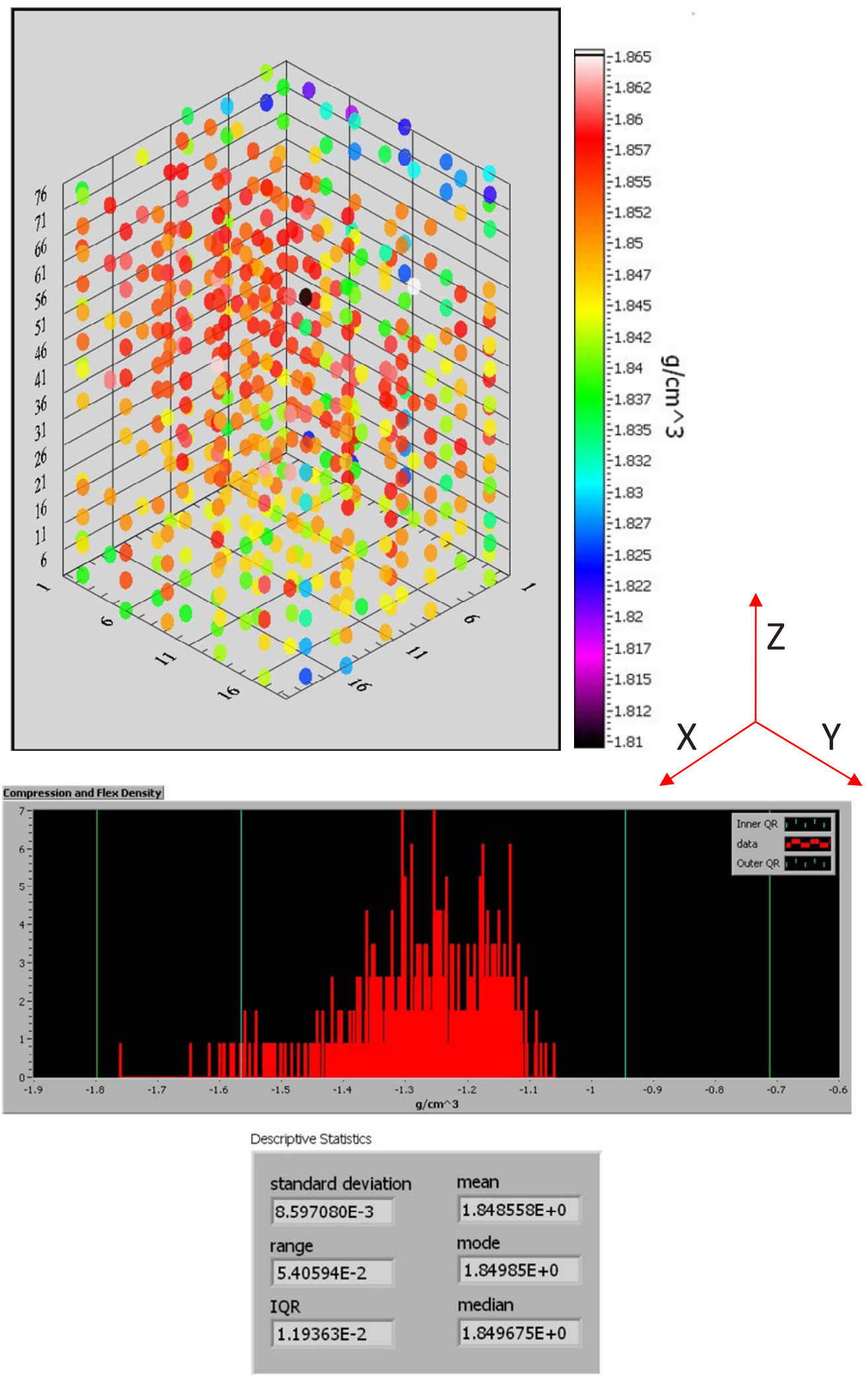

Figure A-1. Density values from pooled compression and flexural specimens. 

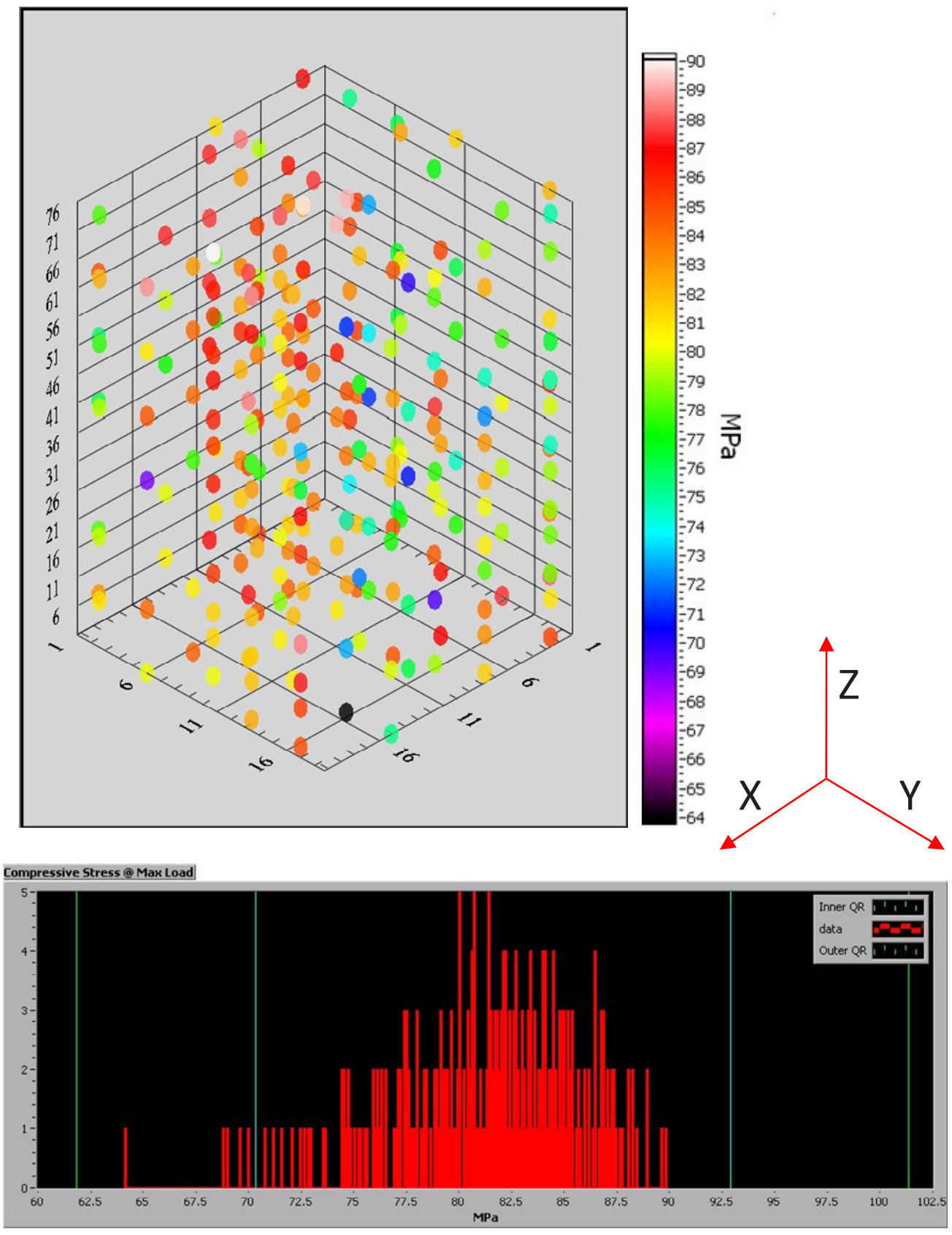

\begin{tabular}{|c|c|}
\hline standard deviation & mean \\
\hline $4.341180 \mathrm{E}+0$ & $8.128307 E+1$ \\
\hline range & mode \\
\hline $2.57990 \mathrm{E}+1$ & $8.07324 E+1$ \\
\hline IQR & median \\
\hline $5.64650 \mathrm{E}+0$ & $8.177300 \mathrm{E}+1$ \\
\hline
\end{tabular}

Figure A-2. Compressive strength (stress at failure). 

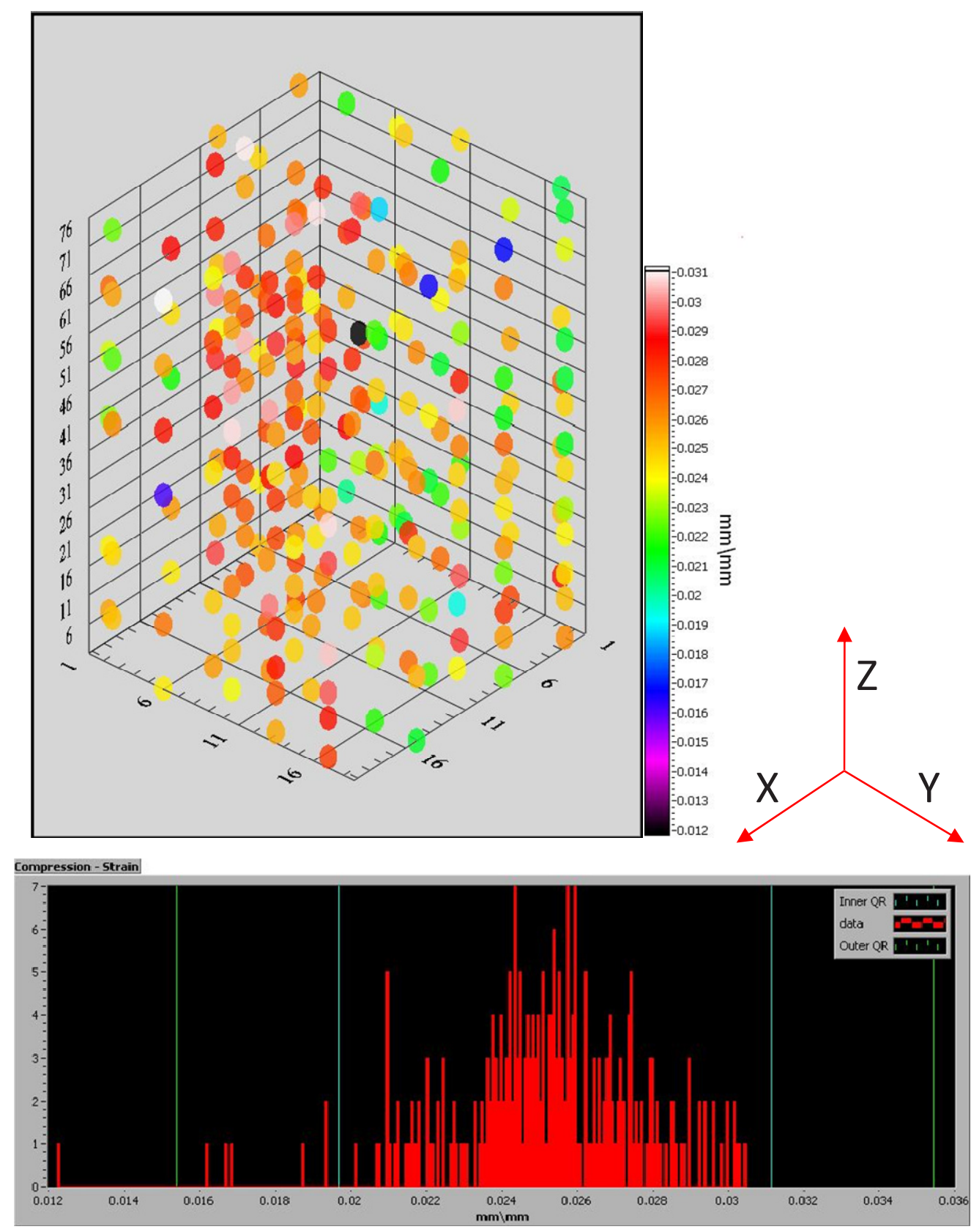

\begin{tabular}{|c|c|}
\hline standard deviation & mean \\
\hline $2.581333 \mathrm{E}-3$ & $2.515481 \mathrm{E}-2$ \\
\hline range & mode \\
\hline $1.82516 \mathrm{E}-2$ & $2.58243 \mathrm{E}-2$ \\
\hline IQR & median \\
\hline $2.86418 \mathrm{E}-3$ & $2.530761 \mathrm{E}-2$ \\
\hline
\end{tabular}

Figure A-3. Compressive strain at maximum load. 

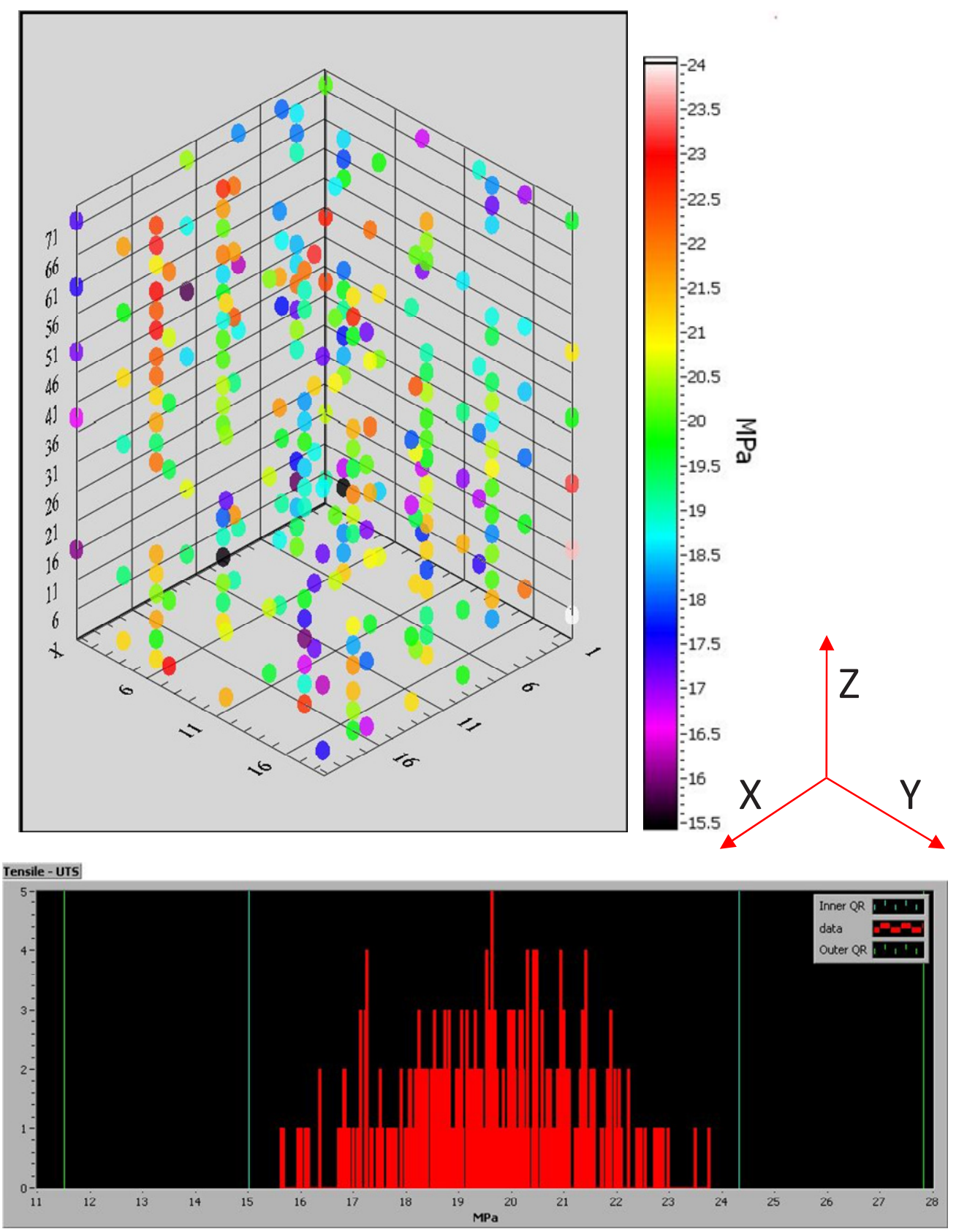

Descriptive Statistics

\begin{tabular}{|c|c|}
\hline standard deviation & mean \\
\hline $1.651636 \mathrm{E}+0$ & $1.961108 \mathrm{E}+1$ \\
\hline range & mode \\
\hline $8.14600 \mathrm{E}+0$ & $1.96473 \mathrm{E}+1$ \\
\hline IQR & median \\
\hline $2.32825 \mathrm{E}+0$ & $1.962700 \mathrm{E}+1$ \\
\hline
\end{tabular}

Figure A-4. Ultimate tensile strength. 

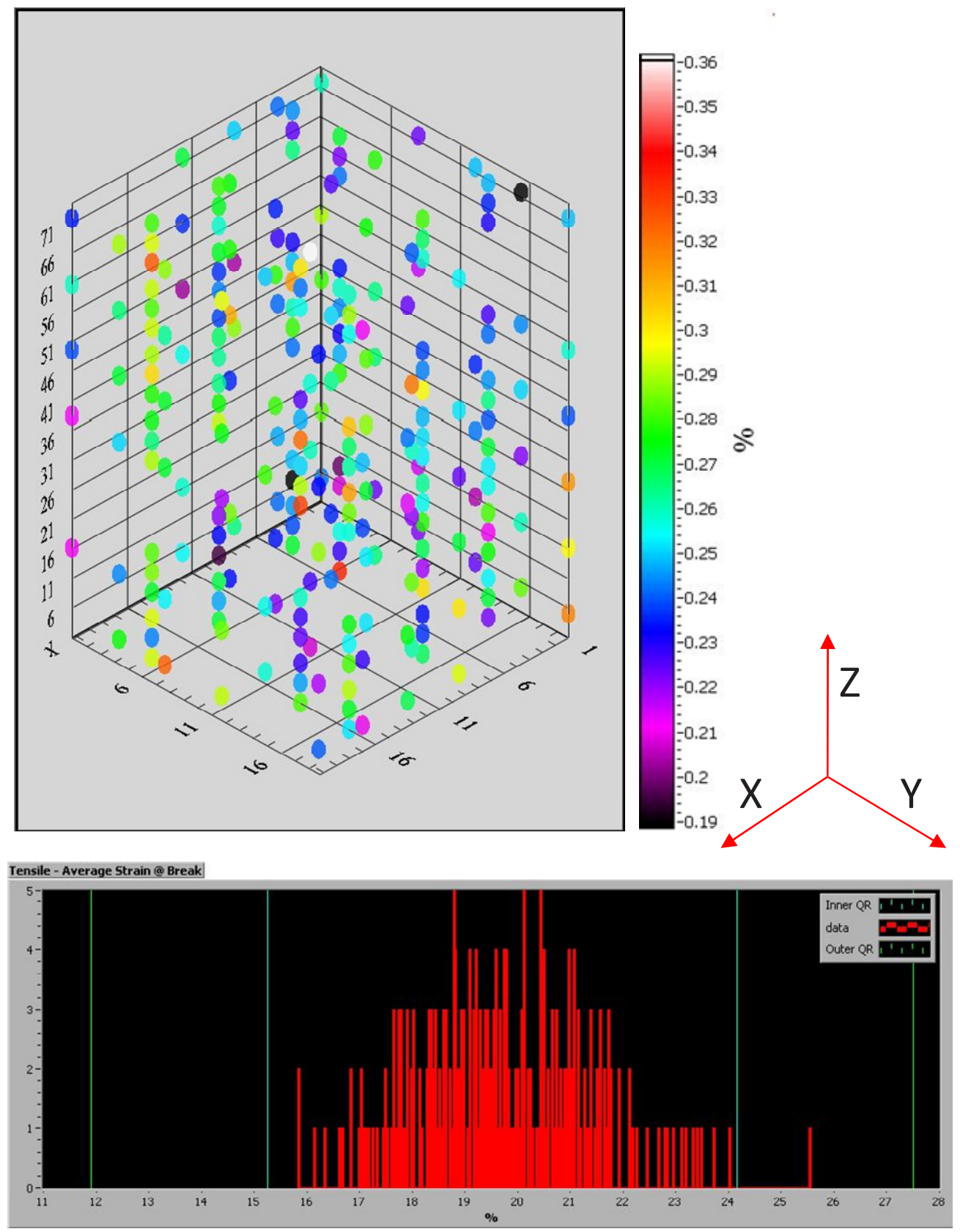

\begin{tabular}{|c|c|}
\hline standard deviation & mean \\
\hline $2.671342 \mathrm{E}-2$ & $2.632625 \mathrm{E}-1$ \\
\hline range & mode \\
\hline $1.60480 \mathrm{E}-1$ & $2.48456 \mathrm{E}-1$ \\
\hline IQR & median \\
\hline $3.66625 \mathrm{E}-2$ & $2.616600 \mathrm{E}-1$ \\
\hline
\end{tabular}

Figure A-5. Tensile strain at failure. 

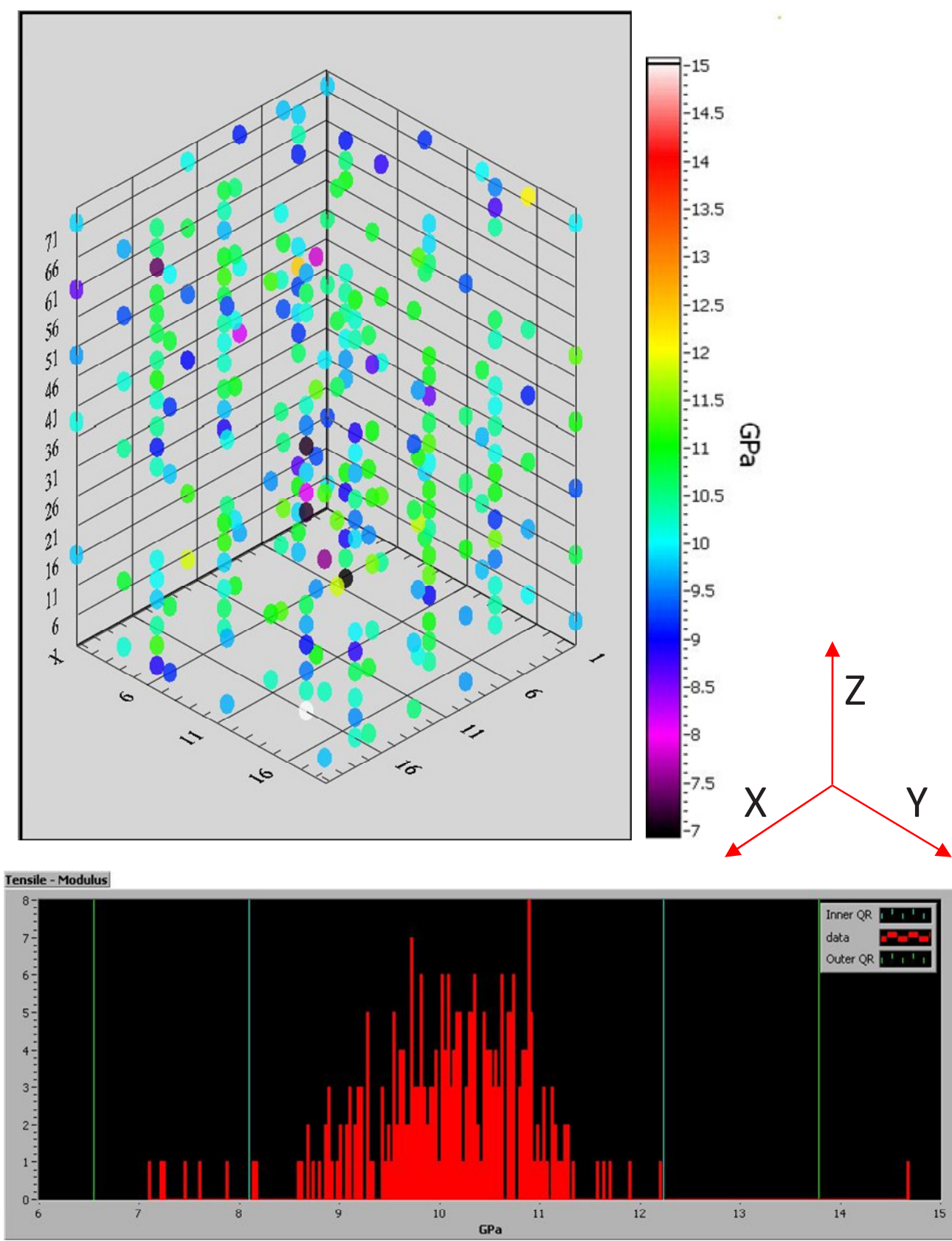

\begin{tabular}{|c|c|}
\hline standard deviation & mean \\
\hline $8.569646 \mathrm{E}-1$ & $1.009938 \mathrm{E}+1$ \\
\hline range & mode \\
\hline $7.61240 \mathrm{E}+0$ & $1.06985 \mathrm{E}+1$ \\
\hline IQR & median \\
\hline $1.03423 \mathrm{E}+0$ & $1.016000 \mathrm{E}+1$ \\
\hline
\end{tabular}

Figure A-6. Young's (elastic) modulus from tensile testing. 

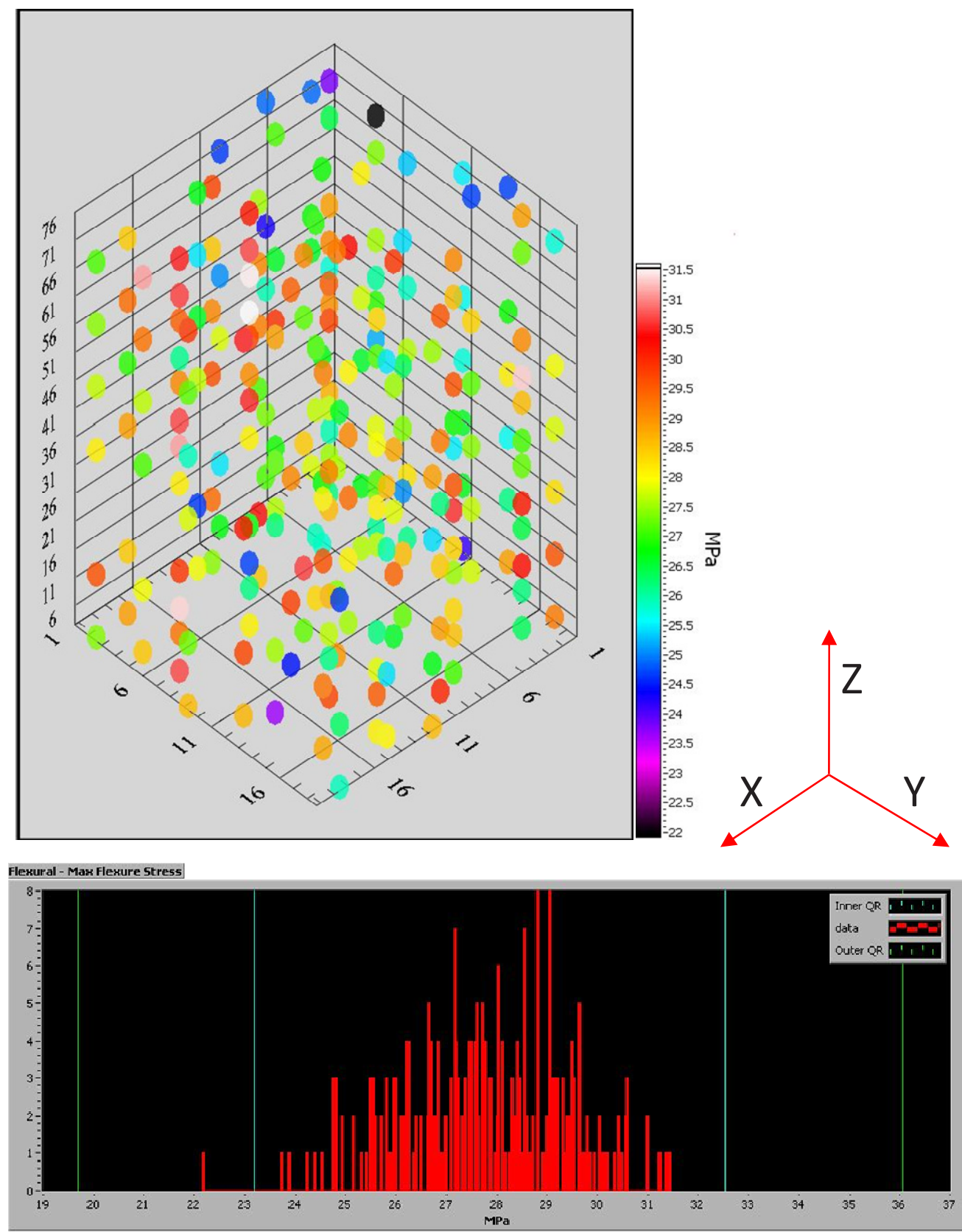

Descriptive Statistics

\begin{tabular}{|c|c|}
\hline standard deviation & mean \\
\hline $1.619704 \mathrm{E}+0$ & $2.776608 E+1$ \\
\hline range & mode \\
\hline $9.30000 \mathrm{E}+0$ & $2.90785 E+1$ \\
\hline IQR & median \\
\hline $2.33750 \mathrm{E}+0$ & $2.775000 \mathrm{E}+1$ \\
\hline
\end{tabular}

Figure A-7. Maximum stress (mm) in flexure. 

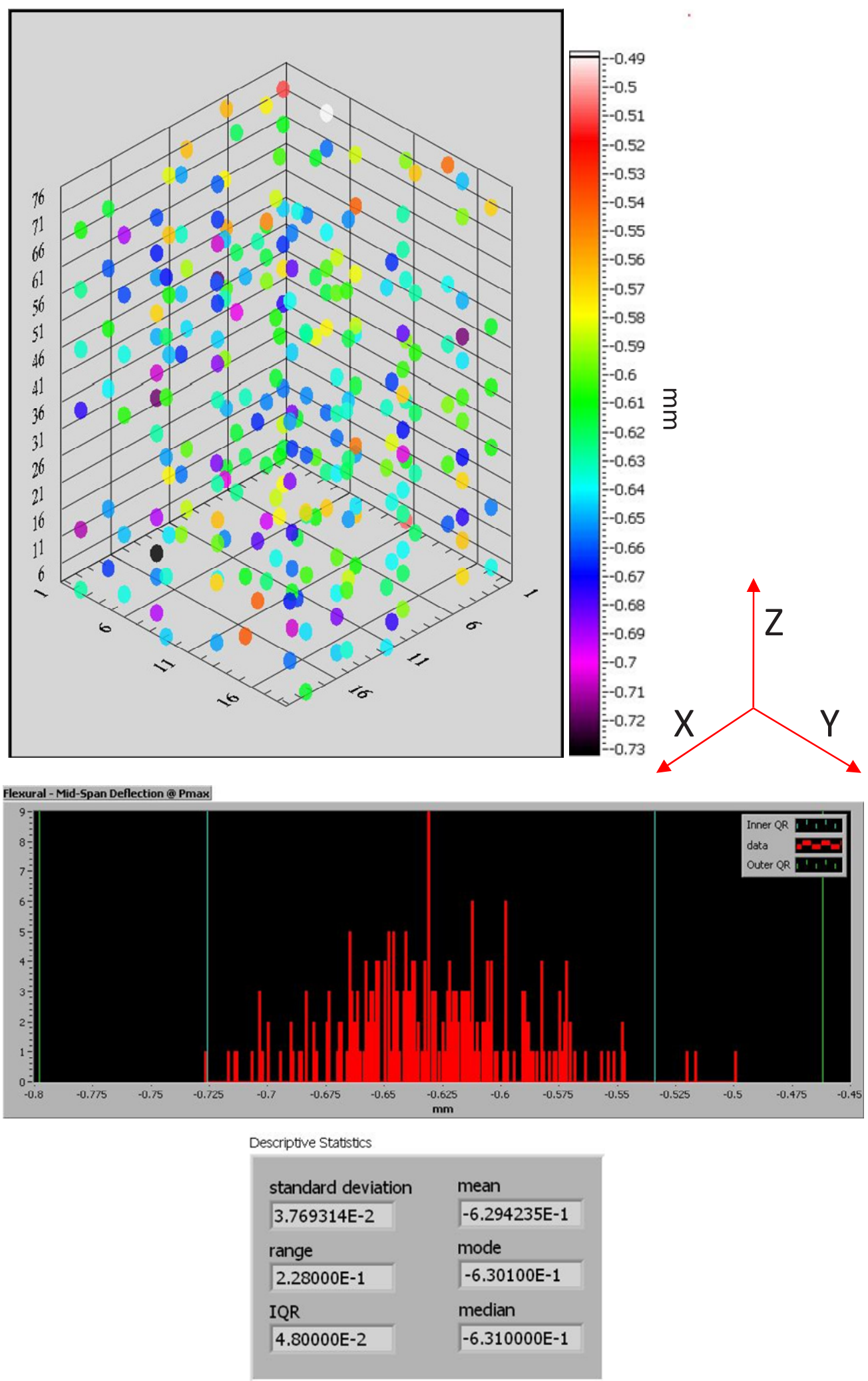

Figure A-8. Maximum displacement $(\mathrm{mm})$ in flexure. 

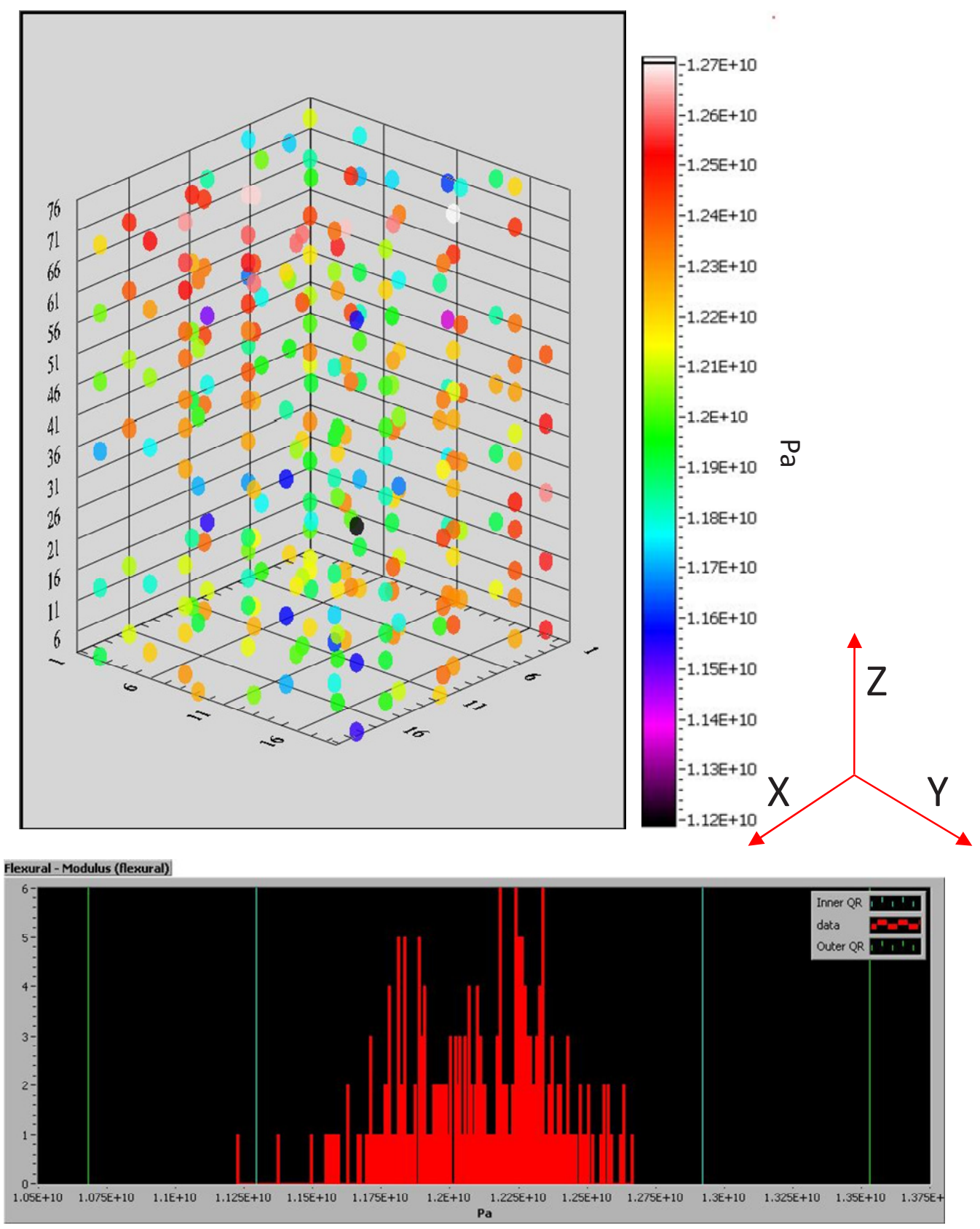

Descriptive Statistics

\begin{tabular}{|c|c|}
\hline standard deviation & mean \\
\hline $2.652132 E+8$ & $1.210647 \mathrm{E}+10$ \\
\hline range & mode \\
\hline 1.44155E+9 & $1.22700 \mathrm{E}+10$ \\
\hline IQR & median \\
\hline $4.06891 \mathrm{E}+8$ & $1.211845 E+10$ \\
\hline
\end{tabular}

Figure A-9. Dynamic Young's (elastic) modulus from flexural fundamental frequency. 

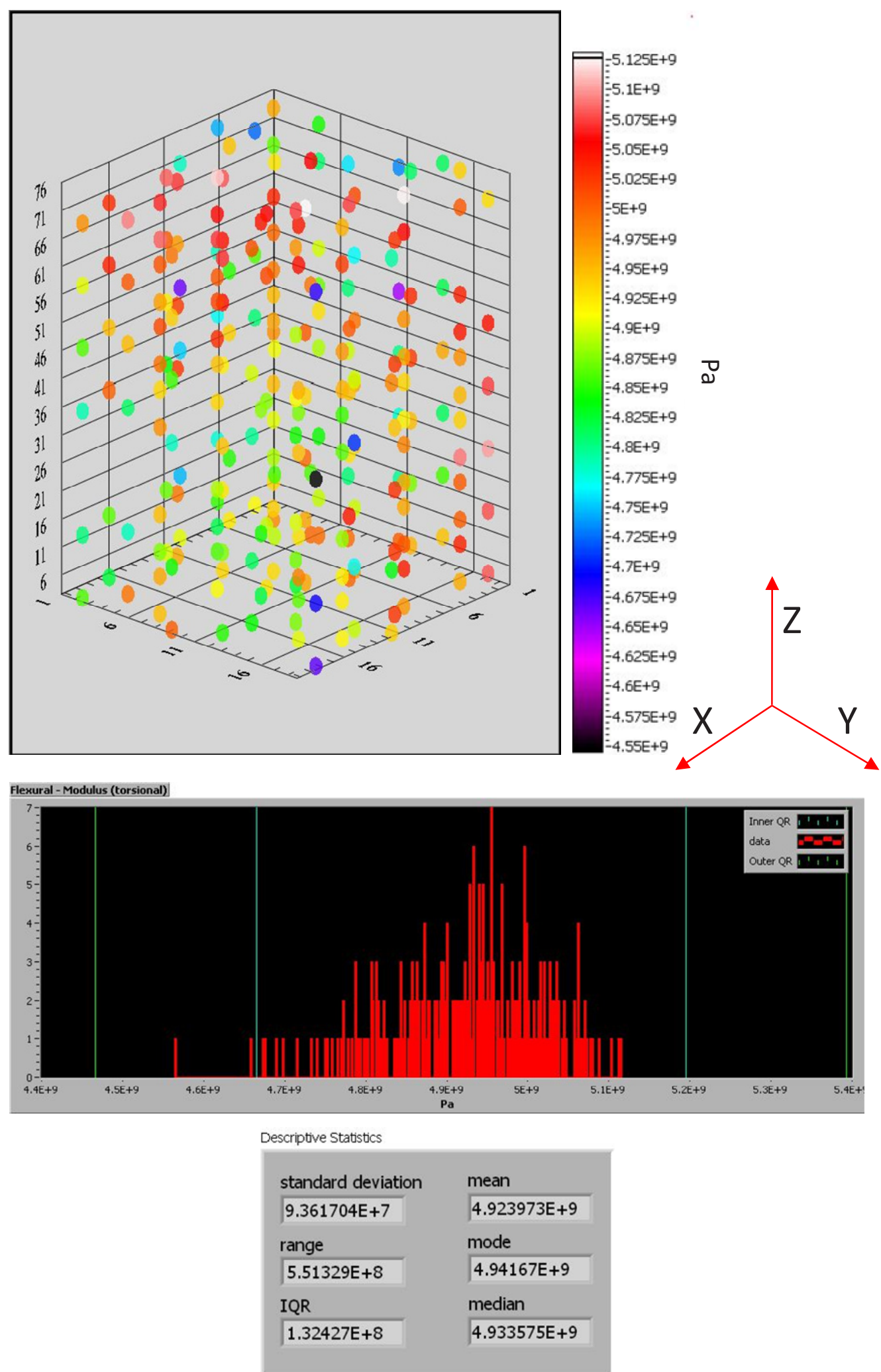

Figure A-10. Shear modulus from torsional fundamental frequency. 
Appendix B

\section{Weibull Probability Distributions}




\section{Appendix B}

\section{Weibull Probability Distributions}

The following appendix is a selected group of Weibull probability distributions based upon characterization data from the first graphite billet. The shape factor, or slope, of a Weibull distribution gives an indication of the spread of data of a particular property. When based upon properties such as strength or strain at fracture, the Weibull distribution is an important tool in determining the probability of failure of a specific component.

The shape factor for these types of property representations in materials analysis is also referred to as the Weibull modulus. A larger modulus value is an indication of a smaller failure rate interval, indicating that a more accurate estimation can be made over the expected performance or response of a component determined by the probability of failure at a certain level of stress or strain.
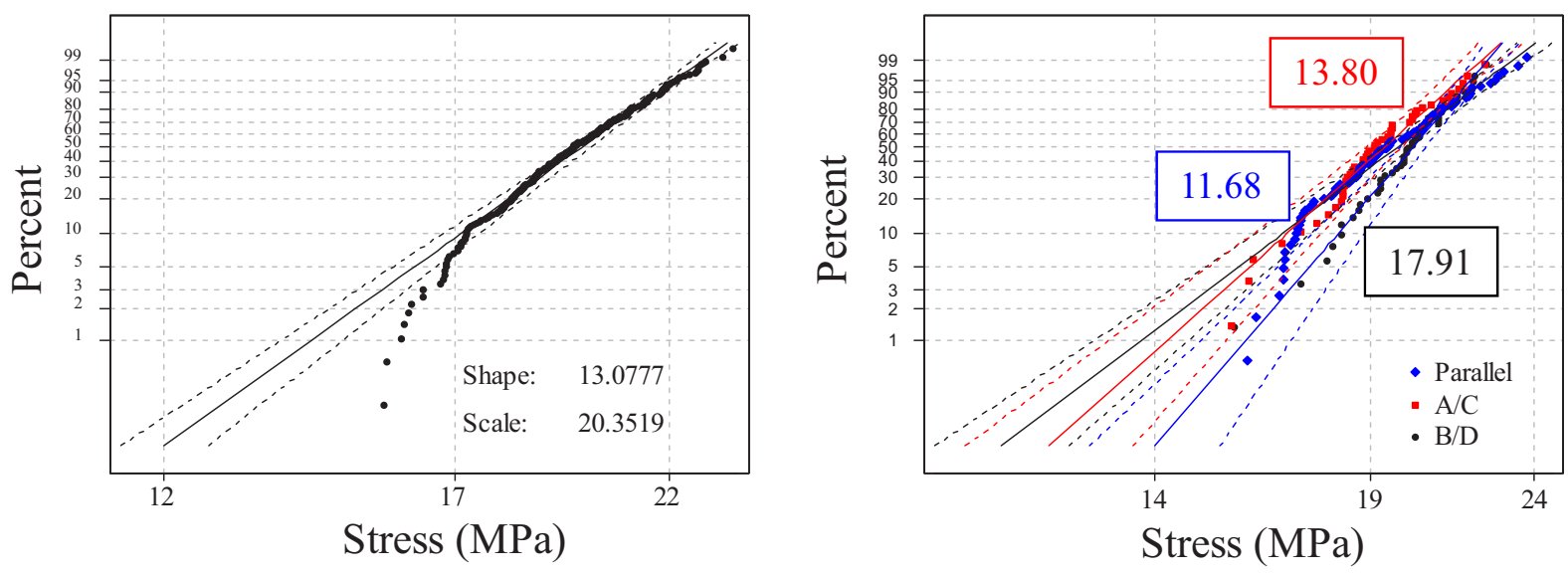

Figure B-1. The Weibull probability distribution for tensile stress (strength) at failure, both for the entire data set (left) and for each individual orientation based upon breaks within the gauge limit of the extensometer. The predictability is lower for specimens stressed to failure in tension in the parallel direction, as evidenced by the lower modulus value (represented in colors that match the graph symbols). 

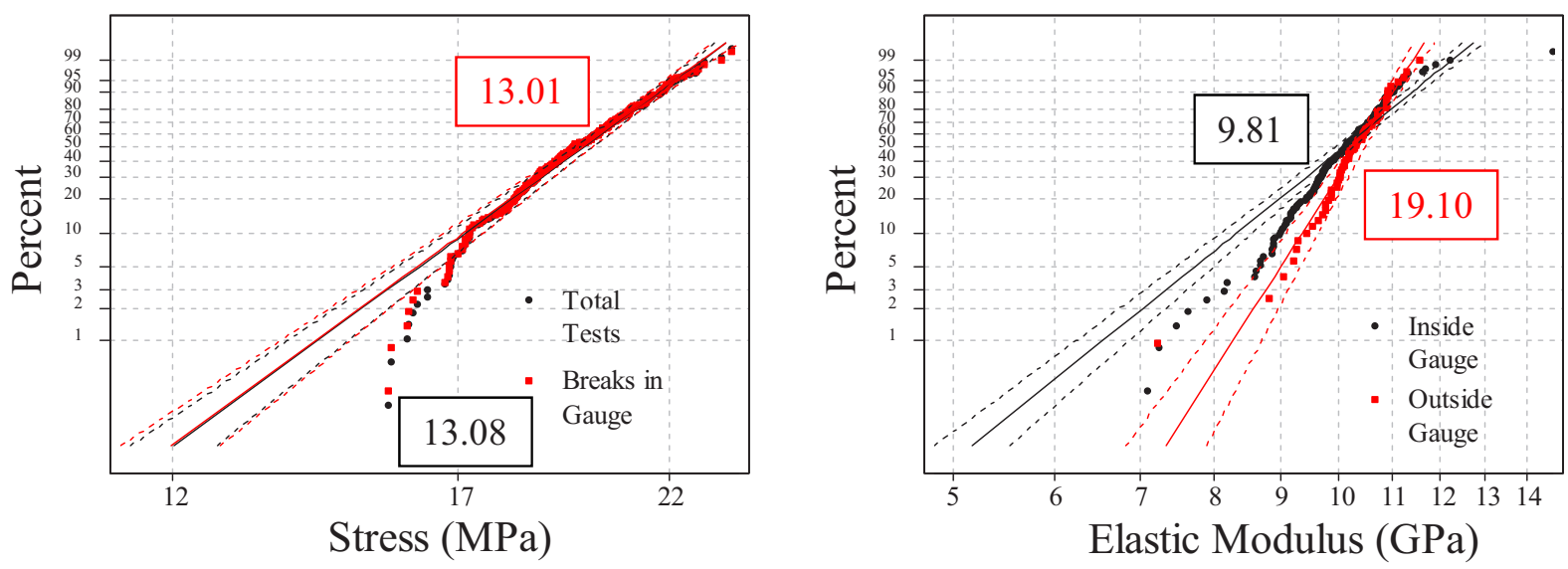

Figure B-2. A comparison of stress at failure for the entire set of tensile test specimens and those that were "valid" tests (broke within the gauge limit of the extensometer) indicates that there was no loss of data reliability when failures occurred outside of the gauge. The higher modulus values indicate that the data actually had increased predictability when all specimens were included in the strength assessment (left). A direct comparison of the modulus of elasticity (right) supports this conclusion, with a higher Weibull modulus for specimens that broke outside of the gauge length than those that broke in the valid gauge region.
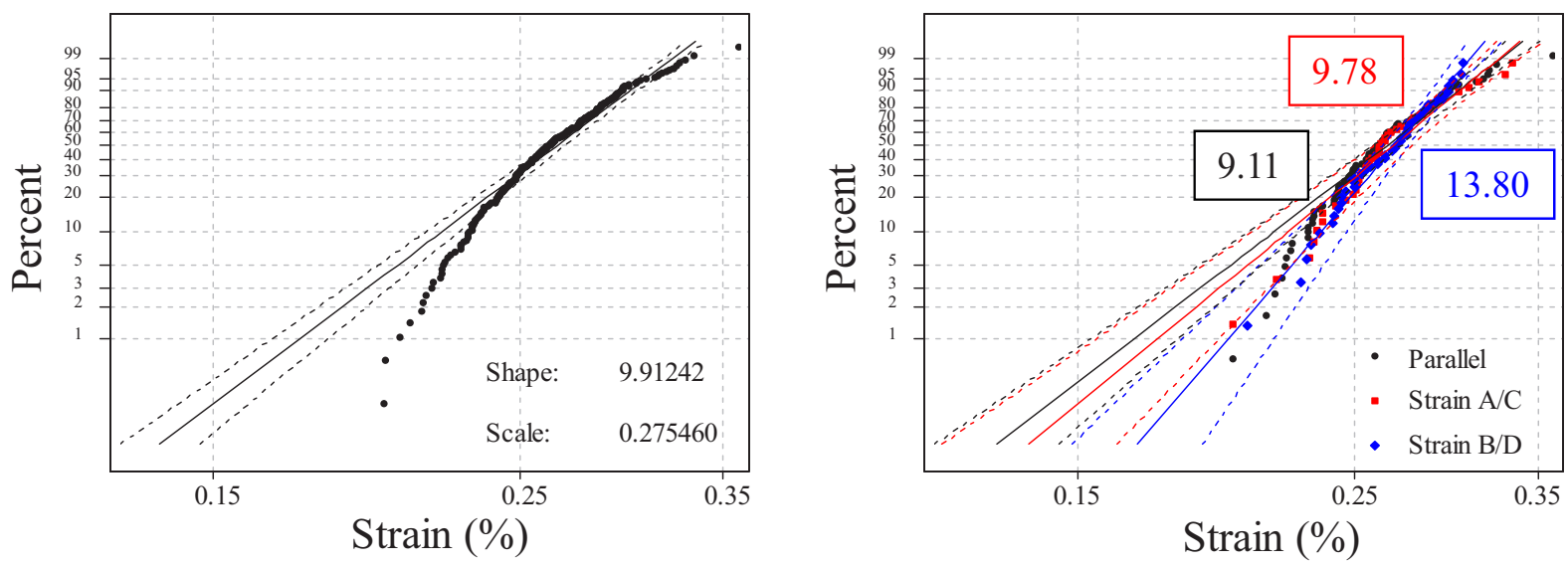

Figure B-3. Weibull probability for the strain at failure in tension, both for the entire data group (left) and for each orientation (right). 

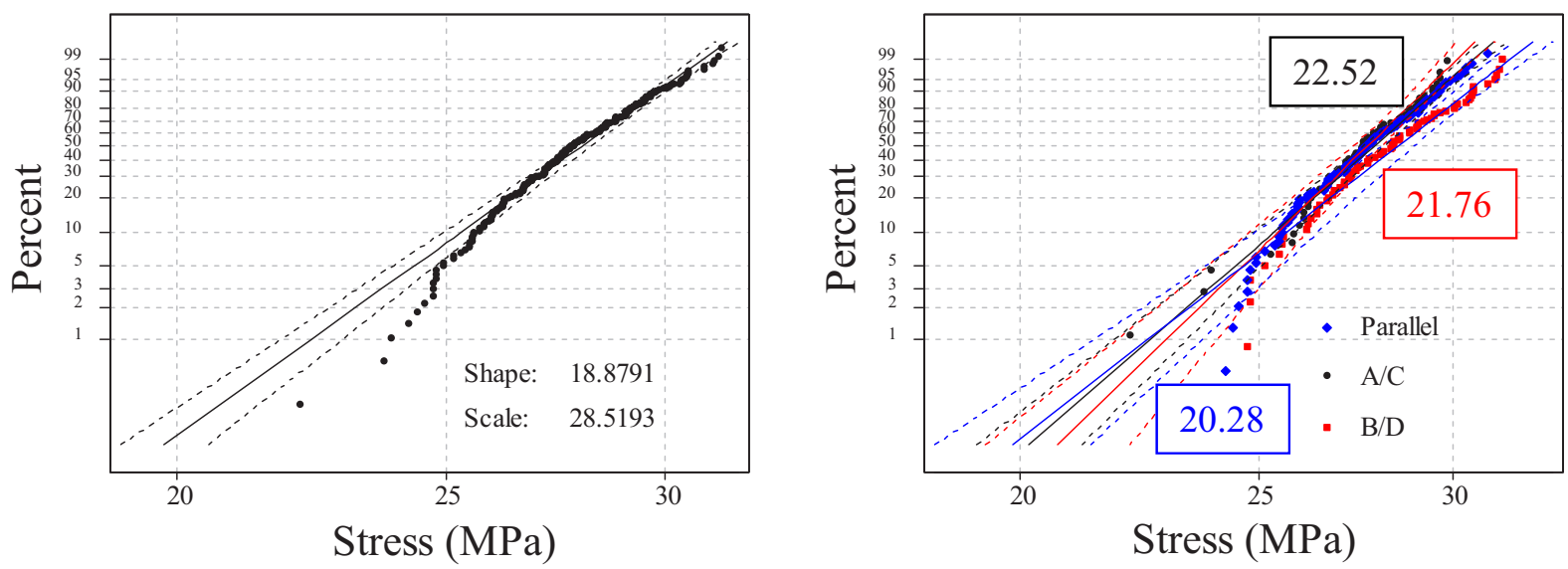

Figure B-4. Weibull probability distribution for the strength of the entire set of flexural specimens (left) and for each individual orientation (right). The values are in very close agreement.
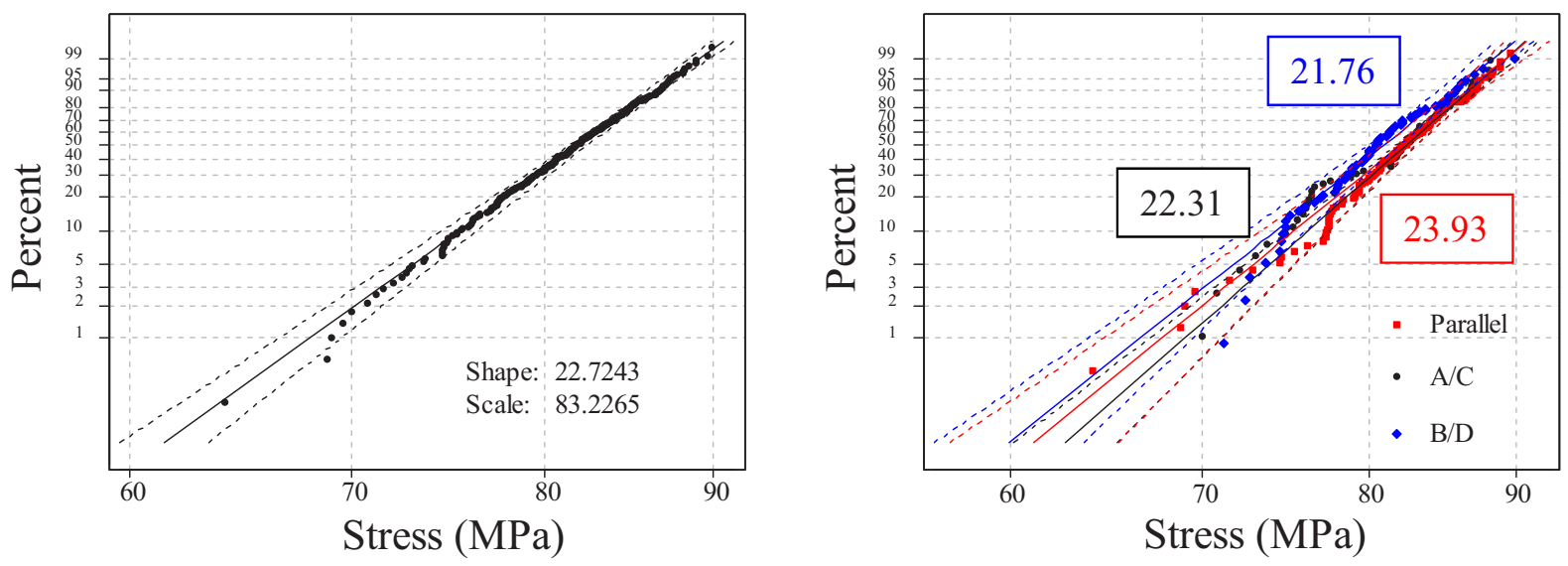

Figure B-5. Weibull probability distributions for compressive strength for the entire set (left) of specimens and for each individual orientation (right). 

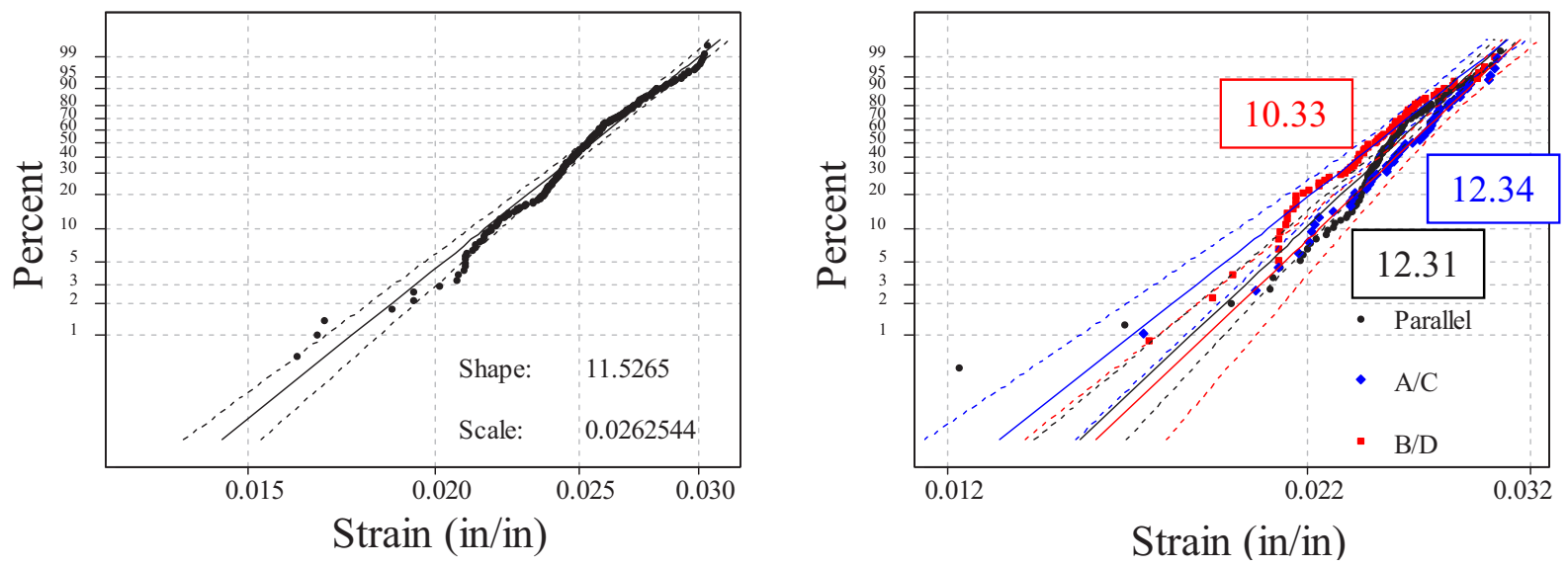

Figure B-6. Weibull distributions for the probability of the strain at failure for compression specimens for the entire set (left) and each orientation (right).

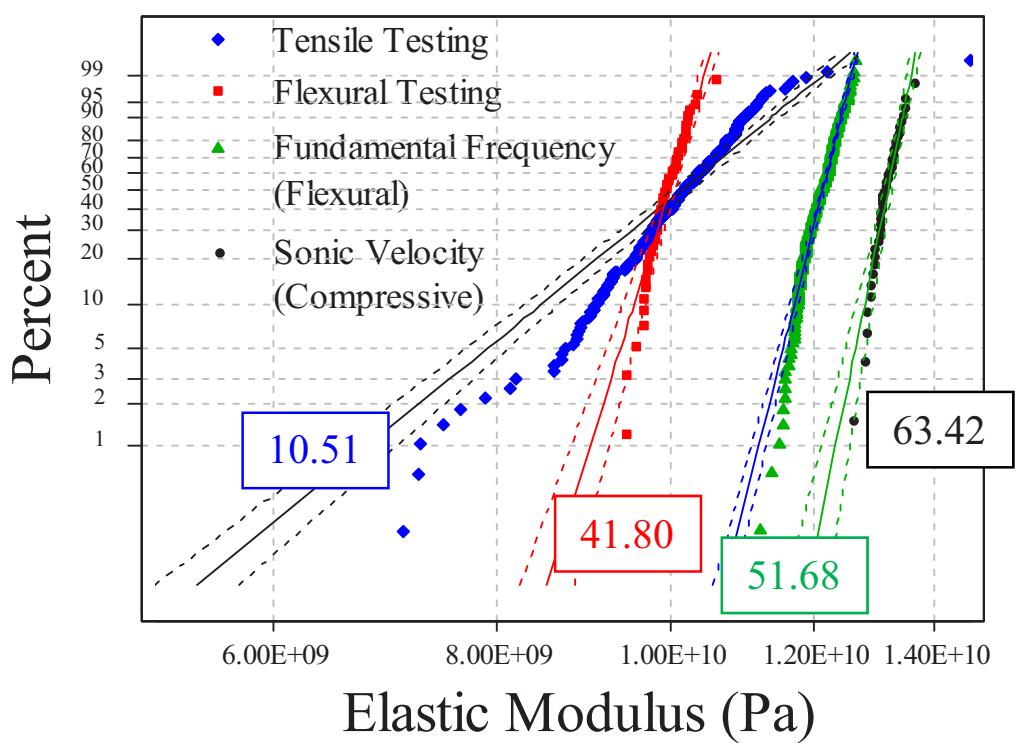

Figure B-7. A comparison of the elasticity moduli for four different analysis techniques. The mechanical test specimens (tensile and flexural) yielded lower property values as well as lower values for the Weibull modulus. The techniques that calculate the elasticity modulus through non-destructive techniques give a much more narrow spread of data, as indicated by the higher Weibull modulus values. 